
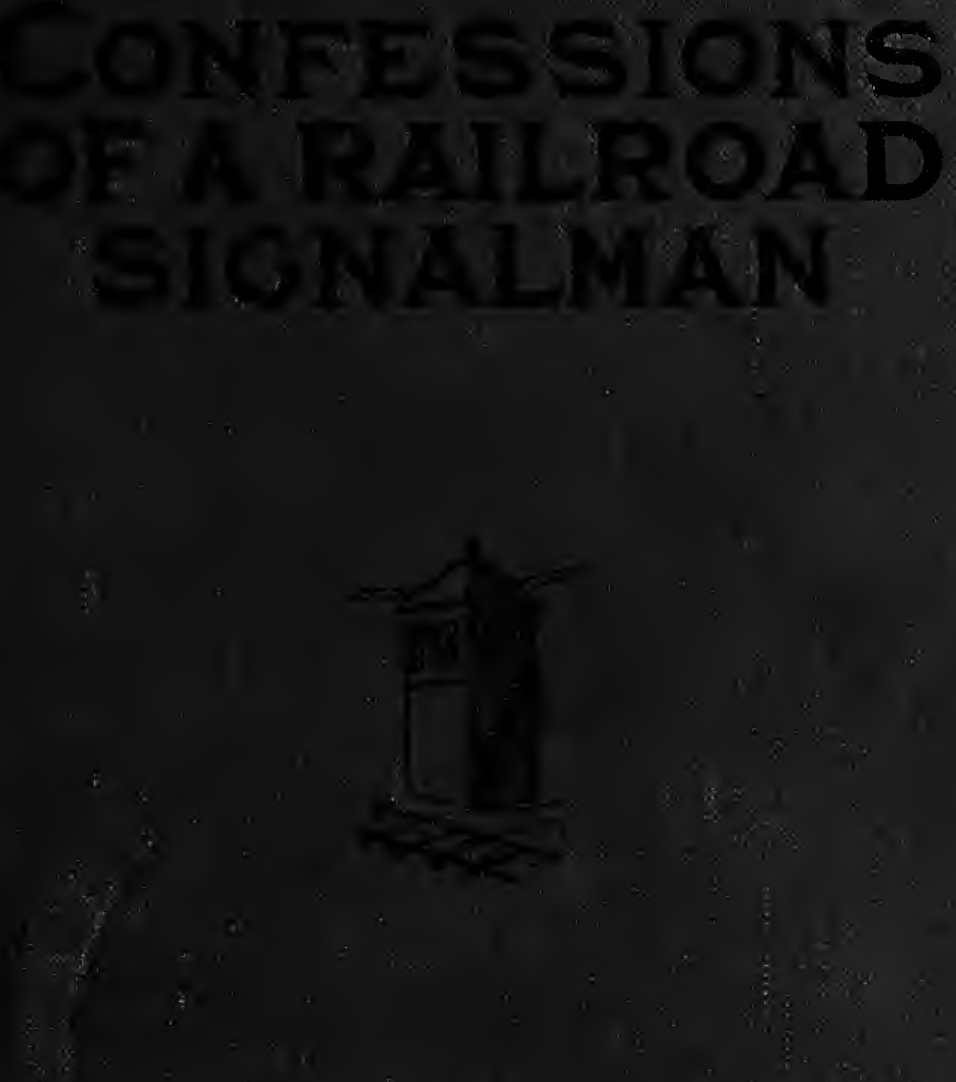

JAMES O. FAOAN:

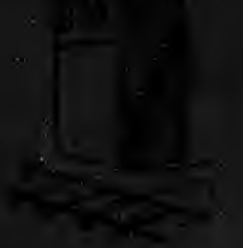




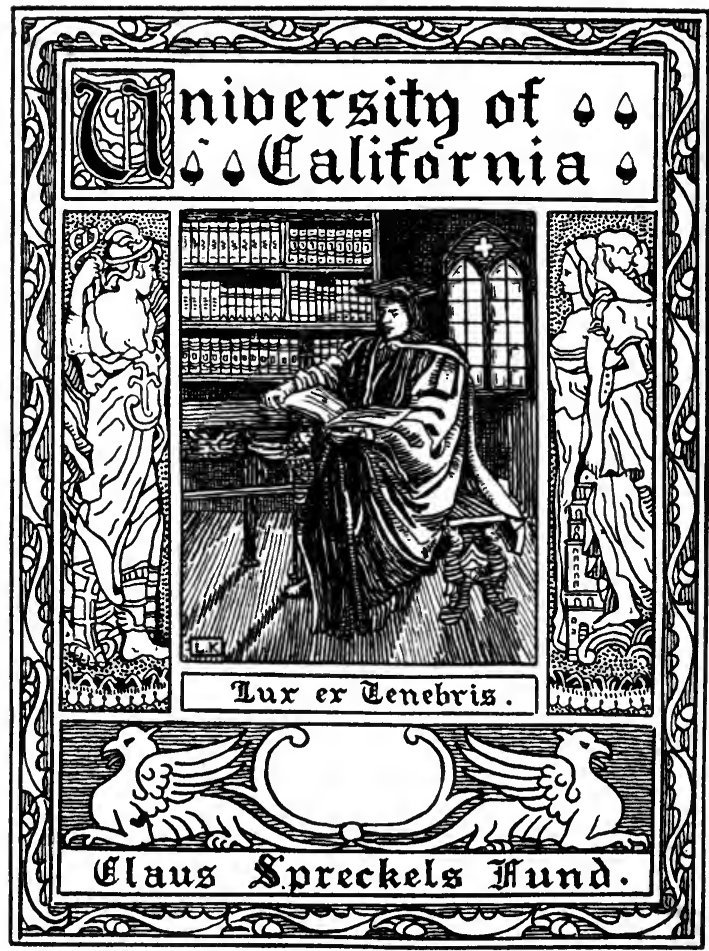




Digitized by the Internet Archive in 2007 with funding from Microsoft Corporation 
CONFESSIONS OF

A RAILROAD SIGNALMAN 



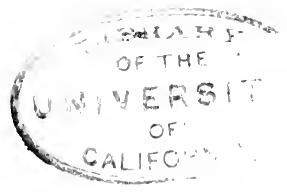




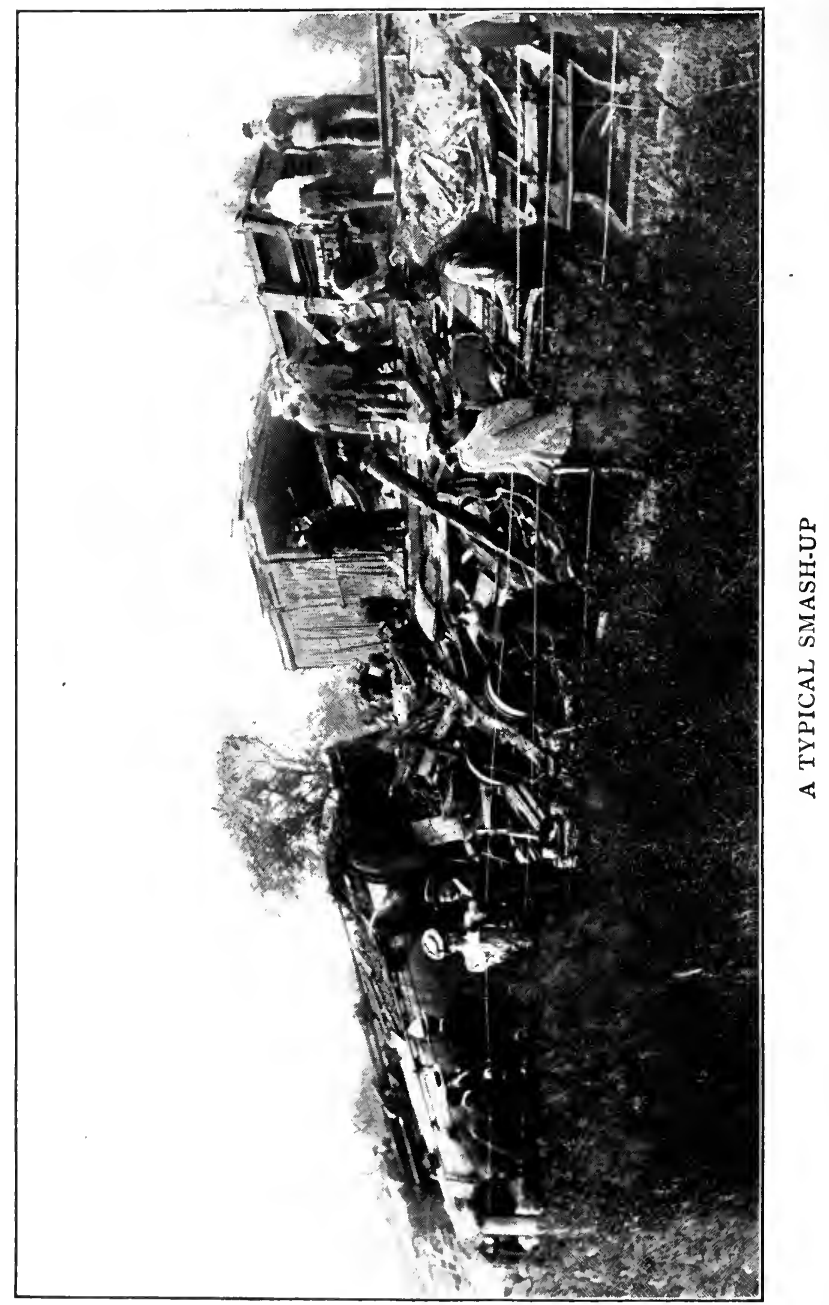




\section{CONFESSIONS OF A}

\section{RAILROAD SIGNALMAN}

BY

J. O. FAGAN

WITH ILLUSTRATIONS
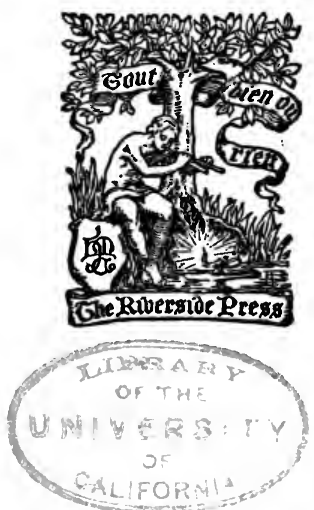

BOSTON AND NEW YORK

HOUGHTON MIFFLIN COMPANY

(ebe atuerzide preje Cambribge

$$
1908
$$




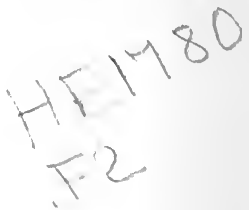

COPYRIGHT I9OS BY J. O. FAGAN

ALI RIGHTS RESERVED

Published October rgos

SECOND IMPRESSION

5. 


\section{CONTENTS}

I. A Railroad Man to Railroad Men I

II. The Men 26

III. The Management 47

IV. Loyalty 69

V. The Square Deal 95

VI. The Human Equation 1 i 8

VII. Discipline 149 



\section{ILLUSTRATIONS}

A Typical Smash-UP

Frontispiece

A Head-On Collision $\quad 26$

A Yard Wreck 52

A Typical Derailment 82

A Rear-End Collision 112

What Comes from a Misplaced Switch I32

Down an Embankment in Winter 150

The Aftermath 176

Acknowledgment is due to the proprietors of Collier's Weekly and of the Boston Herald for their courteous loan of the photographs from which the above illustrations have been engraved. 



\section{CONFESSIONS OF \\ A RAILROAD SIGNALMAN \\ I}

\section{A RAILROAD MAN TO RAILROAD MEN}

Considering the nature and intent of the following essays on the safety problem on American railroads, some kind of a foreword will not be out of place. As much as possible I wish to make this foreword a personal presentation of the subject. But in order to do this in a satisfactory manner, it will be necessary to take a preliminary survey of the situation and of the topics in which we, as railroad employees, are all personally interested.

In the industrial world of to-day, the railroad man occupies a position altogether different from the ordinary run of workers in factories or machine shops. On account of the nature and importance of our calling we are constantly in the public eye. By way of encouragement and as an incentive to good service, public opinion accords to us certain distinctive privileges. That there may be no excuse for laxity of conduct or inefficiency of service, we are looked upon in many ways as wards of the state and the nation. Not only are the hardships we endure 


\section{A RAILROAD MAN TO RAILROAD MEN}

and the dangers we are called upon to face matters in which the public is profoundly interested, but all details relating to our wages and to our treatment by railroad corporations have always been considered by the American people as topics in the discussion of which they are at all times intimately concerned.

Glancing backward at the history of railroad life in America, it is easy to perceive that this public sympathy and encouragement has been the strong right arm that has supported the railroad employee in a long-drawn-out struggle for the bettering of his social and financial condition. In some directions and in some branches of the service, the issues at stake have been bitterly contested, but the final results are probably unexampled among the successful achievements of organized labor. Not only numerically and financially, but also as regards the intelligence and education of its units, the railroad service to-day stands in the foremost position among the great industrial institutions of the country.

The nature of the service we railroad men render to the public in return for these benefits is most important, and, under present conditions, extremely dangerous. Some idea of the hazardous nature of our occupation may be gathered from the facts that, in a single year, one employee in every 364 was killed, and one in every 22 was injured. In the 


\section{A RAILROAD MAN TO RAILROAD MEN 3}

ranks of engineers, firemen, conductors, and brakemen, one in every 123 was killed and one in every Io was injured. This is about the average record of recent years. It means, of course, an appalling number of accidents, and these accidents are manifestly an eloquent reflection of the risks to which the traveling public is constantly exposed.

In many ways humanity is indebted to the railroad man to as great a degree as to the sailor. The latter, indeed, has greater hardships to endure; he is not nearly so well paid, and he has to submit to a much stricter code of discipline. But for some reason the railroad man has the more dangerous occupation, if one may judge from a comparison of the fatalities that occur at sea and on the rail. In a storm at sea, when battened down under closed hatches, with nothing to think about but the fury of the gale and our own helpless situation, we appreciate to the full our dependence upon the courage and watchfulness of the sailor. But the public does not consider a railroad man from quite the same viewpoint, for the reason, perhaps, that the unavoidable dangers on the rail are not to be compared with the ever-present peril that surrounds a ship in its battle with the elements. And yet when we come to compare actual results, that is, the statistics in regard to ship travel and train travel, one is quickly confronted with the conclusion that the 


\section{A RAILROAD MAN TO RAILROAD MEN}

public is fully as dependent for its safety upon the human elements of vigilance and consecration to duty in the one case as in the other.

Looking at our subject from the widest standpoint, however, it is evident that the dangers that threaten a passenger on the steam-cars are more numerous than the passenger himself has any idea of, and these dangers are very uncertain in their nature and difficult to guard against. Constant attention and supervision is being universally exercised by the railroad officials, for the purpose of reducing to a minimum the number of accidents that occur from defective equipment and the like; but the accidents caused by the personal neglect or carelessness of the individual employee is a branch of the subject that calls for a very different kind of investigation and treatment.

In order to get an intelligent and comprehensive idea of these railroad accidents, both avoidable and unavoidable, the National Government has directed and empowered the Interstate Commerce Commission to secure and to publish statistics on the subject. In this way, for a number of years, the public has been kept informed in regard to all casualties of whatever nature that take place on our railroads. But right here the work and influence of the $\mathrm{Na}$ tional and State Commissions, as well as of all railroad managers and individual investigators into the 


\section{A RAILROAD MAN TO RAILROAD MEN 5}

personal side of the problem, come to an end. Being in full possession and understanding of the actual results of our system of operating the railroad, the authorities seem disinclined to adopt any radical measures for the improvement of the service. In a report prepared for Congress some time ago, by the Interstate Commerce Commission, it was distinctly affirmed that these avoidable accidents are mostly due to the failure in duty of signalmen and enginemen.

"There is no escape from the conclusion that the block system is the best-known instrumentality for the prevention of collisions," says the report, "notwithstanding the imperfections that have been shown in the results of its operations."

According to the same report, during a given period, thirteen collisions occurred under the telegraph-block system, and all of these, so the commissioners say, were chargeable, not to the engineman, but to the telegraph operator. Yet in the same period seven collisions occurred on lines operated under the automatic block-signal system, where the telegraph operators are eliminated. These collisions were due to misconduct or neglect of enginemen. It is reasoned from this that the defect in the automatic block system is that the telegraph operator is not there to caution the engineman. The presence of a telegraph operator who attends the signal sta- 


\section{A RAILROAD MAN TO RAILROAD MEN}

tion serves as a caution to the engineman; whereas, when the telegrapher is not there, the engineman is in danger of failing to note the signal. In other words, the Commission finds the telegrapher left to himself is unreliable, and the same conclusion is arrived at in regard to the engineman and the automatic signals. According to the report, to obtain the desired security the best-known method is to rely upon the coöperation of these three acknowledged insecurities.

But apart from this consideration, the point for us railroad men to note is that we have been found directly and personally responsible for the accidents. Our failure in duty has been the actual cause for the loss of life resulting from these collisions. To say the least, these failures in duty are very numerous, and the authorities who are depended upon to look into these matters are of opinion that "the block-signal system is the bestknown instrumentality for the prevention of " these accidents. But, unfortunately, a great many years must elapse before the railroads, both single and double track, can be thoroughly equipped with these signals, and meanwhile the public must remain at the mercy of these failures in duty which in the main, some day, block signals are expected to eliminate.

Working along these lines, however, the progress 


\section{A RAILROAD MAN TO RAILROAD MEN 7}

made by the authorities in eliminating the causes of these accidents and in improving the conditions has so far been very insignificant. There seems to be an inclination in all quarters to let things run their natural course, and to wait for the time when these accidents shall have become mechanically impossible.

But the writer of this book has very different ideas on the subject. He has studied the actual results that have been obtained from these blocksignal systems, and at the same time he has paid particular attention to the behavior and responsibility of the men in regard to these accidents. The study referred to has not been a matter of a month or two, but of many years. For unknown reasons some of my critics have seen fit to question the nature of my experience as a railroad man. Fortunately it is an easy matter to give an account of my qualifications. The mere fact that one has had a varied and lifelong experience as an engineman or a conductor would be only partially significant. But a man who has been a telegraph operator and towerman for twenty-seven years and part of the time chief clerk to a railroad superintendent has certainly some claims to an all-round knowledge of his subject. The extent of the territory covered by this experience is even wider than one would suppose. For a telegraph operator is, of necessity, 


\section{A RAILROAD MAN TO RAILROAD MEN}

one of the best-posted men in the service. He has occasion to observe, and he is more or less obliged to understand, nearly every move that an engineman, conductor, or brakeman has occasion to make in the routine of his work. He has every opportunity to observe just how trainmen of all classes obey the rules and the signals. Add to this opportunity to become conversant with the practical side of railroad life, the knowledge that is derived from attending to the correspondence of a superintendent and the general work of the office. This includes supervision of pay-rolls, the hiring and examination of men, the investigation of accidents, the tracing of trouble of every description, and the handling and movements of both freight and passenger trains. In a general way this has been the nature of my experience, which I think has been eminently practical and not "academic." Consequently, although some of my statements and conclusions may be questioned by railroad men who have had equal or greater experience, I nevertheless think that, in the interests of the public safety, I should be favored with a full and patient hearing.

Addressing the great body of American railroad men, I have no hesitation in saying that the service with which we are connected rests to-day under the shadow of a great shame. The situation cannot be looked upon in any other light, and it remains with 


\section{A RAILROAD MAN TO RAILROAD MEN 9}

us as a body, and as individuals, to apply the remedy. In order that my standpoint and the reasons for my conclusion may be thoroughly understood, I think it will be profitable, as well as interesting, to give a short history of the personal investigation and study which, for many years, I have steadily pursued in the interests of better and safer railroad service.

Manifestly, in order to treat my subject in the widest and fairest manner, all sentimental or personal scruples must be thrown aside. In explaining my position I can in no way be a respecter of persons or traditions. To me the management of a railroad is merely part of the subject-matter which I am called upon to consider, and an organization of railroad men is nothing more or less, so far as my investigation is concerned, than a combination of units constituting a certain influence which I feel myself at perfect liberty to criticise in the interests of the larger social body represented by the traveling public. The death roll and the record of suffering in preventable accidents in the United States is justification, repeated a hundred times over, for any and every conceivable probe into personal conduct or the policy of organizations.

But in holding up the conduct of others to criticism, it is but reasonable that I should begin with my own conduct and work in the matter. By what 


\section{ro A RAILROAD MAN TO RAILROAD MEN}

methods and means, for example, have I arrived at the conclusion that on our railroads the interests of the community have become secondary to those of the employee and his organization? This, of course, must be looked upon as a very serious statement, and it certainly calls for the earnest consideration of intelligent railroad men. In order to understand the nature of my evidence on the subject, it will be necessary to go back with me to the time when my attention was first directed to railroad accidents.

In the year 1892 a very serious accident occurred near the signal tower where I was employed. Although I was not on duty at the time I was naturally very much interested in the case, and I paid particular attention to the evidence that was brought forward at the hearing in the effort that was made to hold an engineman responsible for the disaster.

A passenger train, standing at a "home signal," which was set at danger, was telescoped from the rear by a freight train, running practically at full speed. About 1500 feet from the home signal a distant signal was located. This signal, in the cautionary position at the time, was a distinct notification to the freight engineman to proceed cautiously and to prepare to stop before arriving at the home signal. An additional reason for such caution arose from the fact that the night was dark and extremely 
foggy. The explanation of this accident was to me extremely simple. The signals were all right, and so were the rules for that matter; but, from one end of the road to the other, these distant signals were dead letters. In the daytime, with apparently a clear track, absolutely no significance was attached to them; consequently I was not surprised at this disaster in a fog. But the incident was brought home to me in such a dreadful way that it started a line of thought and an investigation into the safety problem on our railroads, that has lasted until to-day.

But once started in my study, there was no turning back. Within sight of the interlocking tower where I worked there was a freight yard of considerable dimensions; the main lines of the railroad ran through this yard, and cross-over switches connecting one side with the other were protected by what are called yard protection signals. These protection signals, which are located about I 200 feet from the cross-overs, must be thrown to the danger or stop position before the switches can be changed. Once in a while, however, I noticed that the signal in question was put up to danger after an engine had passed, which of course disclosed a very serious state of affairs, for the engine in question was almost certain to get into trouble at the cross-overs. Taking note of this danger, I called it to the attention of the management. The result was, a rule calling 


\section{I2 A RAILROAD MAN TO RAILROAD MEN}

for flag protection as well as signal protection at this particular point, but no attention was paid to other yards on the system where the conditions were more or less similar. As a matter of fact, it was not until a serious wreck had occurred that a general rule on the subject was put into force. This rule ordered the employee, after he had placed the signal at the stop position, to wait a sufficient time to allow a train that might have passed the signal to arrive at the cross-overs and thus to proceed in safety.

Now I would like railroad men in general to pay particular attention to my criticism of their conduct in relation to this rule and to other illustrations that follow. Here is a necessary law, put into force by the management for the safety of travel and the good of the service. It is a direct appeal to the common sense and honor of employees. Nevertheless, in a short time after the order was issued, it was a dead letter. True, very frequently in clear weather the rule is absolutely unnecessary ; but when the weather is foggy, or at places where there is a curve, the failure to observe the rule is liable to result in a wreck. In one month I was a witness to eighteen breaches of the rule on a single division of a railroad.

It must be understood that I am now describing my actual experience with men, management, and rules, and the reasons that induced me to follow the 


\section{A RAILROAD MAN TO RAILROAD MEN I3}

matter up and to inquire if the work I am describing can be termed typical of American railroads.

Of course, one of my first thoughts in regard to the non-observance of rules related to the lack of adequate supervision by the management. To me it seemed to be a remarkable fact that I could easily follow up the working of a rule and the behavior of the men in regard to it, but the management seldom did anything of the kind. In this way my field for investigation became wider and wider, and I quickly arrived at an idea of the seriousness of the situation, from the standpoint of the people who travel from place to place on the cars.

One day a conductor of a freight train came into my office and asked for a train order which, according to the rules, called for the signature of both engineman and conductor. After receiving the order by telegraph from the train dispatcher, I placed it on the desk ready for the signatures. A minute or two later, when I returned from some other work, I saw that the conductor had signed the order for himself and the engineman as well. I said to him, "That will never do. Not so long ago that trick killed three trainmen, wrecked two engines, and cost the company something like $\$ 50,000$. You must go for your engineman." "That's a great note," the conductor replied. "You mean to say you intend to make me walk half a mile and lose 


\section{A RAILROAD MAN TO RAILROAD MEN}

half an hour in order to get that signature; you are the first operator who ever picked me up in this way. Why, they do this thing right along up the road. If the dispatcher was making a meeting point it would be different, but it's done every day in the case of a work train or a gravel train." "That may be very true," I replied, "but you can't do it here; the engineman himself must sign the order." Now this man was actually telling the truth, and in a very short time I had the proofs in my possession.

Railroad men who read these lines must remember that in those days I was simply collecting evidence in a fair and honorable way, for my own private purposes, that would enable me to assign some kind of reason or cause for the lamentable loss of life on American railroads. I found the railroad business wherever I went to be bristling with reasons, and the more I looked into the matter the greater became my astonishment.

It cannot be claimed that my illustrations apply to only one or two railroads, for an examination into these accidents, regardless of locality, will reveal the fact that almost without exception they have resulted from the disregard of rules that are practically similar in nature and intent on all railroads.

In those days, and to a great extent at the pre- 
sent time, railroads were equipped with fixed cautionary signals. On approaching such signals it became the duty of the engineman to run slowly and look out. I discovered, in fact it was a matter of common knowledge and remark, that not one man in fifty did anything of the kind, although accidents from the breach of this rule were of daily occurrence, and the lives of thousands of passengers and employees had already paid tribute to this disgraceful state of affairs. To my mind the personal nature of this general inefficiency was its remarkable feature. We railroad men were running the business, and the management and the public got it into their heads, in some way, that we were doing our duty. Unfortunately, with the facts before me, I was unable to console myself with any such delusion. The nature and variety of the incidents I was able to discover were most astonishing. While I certainly dislike to beat the air in this way with illustrations, the matter of our own personal conduct and our direct responsibility for these preventable accidents cannot be sufficiently emphasized. At any rate, the incidents $I$ am describing must be taken as the incentive and inspiration $I$ received for continued exertion.

Furthermore, railroad men are very well aware that my illustrations cannot be looked upon as ancient history. Those on the inside still hear of 


\section{I6 A RAILROAD MAN TO RAILROAD MEN}

strange happenings from day to day. I think a chapter on narrow escapes would do us railroad men a power of good. It is surely by taking warning from them that disasters on the rail can be best avoided.

Not so long ago on a Western railroad, and about the same time on a New England railroad as well, passenger trains were run for miles on the wrong track against the traffic. This was done in broad daylight, without orders of any description. The mere possibility of such occurrences, involving trainmen from brakemen to enginemen, is almost unthinkable. With such mental and physical paralysis to guard against, of what avail are block signals or the best intentions of a management? The popular contention that these things occur only "in spots" is most harmful. If only he will do a little thinking, any railroad man in the country can study these so-called "spots" without wandering an inch from his own job. The accidents that are liable to occur when the responsibility can be divided between the rules and the management are as nothing compared to those that we railroad men initiate and blindly invite of our own accord. With all sincerity and candor I present a final illustration, not from the past, but from what is positively taking place at the present day.

As we all know, managers of American railroads 


\section{A RAILROAD MAN TO RAILROAD MEN I}

have been wrestling with the "hot-box problem" for nearly half a century. The rules relating to the matter are and always have been unmistakable. "Take no chances. If necessary, set off the car."

On June 17, 1908, a freight train, running fully thirty miles per hour, approached my signal tower with a clear right of way east-bound. At the same time an express passenger train, rushing at full speed west-bound, came in sight. From a distance of nearly half a mile I could see that a car on the freight train was enveloped in smoke and flame from a hot box. As an actual fact, the engineman, conductor, and brakemen were aware of it. A brakeman was on top of the car watching the trouble. But they were nearing the terminal, and on a parallel east-bound track there was a train that all hands were very anxious to pass by or "jump." So, by common consent, they were taking the chance on the hot box, and the engineer "had her wide open." As the freight approached the tower I could see the chips flying from the ties, which indicated that the melted journal had snapped in two. A few seconds later both east- and west-bound tracks were blocked with the twisted rails, broken ties, and derailed cars. The passenger train, consisting of sleepers and crowded coaches, escaped dashing into the wreck by a miracle, - that is, by a mere fraction of time. 


\section{I8 A RAILROAD MAN TO RAILROAD MEN}

This is but an incident in the history of taking chances. Concealed in it, however, is a personal lesson that vitally concerns every man in the service. Do we actually insist upon disaster such as threatened this passenger train before we can be persuaded to come to our senses? In this business of taking chances, which covers every branch of railroad service, both the traveling public and the railroad corporations are at our mercy. Through a long course of years, influence and discipline of all kinds have utterly failed to check it. It is useless to talk about "spots," for most of us take chances systematically. In fact I don't think the managements have any idea of the nature and extent of this evil, for the reason perhaps that they have made no special study of the subject nor watched for and made note of illustrations, as I have. One would think it would have occurred to some railroad manager to issue a general order, with a caption somewhat as follows: "Here is a list of twenty dangerous chances which some of you are in the habit of taking. For goodness' sake, have a care !"

Here, and elsewhere in this volume, it seems to me that it is demonstrated, beyond possibility of question, that thousands of lives have been sacrificed by reason of the palpable neglect and inefficiency of certain railroad employees. It makes not a particle of difference whether we conclude to 
call these careless men a majority, a minority, or a scattered few. Fundamentally it is also quite a secondary consideration that rules and methods of management at times can be shown to be partially responsible for accidents that result from this in. efficient service. For the time being also, let us forget that elsewhere I call attention to the con. duct and influence of the railroad labor organizations as an important factor in the situation, and to the absolute necessity, under existing conditions, of governmental interference. Let us put aside all these considerations, and as thoughtful, well-intentioned railroad men ask ourselves if we are socially and morally interested in this safety problem on American railroads. Do we consider the matter important enough to give to it more than an occasional thought or passing comment? When the lives of our fellow employees, or of passengers, are sacrificed by reason of personal forgetfulness or negligence, have we, the principals, or at least those most nearly concerned in the accidents, any remarks to make or any suggestions to offer? For the future, as in the past, are we going to allow this business to drift? Are we all of the same opinion as the train-master who said to me: "What's the use of writing up these matters? We always have had careless men. We can't expect to get rid of them altogether. Like the poor, they are with us always." 


\section{A RAILROAD MAN TO RAILROAD MEN}

This man forgot, as many of us are liable to forget, that "writing up," as they call it, is the only known method in modern civilization by means of which enlightenment and education can be passed around and disseminated.

But let no one imagine that I have any unreasonable expectations as regards the improvement of conditions on our railroads. I fully recognize and make allowance for the difficulties connected with the problem and for the shortcomings of human nature, but at the same time I insist that if we only open our eyes to our personal responsibilities in the matter, and pay half as much attention to the public interests as we do to our own, an astonishing improvement in the service will immediately result. It is actually a matter of reasonable demonstration that at least seventy-five per cent of the casualties might be avoided by increase of interest on the part of the employee, and the earnest concentration of his best thought on the subject. This awakened interest, however, must not be a subordinate matter. It must be a consecration apart from and above all questions of wages, discipline, or the interests of organized labor. There is no question in my mind as to the efficacy or wonder-working properties of the personal cure. The real question is, Are we big enough to undertake the job? If we continue to avoid the issue, and thus publish the fact 


\section{A RAILROAD MAN TO RAILROAD MEN 2I}

that our social conscience is a blank, we may just as well write ourselves down as the most selfcentred aggregation of individuals in the industrial world. It is ridiculous to suppose that conditions such as I describe in this book can be permitted to continue much longer. Sooner or later public opinion will be called upon to define, with no uncertain emphasis, just how far our private rights can be permitted to infringe upon our public duties.

But while our apathy in these matters must be evident to any thoughtful man, it will certainly add to the impressiveness of the situation if it can be shown that our conduct differs from, and is altogether less praiseworthy than that of other men and other organizations, under very similar conditions. Is it not remarkable that all over the United States, business and scientific associations should be actively bestirring themselves in regard to the railroad accidents?

The railroad labor organization alone is inactive and silent in the matter. The railroad business is a profession, in the operation of which there are certain features that threaten the public welfare. The business of a doctor or a surgeon is also a profession, in which there are many dangers and difficulties that also relate to the public health and safety. There is actually no more reason why surgeons should come together and consult for the good of 


\section{A RAILROAD MAN TO RAILROAD MEN}

humanity and the honor of their profession, than there is for railroad men to do so. As a matter of fact, every profession on earth is jealous of its good name, and plans early and late for the improvement of the service it is called upon to render to the public. In my opinion railroad men should be equally sensitive to the call of the social conscience.

Of course the discussion of these matters relating to the personality of railroad men, to be of any practical value, must be followed by action or experiment of some kind. Years ago, I proposed to the managements of several railroads that we, the men in the operating departments, should be invited to form a "Safety League." I thought it would be a good idea to have a badge or button of some kind. There would then be no doubt in the public mind as to our interest in the problem. "Let us try the experiment," I said. "We can at least show that there is one division of one railroad in the United States where the men have come together, talked over the difficulties, and determined to make an improvement in the records."

But it was pointed out to me that the one great objection to the plan was the fact that leaders of our organizations would immediately veto anything of the kind. They have always frowned upon any such democratic relationship between men and 


\section{A RAILROAD MAN TO RAILROAD MEN 23}

management, such as a Safety League would initiate. It is doubtful, however, if these objections would stand a little public investigation and pressure, and therefore I think the present is an opportune moment to revive the proposition. There would be no chance for friction between labor men and management in the efforts of the League to improve the service. The main object of the League would be to arouse our interest and concentrate our attention upon the routine of our daily work, into which certain factors that imperil the safety of travel have been allowed to enter. We railroad men are still too human to render the best service without a certain amount of emulation and encouragement. A Safety League could be depended upon to furnish this much-needed stimulus. If managers and labor leaders would come out in the open, in the way I have indicated, and let the public see by this practical demonstration of their interest that they are thoroughly in earnest, I am sure they would find the employees ready and willing to second their efforts. That a Safety League among American railroad men would be worth the candle can be thoroughly comprehended if we give a moment's attention to the endless string of fatalities and the millions in money losses that are now the recognized tribute that is being paid to these failures in duty. 


\section{A RAILROAD MAN TO RAILROAD MEN}

For the rest, to the thoughtful railroad man, a final word remains to be said :-

In any comprehensive study of efficiency, prosperity is one of the most important factors to be considered. There is always an intimate relationship between struggle and efficiency. The general rule is from shirt-sleeves to shirt-sleeves, with prosperity as the halfway house. In all manner of human affairs it takes high moral exertion to stave off this fate. In the railroad business to-day the marked prosperity and power, political and otherwise, of the employee, is a positive menace to the safety of travel, on account of the lack of the moral safeguards to which I refer. This statement should not have an irritating effect upon railroad men; it should stimulate thought. The significance of the above conclusion is emphasized, from the fact that our labor leaders appear to be utterly unmindful of "the writing on the wall." With shorter runs, increase of pay, larger personal privileges in every direction, and an ever-widening sphere of power and influence, a corresponding enlargement of our appreciation of our social and moral responsibilities is absolutely essential.

It is obvious, therefore, that the safety problem in regard to preventable accidents must depend to a great extent upon the thought which we are now willing to devote to it. What the managements of 


\section{A RAILROAD MAN TO RAILROAD MEN 25}

corporations and the public can do about it without our assistance can be judged from what they have been able to accomplish in the past. Up to date we railroad men have permitted our leaders to do all our thinking for us. This arises from the fact that we have never thought about or desired anything but material advantages; consequently labor leaders to-day are only too often a reflection of our material desires and of our lack of social responsibility. These men are good, bad, or indifferent, according to the returns we receive from them in cash. In this way they have been uniformly faithful to our interests. But we must not forget that we railroad men, millions of us, are part of the democratic fabric of the nation, and no democracy can possibly flourish upon purely materialistic principles.

The matters to which I direct attention in this volume call for the serious thought of employees, and let us take for our inspiration the truth that the democratic idea of government is itself founded upon the hope that every man will do his own thinking. 


\section{II}

\section{THE MEN}

Money, brains, and intelligent labor form the combination that is attempting to solve the problem of safe and expeditious transportation on American railroads. In order to secure the desired result no expenditure, either of effort or of treasure, is considered too extravagant. So far as concerns speed and comfort, the conditions at the present day leave little to be asked for; but when we come to take account of the human lives that have paid toll to American systems of railroading, we cannot avoid the conclusion that something must be fundamentally wrong in the methods of handling the traffic.

To account for the unsatisfactory state of affairs, there are various popular excuses and explanations. Discussions in regard to block signals, tired employees, faulty rules, and so forth, are seemingly as endless as, up to date, they have proved fruitless. For the most part these discussions are being carried on by professors and students of economic conditions and by clever collectors of statistics, but the men who know all the details of railroad life, the men who pull the signals and handle the trains 


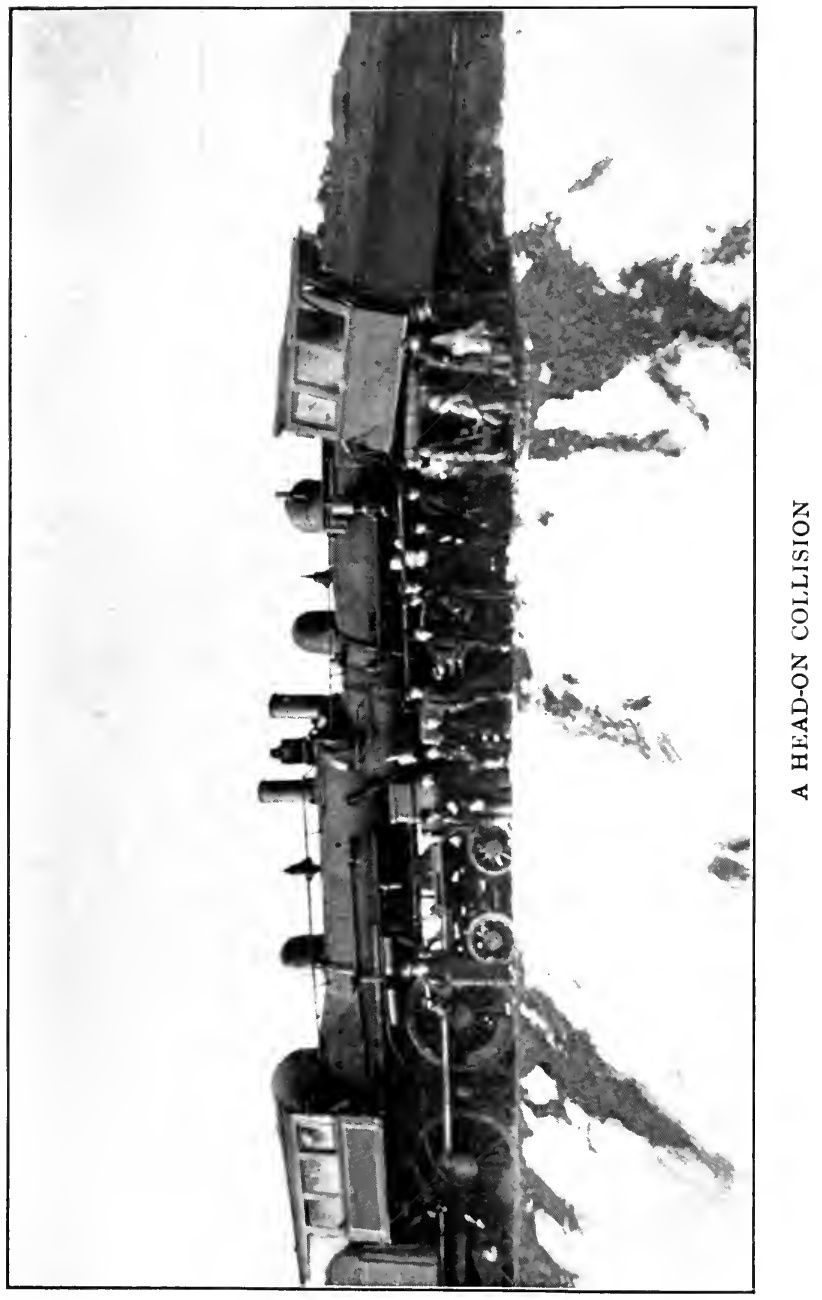




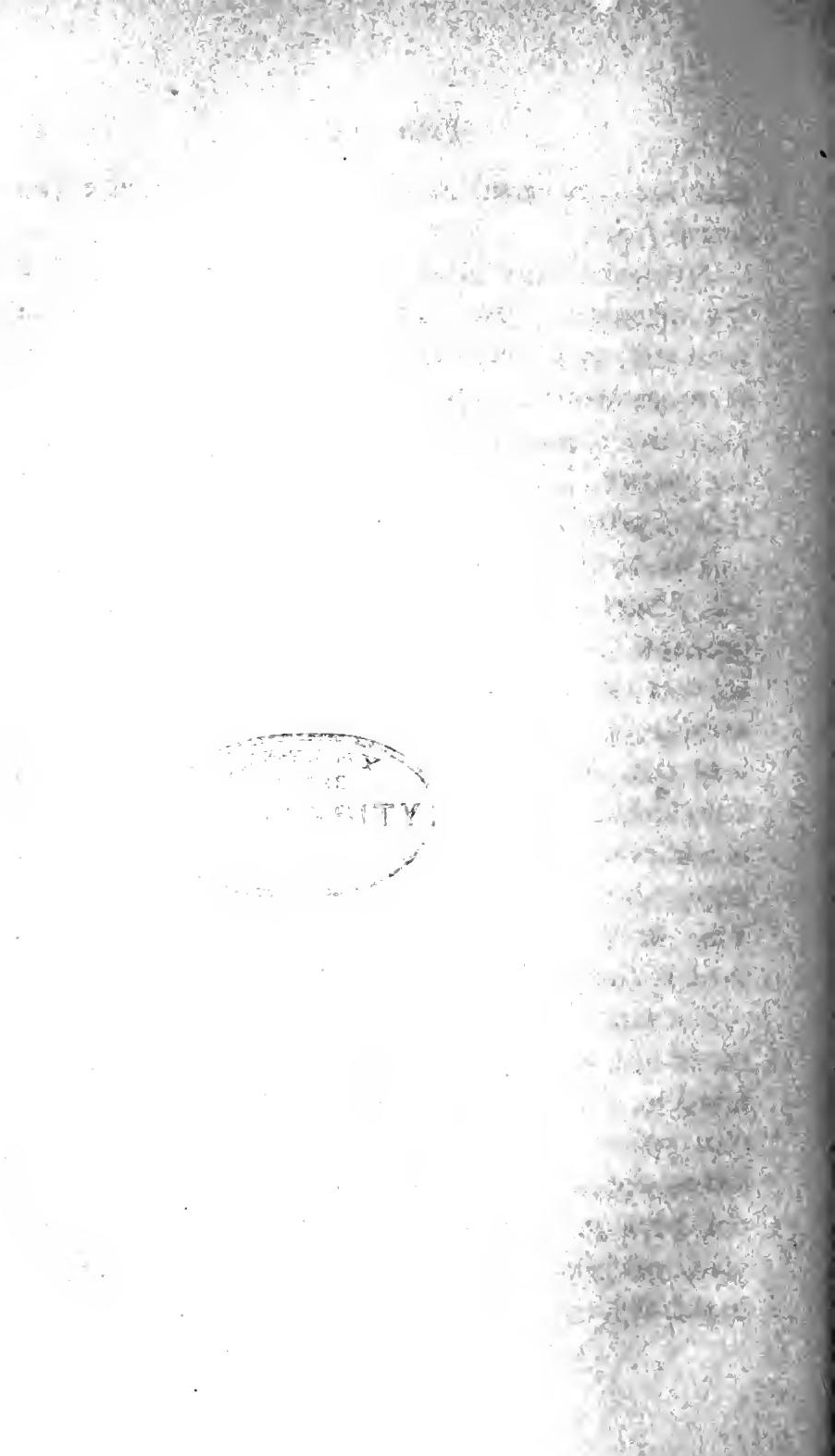


that are concerned in the trouble, have yet to be heard from.

However, regardless of the nature or value of the discussion, the fact remains that we railroad men still continue in the same blind rut, and there is no perceptible improvement in efficiency. Managers and superintendents appear to be helpless in the matter. They are evidently unable to stem the tide of preventable casualties.

The story of one accident is the story of them all. There is a smash-up. Property is destroyed, perhaps passengers are hurt. The superintendent at once starts an investigation. It is practically secret. Not a word in regard to it is allowed to leak out. After a while a decision is arrived at and a verdict is rendered, - in secret. Then discipline is administered. A private communication containing verdict and penalty is sent to the accused party. This, of course, he keeps to himself, and the incident is closed.

But before long another employee, in utter ignorance of the first man's blunder, commits the same mistake. Both of these wrecks may have been serious, perhaps with loss of life, but that makes no difference. Our traditions and ancient habits have not been interfered with and the bills have been paid. Such is discipline in the dark. Great, indeed, is secrecy. 
Yet it is useless to question either the ability or the integrity of superintendents. As a rule they have risen from the ranks, and are thoroughly capable and conscientious. Every avoidable accident is a reflection on their management, and therefore it can be taken for granted that they render the best service possible under the circumstances. But unfortunately they are beset on all sides with obstacles and difficulties. What they would like to do, even in the matter of secrecy and discipline, must frequently wait upon what they are able to do. Time was when an offending employee could be discharged on the spot, without appeal. To-day he claims a hearing. A brother employee, an expert on railroad law and precedent, stands at his elbow as prompter and assistant. In this way, as we railroad men figure it out, the "law's delay" puts a curb on the "insolence of office." Thus the initiative of a superintendent is held in restraint, and management by means of schedules and agreements takes the place of personal direction, while over all hovers the watchful eye of the grievance committee. Meanwhile, we, the employees, look on, watching the game.

When people are killed, when property is wrecked, we have nothing to say. It is for the management to figure out reasons and remedies. Of course, as individuals, we are interested and sorry when acci- 
dents happen, but personally we do not bestir ourselves, nor do we call upon our organizations to bestir themselves in the matter. We simply stand pat on our rights. If a prominent railroad man is questioned on the subject of railroad accidents, he will shrug his shoulders and say, "Human nature." So far as he is concerned, railroad men are to be protected, not criticised. If you turn to the management your errand will be equally fruitless. The superintendent will have little to say. Generally speaking, he has no fault to find with the men, and the men have little fault to find with him. This seems to be a tacit understanding in the interests of harmony. It being impossible to move without treading on somebody's toes, by all means let us remain motionless. As for the public interests, they must shift for themselves. Consequently, in place of earnest coöperation in the interests of efficiency and improved service, there is something in the nature of a friendly deadlock between men and management.

Nevertheless, in spite of many appearances to the contrary, the problem of the efficient and safe running of trains is a very simple one. Fundamentally it is not a question of rules or safety devices, but of personal conduct and habits of thought.

In everyday life when a man fails to make a satisfactory score with a first-class gun we do not place 
the blame on the weapon. If we desire greater efficiency in marksmanship we direct our attention to the man. But in the railroad business such commonplace logic does not seem to apply. When a man violates an unmistakable rule or runs a signal with disastrous results, there immediately arises on all sides a peremptory demand for a different kind of rule or an improved signal. Public opinion, with little understanding of the issues at stake, has a constant tendency to blame systems and managements. Even the Railroad Commissioners, agreeing with or responsive to this public sentiment, almost invariably recommend improvements along these lines. In this way for many years attention has been concentrated upon the machinery of management, its rules and safety appliances, and the personality of the men has been side-tracked. The injurious effects of this policy and the manner in which all hands have conspired to obliterate personality from the railroad business will be evident from the following illustration.

A short time ago, in the vicinity of Boston, an express train telescoped an accommodation passenger train. The track in question was protected by no less than four cautionary rules and signals. In this way the express train received four distinct and emphatic intimations that a train was on the block ahead of it. With the slightest attention to the rules 
or to the dictates of common sense, the protection was sufficient, yet the train ahead was telescoped as it was pulling out of a station. Of course, in placing the responsibility, the plain and real issue in this case was the question whether the express train was or was not running slowly and with extreme caution, as called for by the rules. In order to determine whether the rules and signals were sufficient to prevent a collision, it was surely proper and reasonable to ascertain whether, on this occasion, they were obeyed. But the Railroad Commissioners, after an exhaustive investigation, took a different view of the matter. Their finding or verdict in their own words was as follows :-

"It is not necessary to determine whether the engineman did or did not exercise proper caution; the significant fact is that the discretion actually used led to disastrous results. Under the conditions the signal should have been red."

The harmfulness of this decision will at once be apparent. It cuts the personality out of the business at points where obedience to the rules is the vital issue. Green signals or red signals are equally valueless if ducks and drakes can be played with the rules in regard to them. A decision like this one is confusing and demoralizing to conscientious railroad men, and it converts the management and discipline of a railroad into a thing of shreds and patches. 
To emphasize this point, it should be added that another collision of a similar nature took place about the same time on the same railroad. An express passenger train approached a fixed signal which indicated caution. The engineman, on the lookout, but with the caution up his sleeve, kept on his way without any reduction in speed. A moment later he encountered a red fusee which called for an absolute stop, but it was too late. Neither the fusee nor the flagman frantically waving his red flag availed to arrest the momentum of the flyer, which dashed into the rear of another passenger train standing at a station.

Now, with all deference to the Railroad Commissioners, the "significant facts" in these accidents are the personal conduct of the employees and not the nature of the signals or the wording of the rules.

Of course, taking a wider view of preventable accidents, it is always an easy matter to divide the responsibility for them between the men and the management. This is the usual and popular method of treating the subject. But the idea, reasonable at times, has been overworked, and has now degenerated into a principle that responsibility should always be divided. Consequently, while we are busy adjusting the division, we frequently lose sight of the real issues, and the offenders are allowed to escape. 
Fundamentally, then, it must be confessed, we railroad men are to blame for these preventable accidents. Most of the trouble can be directly traced to our own personal behavior, that is to say, to our conduct and habits of thought as railroad men. This is by no means a reflection on our character as sympathetic and reasonable human beings. Our intentions are all right, but our training in the railroad business has been all wrong.

But it is of little use to talk or write about personality in the abstract. As practical men dealing with a practical topic, we must follow the railroad man out on the road, we must watch him at his work, and we must take notice of the common sense, the caution, and the good judgment or otherwise, which he habitually displays in the execution of his duties. Then, and not until then, can we expect to become qualified to place our opinions or conclusions on record.

Now the regulations relating to the running and protection of trains are very similar on all railroads, and therefore the following rule taken from one of our current working time-tables may be looked upon as thoroughly representative.

"A freight train must not leave a station to follow a passenger train until five minutes after the departure of said passenger train."

To any ordinary thinker this rule will appear to 
be plain, positive, and for the most part necessary. Yet as a matter of fact no attention whatever is paid to it either by enginemen, by conductors, or for that matter by superintendents. Its violation has been the cause of collisions and loss of life, but that does not seem to bother us, for we continue to disregard it. Let us take another illustration.

At the point where the writer has been employed for many years, there is a junction of four-track and two-track systems. The rule for the handling of trains at this point is as follows :-

"All trains will approach and enter upon fourtrack sections under complete control."

There is nothing misleading or uncertain about this rule. The instructions to enginemen are positive. The towermen at these points understand how necessary and important this rule is. Besides, it is the written result of the experience of the officials. Nevertheless, it is totally and consistently ignored by enginemen. But enginemen are not alone to blame. Conductors should at least be conversant with the rules. The railroad officials who ride on these trains might also very reasonably be expected to notice the persistent violation of regulations for which they themselves are responsible. Yet even the trains bearing the Railroad Commissioners will rush over the territory in question as fast as the wheels can turn. The conditions and the rules in 
this case are practically the same as were those at Salisbury, England, at the time of the recent disaster in that city.

Now as it seems to me, the all-important facts in these cases do not relate to the nature of the rules, nor even to their non-enforcement, but to the downright neglect of railroad men to do as they are told. For, granted observance of them, all other questions in regard to the rules dissolve into thin air.

Unfortunately, the rules I have quoted and the interpretation put upon them by railroad men cannot be taken as examples standing alone, for they are merely illustrations of a principle that covers the whole cautionary field in our railroads. In some way we have got it into our heads that these rules are permissive, not positive. This permissive principle means the exercise of our own judgment according to circumstances, regardless of the rule. Acting under the influence of this principle, the flagman protects his train to the very letter of the rule when it is manifestly necessary, but when, in his opinion, it is not, he takes chances. In this way he forms a habit of using his own judgment in regard to a positive rule. Sooner or later this means a preventable accident.

The engineman encounters a single torpedo. According to his rules, he should bring his train to a full stop. But as he happens to have a clear track 
for a mile ahead of him he keeps on. He, too, forms a habit which has to be reckoned with some day.

Again, all trainmen understand that an express train has no business to run past a station while accommodation trains are discharging passengers. It is by no means an uncommon occurrence, however, to see an express train disregard these positive instructions, on the strength of hand motions given by trainmen on the accommodation train to the effect that they are about to start, and that the way is safe and clear for the flyer. Yet in this manner accidents happen, and passengers from the accommodation are always likely to be caught in a trap between the trains.

But the dangerous and widespread effects of the permissive principle applied to important rules will be appreciated to the full when we study the interpretation which railroad men in general are in the habit of applying to the word caution.

On all railroads there are certain fixed signals for the guidance and information of employees. When caution is called for, the light is usually green and the semaphore horizontal. Now, as the writer looks at it, when any signal indicates caution, it is not to be looked upon as a permissive or conditional signal to be interpreted at will by different enginemen. According to the rules and to common sense when a train, at the time a cautionary signal is 
sighted, is running thirty or forty miles an hour, it calls for a positive and not a theoretical reduction in speed. The cautionary signal is not merely a piece of information to be stowed away in the brain of the enginemen, to be utilized when a rear end or a broken rail is sighted.

Although for a number of years the inflexible enforcement of the rules relating to these cautionary signals has been advocated, yet to-day train after train will run past these semaphores and green lights without any reduction in speed, provided the track ahead of them is seen to be clear.

Here we tackle the very heart of the matter, for in so far as the rules and common sense are concerned, it should not make a particle of difference to the engineman whether the track ahead is or is not known to be clear of trains; his instructions call for cautious running, and by no possible interpretation or juggling with words can cautious running, or running under control, be taken to mean running at full speed. Yet in the way $I$ have indicated the cancer of a very dangerous habit has been allowed to grow into the American system of managing trains. This wrong interpretation of the word caution by enginemen and others has without a shadow of doubt during the past few years cost the corporations thousands upon thousands of dollars and multitudes of human lives. For if railroad 
managers labor under the delusion that enginemen can run cautiously at full speed when the track is clear, and avoid disaster when from unforeseen reasons another train happens to be on the same section, they are very much mistaken.

Practically speaking, then, the permissive principle covers the whole field of railroad life, and is a constant menace alike to the interests of the corporations and to those of the traveling public. As a matter of fact, we, the employees, are bigger than the rules. According to our way of thinking, it is not alone necessary that a rule should be plain and sound from a general standpoint, but its downright meaning and necessity must also be evident in each and every particular instance. If it fails to stand this test, we consider ourselves at liberty to use our judgment in regard to it.

Illustrations of the danger that lurks in this permissive principle can be multiplied indefinitely. But, after all, it is only a link in the chain, for there are other features in the personality of railroad men that call for serious attention.

The other day, within a few miles of Boston, an express passenger train approached a railroad crossing at grade. For some reason the gate-tender was negligent and failed to lower the gates. By reason of just such negligence, teams are frequently struck and lives are lost at these crossings. On all railroads, 
the rules are quite plain and unmistakable in regard to such matters. It is the duty of the engineman to report the incident to the management. As a matter of fact on this particular occasion the engineman failed to do so. He failed to appreciate the fact that the safety of the public at these crossings is altogether dependent upon the strict observance of the rules. He had scruples and emotional objections, perhaps, to reporting this gate-tender, and rather than do so he took all the chances in connection therewith, chief among which is the simple fact that on a railroad unchecked negligence can be depended upon to breed disaster.

That railroad men in general are either indifferent to or ignorant of the importance of the above fundamental fact will be made still clearer by another illustration. On September I6, I907, that is, on the day following the disaster at West Canaan, N. H., the writer was a witness of the violation of two most important rules by a number of enginemen, conductors, and brakemen. A switch leading from the west- to the east-bound main line was left open while an express passenger train was passing inward bound. A freight train was on the west-bound track waiting to back over. Two minutes later, with his train only halfway in to clear the main line, the engineman on the freight whistled in his flagman in the face of an accommodation passenger train 
which had followed the express. From beginning to end, on the permissive principle, it was a perfectly safe transaction, for there was a mile of straight track in both directions; but the rules for the running of the trains and for the safety of the public were violated. The witnesses were seven or eight veteran railroad men, who looked upon the affair as perfectly proper and justifiable under the circumstances. It never entered the heads of these men that the affair should be reported to the management. That some of the best men in the service should behave in this way, as it were in the very shadow of the accident at West Canaan, is almost inconceivable. Of course, if these incidents stood by themselves their significance might be comparatively trifling; but as a matter of fact they are illustrations of a condition which is thoroughly typical of American railroads. This condition or situation may be briefly yet correctly outlined as follows :-

There is practically no out-on-the-road supervision on American railroads.

Railroad managers depend upon the reports of employees for information in regard to violations of rules. But employees do not, and cannot be compelled to, report their associates ; consequently negligence of all kinds is practically unchecked.

Finally: unchecked negligence can be shown to 
be the root and direct cause of nearly all preventable accidents, and loss of life therefrom, on American railroads.

Here we have a conclusion worth looking into. At a glance we perceive that negligence is the prime and fundamental fact. It is the direct cause of the trouble. The fact that the negligence is unchecked is important, yet secondary. It should be treated as a separate issue, and it must stand or fall on its own merits.

But our conclusion that accidents result in almost all cases from unchecked negligence should be supported by evidence and proof. For examples in support of it, let us take two of the most disastrous wrecks in the history of New England railroads.

On November 26, 1905, at Baker Bridge in Lincoln, Mass., seventeen people were killed and thirty injured. An express passenger train was following an accommodation train, which was somewhat late. Cautionary signals calling for reduced speed and careful running were passed at intervals by the express train, but, according to the evidence, the engineman paid no attention to them; hence the accident. Now the habitual negligence in regard to these cautionary signals was a matter of common knowledge. In fact, attention was called to the matter both before and after the accident by the writer. The unchecked negligence in this particular 
case was therefore directly responsible for the accident and the loss of life.

Again, on September I 5, 1907, at West Canaan, N. H., twenty-five people were killed and forty injured. The unchecked negligence in this case is by no means so striking as in the previous example, and yet the evidence pointing in that direction is quite as significant. A mistake occurred in the transmission of an important train order. This mistake was the direct cause of the accident. For various reasons it was impossible to say by whom the mistake was made.

Now let us turn to our book of rules and take note of the following instructions to train dispatchers and operators: "In transmitting messages write slowly and firmly," etc.

With all proper consideration for hard-worked and conscientious train dispatchers, I am compelled to confess that train orders are seldom if ever sent "slowly and firmly." Operators will bear me out in the statement that orders are transmitted by dispatchers as fast as the men can handle them. That is to say, between veterans in the business they are rattled off at the highest limit of speed. The men concerned in the accident at West Canaan were veterans. Had the man at West Canaan been a "plug," that is, a green hand, in all probability the accident would not have occurred. While, of course, 
this is merely a supposition, yet the fact remains that the men would have been transmitting slowly and firmly, and the chances for a mistake would have been reduced to a minimum.

I thoroughly understand and appreciate the difficulties with which the train dispatcher has to contend. I am quite aware that he is called upon to handle trains with the utmost dispatch; nevertheless, I insist that, in order to reduce chances of accident to a minimum, train orders should in all cases be transmitted slowly and firmly. I stand by the rules. The issue is between speed and safety, and in all cases the latter should be given the right of way.

Thoughtful railroad men, who understand the situation on the railroads at the present day, are yet very slow in suggesting remedies. They say, "It is up to the management to enforce the rules." On the other hand, if a superintendent can be persuaded to express an opinion he will retort, "It is up to the men to obey the rules. They are plain enough and sufficient for the purpose, but we cannot station a spy at every switch to make sure that the rules are obeyed. We have to depend on the personality and general intelligence of our employees."

It will, I think, be evident from the facts and conditions that we have been considering, that whatever secondary causes there may be for pre- 
ventable railroad accidents, the trainmen themselves hold the key to the situation. They are at liberty to obey the rules, and thus solve the problem in the only way in which it ever can be solved; or, they can continue to place upon these rules a wrong interpretation, and thus evade their manifest meaning and purpose. As matters stand to-day between labor organizations and railroad managers, it is very doubtful if by any practical system of supervision or discipline the rules for the safe and efficient running of trains can in all cases and at all times be adequately enforced. Thus the whole business resolves itself into a personal matter with us as conscientious railroad men. Singly and collectively, it is up to us to do the square thing, if necessary, in spite of the management.

As the case stands to-day, we railroad men are in a class by ourselves. We are well-paid, welltreated, well-educated, and well-organized. In all that pertains to our material well-being we compare more than favorably with any other class of workers in the country; but considered as responsible individuals intrusted with the care of railroad property and the safety of the traveling public, our records are very unsatisfactory. The truth of this conclusion is not open to question. We cannot escape from the statistics and the figures; and, day by day, the evidence against us continues to accumulate. 
There are many people who think that the intelligence and education of the twentieth-century railroad man can be depended upon to guard against the shortcomings to which I have called attention. On the contrary, I am inclined to think that the intellectual independence of the railroad men is in itself a danger to be guarded against. Standing by itself, the statement that knowledge is power is a fallacy. Knowledge is only a means. Its benefit to any one is always an open question. In other words, the secret of power is in the application of knowledge. Thus when we analyze a modern railroad accident we are forced to the conclusion that many railroad men take chances by reason of the supreme confidence which they possess in their own cleverness and ability to deal with an emergency, however sudden. This resourceful characteristic of Americans is a splendid thing from a general standpoint, but in the railroad business it has its stern limitations. Only too many of our accidents are illustrations, not of lack of knowledge or resource, but of the downright misapplication of these intellectual features. In some cases we find an over-supply of self-confidence, in others a disinclination to knuckle right down to the observance of plain and positive instruction. In such cases a man cannot be called the fortunate possessor of intellectual advantages, but their manifest victim. 
Railroad managers, therefore, sooner or later will come to understand that the one thing needed in the railroad business at the present day is to educate employees to appreciate the fact that successful and safe railroading in the future will have to depend, not upon the multiplication of safety devices or the reconstruction of rules, but upon the personal effort and conduct of conscientious, alert, and careful men.

Meanwhile, thought counts; and it is a good idea for practical railroad men to look into and study these problems, each according to his ability and the light that is in him. 


\section{III}

\section{THE MANAGEMENT}

THE problem of safety in railroad travel has been discussed, from widely different points of view, by many conscientious investigators. The methods of these writers in marshaling facts and drawing conclusions are usually identical. The formula consists of a variety of accidents, a variety of causes, and a variety of possible or proposed remedies. For results, up to date, we have a library of information, but not a suspicion of improvement, in the record of preventable fatalities. Meanwhile, in the public mind there is confusion of ideas and considerable doubt as to the practical outcome of all this discussion. This is a natural state of affairs, for the reason that the only factor in the situation which is constant, and about which there is no difference of opinion, is the impotency of railroad people in coping with the difficulties.

Now, after all that has been spoken and written on the subject of efficient and safe railroad service, the problem remains, as at the beginning, essentially personal, social, and ethical in its nature. Nearly all questions in regard to it must, sooner or later, be thought out in this direction by railroad 
employees and managers. We may continue to work over and reconstruct our rules and to multiply our safety devices until we compel trains to creep from station to station; yet the problem will remain unsolved, the needless and disgraceful sacrifice of life will continue, until trainmen, enginemen, and managers put their heads together and agree to adopt a new code of railroad morals. My meaning when $I$ allude to railroad morals should be clearly understood.

On nearly all railroads a given rule is obeyed at one point and disregarded at another, on account of different sets of conditions. This conduct leads to accidents when men who have habitually disobeyed the regulations at points where such action is harmless undertake to behave in the same way under conditions when a strict observance of the rules is vitally important. Generally speaking, managers are cognizant of this state of affairs, and thus in a measure they are morally to blame for it; but I do not think that they realize the extent of the evil, for the reason that any organized out-of-door supervision is unknown, and thus the report of an accident, that is to say, the result of these practices, is usually the first and only information on the subject that reaches the manager's office. The blame for accidents that happen in this way cannot be said to rest upon any particular class of employees 
or to depend upon their intelligence or length of service. Among the culprits you will find some of the oldest and most experienced men as well as some of the greenest. This goes to show that the trouble is inherent in the system, and a part of the everyday life and character of armies of railroad men.

But in a straightforward investigation of this nature it is particularly desirable to get hold of all the facts that can be used in any way to throw light on the situation, and there is only one method, as yet untried, for properly securing and emphasizing these facts. Let us call this the confessional method. In the hands of a competent witness it can be depended upon to furnish us with all the information necessary for a thorough comprehension of our subject. This confessional method has nothing to conceal. It has no axe to grind, no interests to protect. It is born of a heartfelt appreciation of the seriousness of the situation on our railroads. Mindful of the ever-increasing and lamentable loss of life caused by the unstudied indifference and negligence of employees, as well as by the blindness of the authorities to the real issues and dangers, it approaches and takes hold of the problem somewhat in the spirit of the King in "Hamlet," when in an agony of remorseful retrospection he exclaimed, "Try what repentance can : what can it not?" 


\section{THE MANAGEMENT}

That there is an urgent call for this confessional method of supplying the facts in this railroad business is capable of easy demonstration. When an accident takes place on a railroad, some kind of an explanation or reason for its occurrence is immediately called for. Consequently there is a lining up of opposing interests. A certain management has to be vindicated, certain employees to be defended. In the investigation that follows, an array of facts defensive and otherwise is brought forward in the interests of the opposing parties ; but evidence and facts that are likely to reflect on both men and management, and perhaps on the handling of the case or of other cases by the Board of Railroad Commissioners, are studiously avoided. The facts that are suppressed in this way usually contain the heart of the whole business, and are the very points in which the public is profoundly interested. An illustration in point will make this doubly clear.

About a year ago, in an accident near Troy, N. Y., five passengers were killed and many were injured. A special passenger train crashed into the rear of a regular passenger train. There is a sharp curve in the track a short distance above the scene of the collision. Had the special been handled carefully round this curve instead of recklessly, the accident would not have occurred. Caution, of course, is 
necessary in running round sharp curves, and the rules on all railroads are plain and emphatic on the subject. But the authorities who investigated this accident treated it as an isolated instance of individual carelessness. Within a period of six months these gentlemen are called upon to pass judgment on probably twenty wrecks, every one of them bearing the same earmarks of disobedience as this disaster near Troy, yet no one ever dreams of hunting up a common cause for dozens of accidents that are exactly similar and brought about in the same way. To be precise, this accident at Troy was the result of a habit. At a glance we perceive that the public is a hundred times more likely to be interested in the uprooting of such a bad habit as running recklessly round curves than it is in placing the responsibility or punishing the offender in any particular instance. Yet who ever heard of a verdict that placed the blame for an accident on a habit? The reasons for the oversight are obvious. A dangerous habit, long continued and unchecked, is a decided reflection on men and management, and, indeed, on the Railroad Commissioners, whose vigilance it has escaped ; and consequently no evidence or facts in regard to these bad habits are ever permitted to find their way into investigations. It will be evident, therefore, that the confessional method can be profitably employed in supplying a few missing 
links in our knowledge of actual conditions and methods of operation on the railroads.

To begin with, it will be well to take note of an estimate, made after a careful study of the figures, that fully eighty-five per cent of the fatalities that occur on our railroads can be directly traced to the negligence of employees. Regardless of the accuracy of this estimate, it certainly points to a very serious state of affairs. In studying the nature of these accidents and the conditions under which they take place, one cannot help being impressed with the fact that almost every possible way in which trouble can occur on a railroad is foreseen and provided for by some rule or safety device. So carefully has the ground been studied and worked over, that in every case of preventable accident it can almost be taken for granted that an employee is to blame. That is to say, the management of a railroad is always found to be impregnably protected by the rules and regulations from any direct responsibility. But, after all, this is only one side of the shield, for clearly the moral responsibility of a railroad manager cannot be said to cease with the printing of a batch of rules or the erection of a system of signals. It is not only necessary that rules should be plain and sufficient in themselves to prevent accidents, it is also equally essential that reasonable and systematic efforts should be exerted 


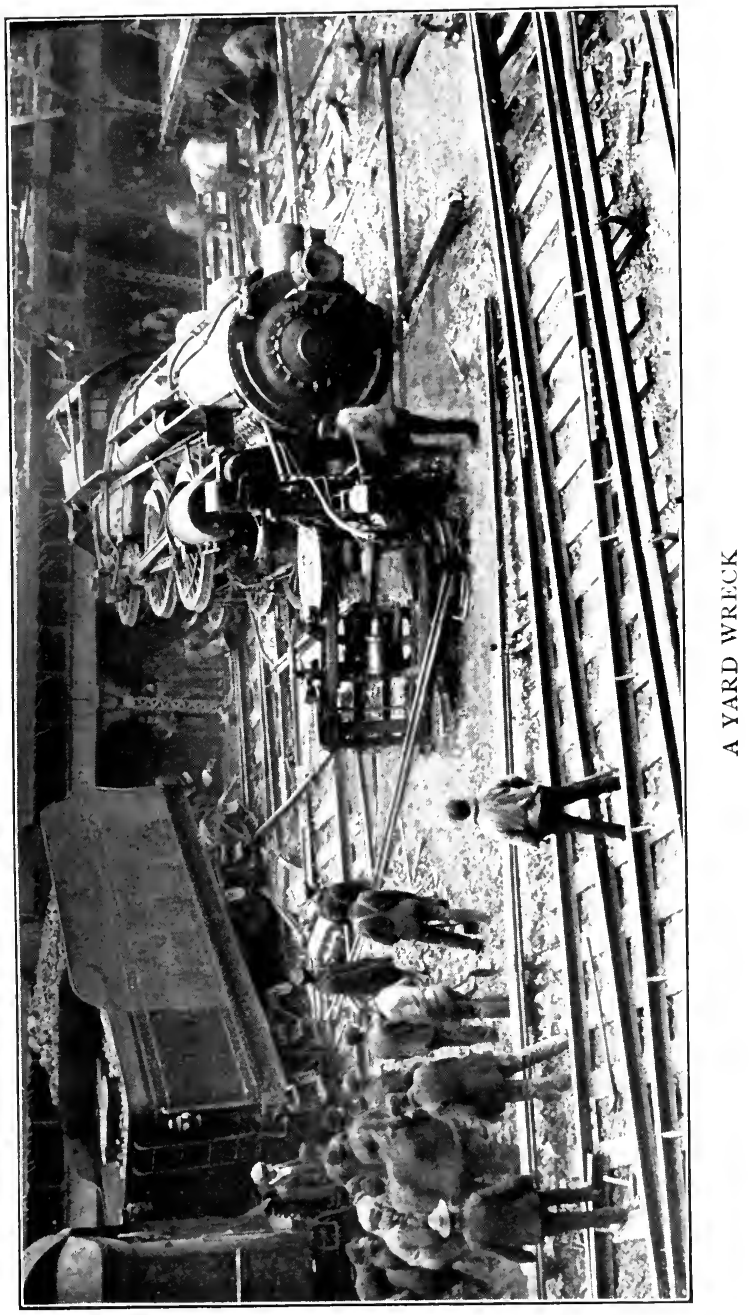




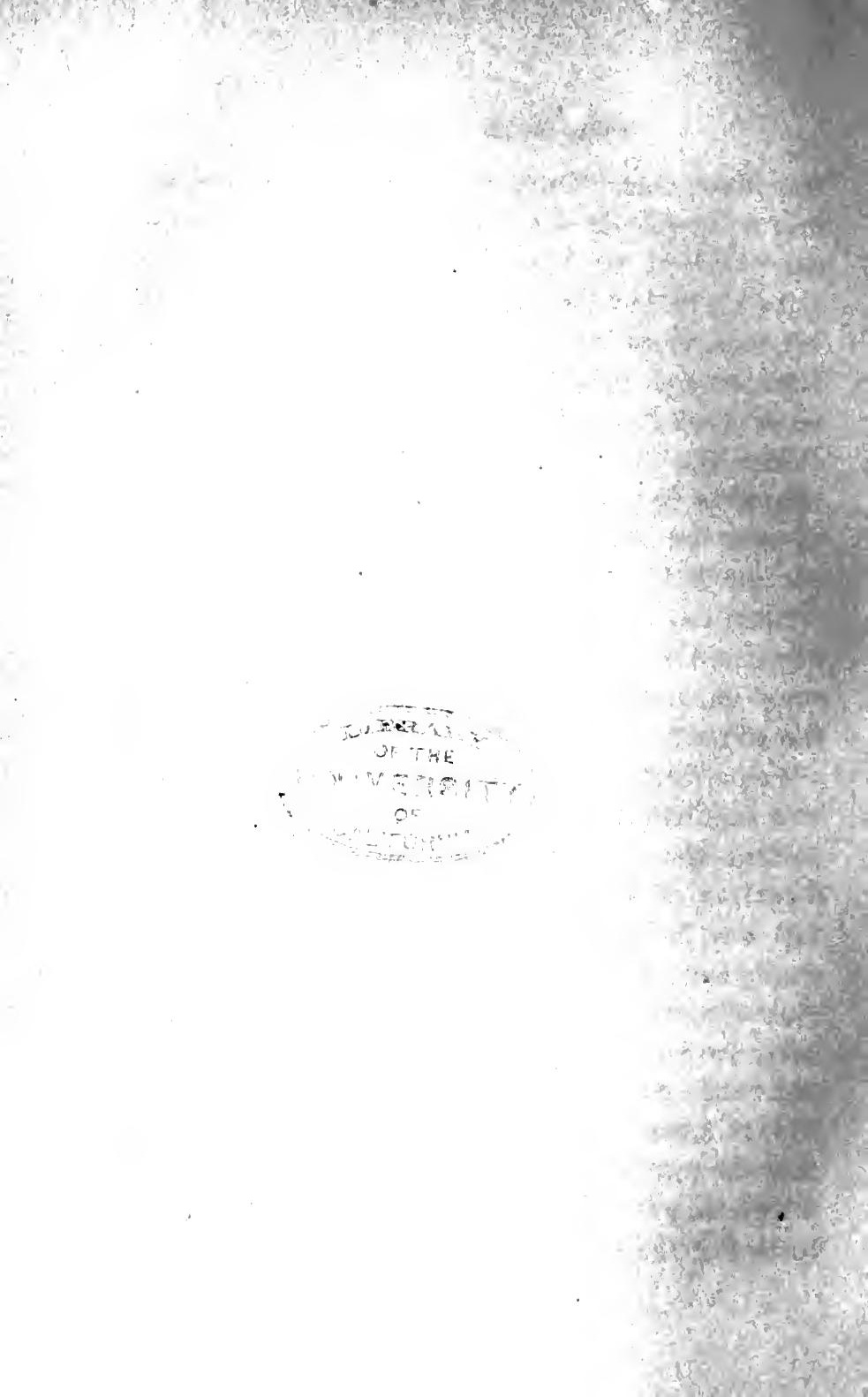


to enforce them. On a railroad, as elsewhere, the means employed for the supervision of personal conduct and for the enforcement of necessary rules are all included in the term discipline. Without some organized and effective system of discipline no industrial establishment of any kind can be successfully administered. On railroads in particular, the department of discipline is intimately related to the interests of the traveling public. Let us then examine in a practical manner the nature and methods of the discipline that is in force at the present day on what may be considered the most important railroad in New England. A little personal experience will throw the necessary light on the subject.

Some time ago, happening to notice that important regulations were being habitually ignored by a certain class of employees, the writer called the attention of the management to the matter. In this way, from time to time, many cases of simple negligence, which had no serious consequences, were reported to superintendents. Thinking it all over, the writer finally became anxious to find out just what disposition was made of these reports. For it must be apparent to any thinking person that the practical value of any system of discipline must always depend upon the efforts that are put forth and the success that is achieved in checking 
and in preventing the repetition of these instances of what may be called trouble in the bud. The reports to which I refer were acknowledged by the management, and there the matter ended. But as I happened to be studying the subject at the time in a systematic manner, I was by no means satisfied with this abrupt conclusion. So I made an investigation on my own account, and easily discovered that practically all other interested employees were unaware of and had not been notified in regard to the violation of these rules because, as the men explained, nothing had happened. That is to say, it was necessary to hurt somebody or smash up a few carloads of freight before any efforts could be exerted according to the rules to put a stop to the negligence. This became very clear to me, when, upon making further inquiries, I was informed that the men had been disciplined to the full extent of the rules. Now my object in the investigation was not to get at the nature or the amount of the discipline, but simply to be able to arrive at an estimate of its value in checking and restraining others from committing similar mistakes. In this way I soon arrived at the conclusion that a system of discipline that works in the dark in this way is of no practical value whatever. It is a weakness of management, which positively undermines the operating department and leads the way to all sorts of disaster 
and loss of life. Its continued existence in practical railroad management is a standing menace to the safety of the traveling public. As a matter of fact, lives are still being frequently sacrificed and much property is almost daily being destroyed as direct tribute to this incomprehensible system of discipline.

The exact method by which this system is put into operation, and the regulations which govern employees in regard to it, will be understood from the following extracts from general orders on the subject, issued by what is sometimes considered one of the best-managed railroads in the country :-

"The System of Discipline by Record having proved beneficial both to the road and to employees, it has been decided to extend the same by the addition of merit marks. . . .

" Each employee will be promptly notified of unfavorable entries made in the record book opposite his name. He will upon request be shown his record at any time, but will not be permitted to see the record of another person.

"Bulletins, omitting name, date, train, and location, but containing facts and conclusions and such comment as is applicable, will be issued from time to time if considered necessary."

The significance of this general order to employees should be thoroughly understood. Practically interpreted, it means that when an employee 
commits a mistake or is guilty of negligence that endangers life and property, the affair is to be looked upon as a secret. This interpretation is correct according to the actual operation of the system on the railroads. Neither in the interests of the public safety nor for any other reason can the facts in the case, as regards date, name, location, and train, be utilized or published for the prevention of future accidents of a similar nature. This is the law of the road; and while it remains in force any employee can claim the full benefit of its provisions. The practical illustration in my own experience given above is fully explained and accounted for by this general order. But the most astonishing feature in relation to it is that with the records before us it should continue to be considered and heralded as "beneficial" either to the railroads or the employees, not to mention the public. For a full explanation of this peculiar state of affairs we must turn to another quarter.

It is a well-known fact that the American railroad man, the trainman and engineman in particular, has deep-rooted objections to being "posted" in any way. We have consistently emphasized our objections from the time, years ago, when our likes and dislikes first began to cut a figure in the plans of the management. So to-day we are prepared to go to almost any extreme rather than submit to 
any system of discipline that will publish our mistakes and advertise us personally by name as examples, even although such action can be shown to be absolutely indispensable for the proper safeguarding of life and property. With all the facts against us, we think we can be trusted to render the best service and to live up to the rules without the assistance of publicity in any form. We consider discipline to be a private matter, to be settled between ourselves and the management; and thus the workings of the system have been arranged without any reference whatever to its effect on the interests of the millions of people whose lives are placed in jeopardy by its arrangements. As a matter of fact, then, the system of discipline which I have described is the result of long-continued pressure and consequent concessions by the management to the demands of employees. These concessions have been granted for the most part in the interests of harmony. What the exact nature of this force or pressure is, which, acting on behalf of railroad employees, has been able to influence railroad legislation and management to the total exclusion of the public interests, calls for the closest investigation.

A short time ago, in a report issued by the New York, New Haven and Hartford Railroad, President Mellen stated that so far as his system of 
roads was concerned, increase of pay had invariably been followed by decreased efficiency. Mr. Mellen, of course, has the reports and the figures to substantiate his opinion. The statement is plain enough, although its meaning is somewhat obscure. That decrease in efficiency has been the natural sequence and effect of higher wages, or that men lose interest in their callings or grow more careless in their habits with every addition to their material prosperity, is manifestly absurd. Mr. Mellen has not informed us that he looks upon the matter in this light, although his words may reasonably be considered to bear some such interpretation. Be this as it may, he certainly calls attention to a very uncomfortable coincidence. In effect Mr. Mellen's words may be taken as a direct challenge to railroad men to come forward and explain a state of affairs that has the appearance of being very much to their discredit. The implied challenge can be immediately and concisely replied to in this way. The efficiency of the service rendered by employees to the New Haven road has by no means been impaired or decreased by any consideration of wages whatsoever. Nevertheless, the power or pressure that induced Mr. Mellen and other railroad managers to add large sums to their pay-rolls is also responsible, by the exercise of its influence in other directions, for the decreased efficiency. Increase of 
pay and decrease of efficiency are both indications of loss of grip by the management. Hidden away in this simple statement there is a whole world of significance. Here are fundamental facts, from a fearless consideration of which we shall be able to derive a logical and clean-cut explanation of the present situation on American railroads.

The force or influence to which I call attention is of course the Railroad Labor Organization. But it should be clearly understood that my conclusions in regard to these unions are not to be taken as a reflection on their character and work while acting in legitimate channels. The debt we railroad men owe to our organizations admits no question. The beneficial results are before us in almost every department of the railroad business. They have established a fraternal feeling among us. On all sides they have aroused a spirit of mutual helpfulness. They have also succeeded in advancing wages, and in this way contributed to the comfort and prosperity of almost every man in the service. Furthermore, they have been particularly active in inciting legislation for the protection of life and limb among workers. These facts must not be forgotten or minimized, for they are worthy of all commendation. But in this matter of the personal conduct and efficiency of railroad men in relation to these terrible railroad accidents, we have first 
of all to consider the paramount interests of society; and while humanity has no quarrel with the unions while they attend to their legitimate business, it certainly can be said to have a grievance against them that calls for prompt attention and remedy. This grievance consists in the fact that, for a great many years, the influence of the railroad labor organizations has been consistently exerted, not only to raise wages and to improve conditions, which of course is perfectly proper and justifiable, but also to nullify discipline, to destroy personal management and authority, and to obliterate from all schedules and working agreements any reference to or consideration for the paramount interests of the traveling public. It is not necessary to quote paragraphs from these agreements, which for the most part are secret documents. Given two angles of a triangle, it is an easy matter to calculate the dimensions of the third. Similarly, given the actual conduct of the men and the behavior of the management in relation to it, we can derive very accurate conclusions in regard to the work and power of the organizations.

Yet let no one imagine that this interference with the management in the matter of discipline is brought about by design or is directly intentional. On the contrary, in a very natural way, it has grown out of a system whose main object has 
been to secure justice and equal rights for every individual employee. But unfortunately, in pursuing these personal ends and objects, the rights of the community have been forgotten. It is easy to demonstrate that in the railroad business this fair play to the individual frequently means a sacrifice of the public interests. In the operating department of a railroad, illustrations of this point meet us at every turn.

In any ordinary business establishment there is at all times a certain amount of weeding going on for the good of the business. This is done on the personal judgment and initiative of the manager. In this way a high average of efficiency is attainable in all departments. But in the railroad business no such personal action on the part of a superintendent would be tolerated for a minute. It is surely reasonable that among the thousands of men who enlist in the railroad ranks there will be many who after a while will give evidence of unfitness for the service. Regardless of the power of the superintendent in theory, these men, if they are members of an Order or Brotherhood, must actually hurt somebody or do considerable damage to property, before they can be removed. That is to say, there is no elimination of weak spots until something happens. But this is not all. When a vacancy occurs in the service, it is immediately advertised, and the 
oldest bidder in point of service takes the position. In some of the agreements with the management the seniority rule is said to be absolute, in others it is modified by the clause, "with the approval of the superintendent." But in a business of the nature of a railroad the public interests demand that at all points the best available man should be in charge, regardless of his length of service or his rights as an individual. But the labor organizations do not permit the public interests or those of the corporation to interfere with what they consider to be the just and inalienable rights of each and every employee. Applied to the railroad business, the fixed principle that every man shall take his turn is fundamentally wrong and demoralizing. It is one of the wedges that are being used to destroy personal supervision and management and to substitute management by machine methods. In my opinion its tendency is in the interests of poor service. Healthy competition in good behavior is almost obliterated, while honest ambition and esprit de corps get very little encouragement. It has the general effect of removing the attention of employees from the management and concentrating it steadfastly upon the organization, that is to say, upon the source from which increase of pay and all other blessings are expected to flow.

Of course, I cannot expect railroad managers to 
agree at all points with my estimate of their powers and functions, or of the helpless situation in which they now find themselves. Just at present, however, I am not interested in opinions from any quarter. The facts that interest me, and I think the public as well, relate to what these railroad managers have done in the past and are actually doing at the present day, with such powers as they possess, in the interest of safe and efficient railroad service: It may be very interesting to be informed that a superintendent has the power promptly to discharge an engineman for running a danger signal and placing the lives of five hundred passengers in utmost peril, but it is much more to the point to impress upon the public mind that the action of the official will not amount to a snap of his finger if an organization puts down its foot and signifies its opinion to the contrary. Illustrations of these facts are not far to seek. Only a short time ago an engineman was promptly discharged for disregarding a signal in a most inexcusable manner. The case was passed up higher for the approval of the general manager. Meanwhile the man had discovered some kind of an excuse for his action, and a committee was appointed to look into the matter. There being a total difference of opinion between the management and the grievance committee, the heads of different organizations were summoned from some western 
city to help straighten out the deadlock. After a while the man was put back on his engine, and the report passed round that the case had been settled in this way in the interests of harmony. No wonder the superintendent who was concerned in the matter threw up his hands in disgust and exclaimed, "What's the use ?"

This method of interfering with the regular course of discipline may perhaps be proper and commendable in a cigar factory or a cotton mill, but on a railroad, where the lives of countless people are dependent upon obedience to the rules, its effect upon the service is absolutely fatal. But unhappily this is not the whole story, for it must be confessed that the public frequently joins hands with the organizations in defeating the ends and aims of discipline. After some of the worst and most inexcusable accidents that have ever occurred on New England railroads, petition has followed petition into the railroad offices with the expressed object of influencing the management to reinstate men in the service who have been convicted of inefficiency or unpardonable carelessness. Of course a superintendent should thoroughly investigate every case on its merits, but the verdict of the management should be final. The wisdom of this policy might be questioned if superintendents were political appointees or owed their positions to "graft" or 
"pull." As a matter of fact these men are among the hardest worked, most thoroughly capable and conscientious men in the United States. No combination of opinion from the public, the railroad commissioners, and the labor organizations is half as likely to be just and impartial as the individual judgment of the superintendent on the spot. The following significant remark by one of those gentlemen may well be taken to heart by the public as well as by employees : "With a free hand, we could put a stop to this killing in a week."

The story of railroad management is now before us, and the record of accidents all over the United States is the price that is being paid for it. As I have described the situation, the circle of cause and effect is now complete. Beginning with the negligence of employees, which must be considered as the primary cause of these accidents, I next took up the matter of discipline, whose function it is to control and put a stop to this negligence. The system was found to be altogether inadequate and useless. Finally, I attempted to demonstrate that the labor organizations are responsible for the nature of this discipline, and thus indirectly for the accidents that have resulted from its inefficiency. Systems of discipline vary on different roads; nevertheless these contentions are sound and universally applicable, for the blight of interference 
with the management has in greater or less degree withered every system of railroad discipline in the United States, and exposed the traveling public to the mercy of service that is inefficient and demoralized.

For the rest, it will be evident that the foregoing diagnosis of the situation bears on its face unmistakable indications of the nature of the cure. At all cost, interference with discipline must cease. This conclusion admits no compromise. At the present day every decision made by a superintendent is practically subject to the approval of the Grievance Committee. But this is not all : the railroad manager is handicapped and held up at every turn. In his dealings with the labor problem, if by any possibility he manages to escape the fire, it can only be by taking refuge in the frying-pan. An illustration in point is the problem of keeping expenses within reasonable limits and at the same time administering discipline to the very men who, backed by powerful organizations, are continually insisting upon additions to the pay-rolls.

But now, granting the situation and the difficulties as I have described them, in what direction are we to look for relief? As it seems to me, an unmistakable expression of public opinion would, in the first place, go far in starting us all thinking and working in the right direction. But even this 
will have little effect until railroad men wake up out of the self-satisfied trance in which at present they seem to be comfortably slumbering. Time was when our forgetfulness of the public interests could be accounted for by our own poverty and sufferings. But these unhappy conditions no longer exist, for to-day we are probably as well paid and otherwise as well provided for and equipped as any class of workers in the United States. Nevertheless, when we are informed that in the year 1906 ten thousand people were killed and one hundred thousand injured on American railroads, the knowledge does not seem to " give us pause " in any way, or to ruffle our individual self-satisfaction; while our organizations look at their surroundings silently and impassively as the pyramids and obelisks look upon the Egyptian deserts.

But affairs have now come to such a pass on the roads that at last we are imperatively called upon to answer questions and explain our position. Our best friends are beginning to criticise us. They remind us that interference with discipline is in reality an attempt to take part in its administration, and that our unions were never intended or organized for that purpose. For a great many years an educational campaign has been in progress all over the country for the purpose of reminding us of our duties and obligations to our unions. This educa- 
tional method has been extremely successful, and has brought into being armies of laboring men thoroughly loyal and self-centred. But the result of this system on the railroads has been so disastrous to human life that at last we are beginning to realize that there is a limit even to the pursuit of our individual well-being.

In paying attention, even at this late date, to the higher call of the social conscience, we railroad men shall enter a new world with brighter prospects and a wider horizon. The nobility of labor has always been the proud watchword of American civilization. Let us be watchful lest we forfeit our claim to share in this national distinction. By recognizing our duties and responsibilities to society in our treatment of these railroad problems, we shall finally take our place in line with those who through sacrifice and high endeavor are destined, in good time, to cut out their way to industrial freedom. 


\section{IV}

\section{LOYALTY}

THE relations, coöperative and otherwise, that exist between the men and the management of a railroad are intimately connected with the safety and efficiency of the service. Generally speaking, the public is quite ignorant of the nature of these relations. The men and the management may be working harmoniously with a constant solicitude for the safety and well-being of the patrons of the road; or, on the other hand, they may be intrenched in opposing camps, mutually watchful and suspicious of each other, and more or less forgetful of the wider and vastly more important interests of the community at large. One way or the other, the public knows little or nothing about the actual situation. The managers of railroads are not in the habit of discussing such matters or of taking the public into their confidence; our organizations of railroad men likewise pursue the even tenor of their way. It seems to the writer that the time is opportune for a candid discussion of this topic, with a view to the education of public opinion, and in the general interest of travelers by rail. A very brief preliminary survey of the situation will not be out of place. 
It is, of course, unnecessary to dwell upon the tremendous importance of the railroads as a factor in our national life. Their ramifications are like countless veins or arteries penetrating every nook and corner of the continent. Backward and forward through these arteries there passes and repasses an endless procession of commerce and travel. In times gone by these huge systems of national and international intercourse have, for the most part, been directed and kept in working order by boards of management more or less personal and irresponsible in their methods of administration. But within a few years a great change has taken place. A new partner, in the person of the railroad employee, has literally pushed his way into the manager's office. So important a factor has he now become in the councils of a railroad corporation that hardly a move can be made in the operating department without first consulting his rights and wishes. Not only is the power and influence of the railroad employee at the present day an important factor in railroad management, but, in the opinion of competent judges, the time is not far distant when manager and employee will meet on equal terms and together legislate for the interests of all concerned. Now, granting the ever-increasing power of the employee in framing the rules and influencing the management, what is there to be said about the 
division of responsibility? The question calls for the most serious consideration of railroad men. Manifestly, it also concerns the public interest; for, in criticising conditions on our railroads, public opinion should be thoroughly informed concerning the situation, so that in all fairness it may call for remedies and reform from the right quarter.

At the present day, when an accident happens on a railroad and lives of passengers are sacrificed by reason of the carelessness or neglect of employees, practically the whole moral and financial responsibility is immediately assumed by the management. Heartfelt regret is at once expressed by the highest authorities, the injured are visited by sympathetic officials, and every conceivable kind of bill or expense is at once acknowledged and paid. On the other hand we, the employees, singly and collectively, ignore the whole business. We simply stand back and let the press and the authorities figure out reasons and remedies for themselves. We neither adopt resolutions of sympathy nor pay out a single dollar to benefit the families of the dead, or to alleviate the sufferings of the injured.

Considering the division of power, does this adjustment of responsibility appeal to any fair-minded person? It has occurred to some of us that if we or our organizations were assessed in hard cash in proportion to our responsibility for some of these 
preventable accidents, the casualty lists on our railroads would very quickly assume microscopic proportions. An "Employees' Liability Act" would, of course, be looked upon as an absurdity; yet if unprejudiced judges were to analyze a few of our accidents, they would quickly conclude that the idea is sanely and soberly logical. They would simply consider the matter in the light of fair and square taxation with unmistakable and ample representation. It must not be forgotten that the manifestation of power by railroad labor is to be looked for not so much in the wording of schedules and agreements as in what the managements of railroads under pressure feel constrained to refrain from doing. The fairness and cogency of this argument may not "be as deep as a well" nor "as wide as a church door," but I think, in the words of Mercutio, "'t is enough." The questions and considerations that arise in this way in regard, to the interests of the public, the management, and the men, are all comprehensively included and can be profitably discussed under the simple caption of loyalty, - on the one hand, loyalty of the men to their employers, and, on the other, loyalty of the employers to the men.

No sincere well-wisher of the railroad employee will question the importance of the relation that exists, or that is supposed to exist, on American 
railroads, between labor and loyalty. Volumes have been written about loyalty in the abstract. For the most part politicians and teachers of national morality and patriotism have monopolized these arguments. The former would sink individualism in the interest of the machine, the latter for the good of their country. Granted the purity of their motives, the efforts of these people are entirely praiseworthy; and yet the significance and importance of loyalty in the industrial life of the nation can by no means be said to be included in the teachings of either politician or patriot. On American railroads, in particular, the question of the loyalty of employees to the corporations and to the interests of the public is vastly more important than a superficial glance at the subject would lead one to suppose. Understanding as we do the ever-increasing influence of the employee, the problem which we have now to consider relates to what at the present day he is doing with his power, and to what, with his everincreasing importance, he intends to do with it in the time to come. The future holds in it the answer to these questions in terms of selfishness and abuse of power, or in terms of loyalty to himself, the corporations, and the public.

To attempt to give a definition of loyalty to apply to and to cover this railroad business would simply be time and effort thrown away. It is one thing to 
impress upon learned and critical readers that individualism is in error and that loyalty is "willing and practical devotion to a cause that is outside of the individual and larger than he is." It is quite another affair, and altogether more important, to reproduce our philosophy in terms of actual conduct and behavior. Not one railroad man in a thousand has either the time or the mental training to study theories, and from the teachings of professors to work out rules for his daily guidance; yet it is manifest that the most useful and wholesome ideas can be put to little practical utility in this railroad business until the employee is aroused, and some practical interpretation of them brought home to him with unmistakable sincerity and emphasis. While, therefore, it is unnecessary to supply railroad men with a definition of loyalty, it will be just as well to call attention to some of its most important features.

Loyalty then, as applied to the railroad service, means the safety of the traveling public so far as human safeguards can be depended upon. Again, comparing the service as it actually is with what it might be, loyalty means the elimination of numerous petty delays, and at times serious blockades, which, at the present day, on many railroads, are so annoying to the traveling public. This matter of delays to passenger trains is quite an important 
feature, and it is surprising how much the personality of the men and their interpretation of loyalty to the public interest figure in the problem. Furthermore, a stricter interpretation of loyalty by employees on any given railroad can easily be shown to mean a positive reduction in operating expenses to the tune of thousands upon thousands of dollars. These additional resources placed at the disposal of the management would mean, of course, funds wherewith to satisfy the never-ceasing demands of employees for better conditions and increase of pay. Finally, loyalty means fidelity ; and with fidelity comes sympathy; and with sympathy comes practical and earnest coöperation between management and men, without which safe and efficient service is liable to be a mere delusion and willo'-the-wisp. .

Now, while it is a pleasure to bear witness to the steadfast loyalty, frequently under trying conditions, of numerous individual employees, it is nevertheless the duty of the unprejudiced investigator to call attention to the fact that the tendency of the forces that are at work in this railroad business at the present day, on the part both of the men and of the management, is simply and positively to eliminate loyalty as a useful and essential factor in the administration of affairs. While the public, the management, and the men are mixed up in the re- 
sponsibility for this unsatisfactory condition, the blame for the lack of sympathetic coöperation, which is only another term for loyalty, that exists among us, must, to begin with, be laid at the door of the employee himself. This is by no means the hasty opinion of an individual thinker. Professor Royce, an eminent authority on the subject, in a lecture delivered at the Lowell Institute in Boston, describes the situation very emphatically in the following language :-

"The trades-unions demand and cultivate the loyalty of their members; but they emphasize the thesis that to be loyal to his union the laborer must disregard certain duties to the community at large and to the nation, duties which loyalty to loyalty seems obviously to require."

By loyalty to loyalty, Professor Royce means "the maximum of loyalty to the world." But professors and students of industrial conditions are by no means unsupported in their conclusions. That labor leaders themselves are aware of the inherent weakness of our position may be inferred from the following extract from an editorial in "The International Railroad Employee" for November, I907.

"I may not lay claim to either the age or wisdom to advise my brother workers what to do, but if you will consider some of my suggestions relative to your actions and surroundings, and talk them over 
among yourselves, I am sure you will be able to find the world brighter for you. You seldom, if ever, give any serious thought to bettering your condition except by hoping for better wages. Your ideals begin and end with wages, and so long as that be true there is no possibility of your condition being bettered."

Surely this is a most uncomfortable and damaging confession. Interpreted in terms of railroad service, it should have the effect of causing the public to sit up and think it all over. With all our education and enlightenment, is it really a fact that the ideals and humanity of the American railroad man can be crammed into a nutshell in this way by honest and practical investigators, and labeled "wages"? At the present day the assertion that corporations are soulless has almost the nature and force of an axiom. It would now appear, according to the authorities just quoted, that the policy and ideals of labor, as represented by the American railroad man, are not only soulless but brainless as well.

So far in this discussion we have been dealing with theories and opinions. It now remains to be seen, by actual example and illustration, upon what ground or basis these theories have been advanced. In plain English, what is the actual and manifest cost, in character and dollars, of this lack of loyalty to the world at large which is a distinguishing fea- 
ture of railroad life at the present day? It is hardly fair to call it a lack of individual loyalty, for at heart the American railroad man is thoroughly loyal; but, unfortunately, the systems of labor organization and management under whose direction he works, practically call upon him to renounce his personal principles in the interest of schedules and agreements which constitute the machinery of the operating department.

It may, of course, be taken for granted that managers of railroads are well aware of the importance and value of practical loyalty in all branches of the service; and yet when one examines the evidence with a view to ascertaining what they actually do for its encouragement, one is driven to conclude that there must be some kind of a hitch somewhere. As an illustration let us take the following incident, which is almost an everyday occurrence :-

Freight train No. I pulls into a yard a few miles outside the terminal. The train and engine crew are on overtime; that is to say, every hour they remain out on the road means a great many dollars in wages over and above their regular pay. Before long, another freight train, No. 2, overtakes train No. I. Instead of pulling into the yard and doing its work in turn, this second train runs up the main line and backs in ahead of train No. 1 , thus putting it in a pocket. In this way train No. I is delayed 
three or four hours, thus causing the engine to be late for the return service; and altogether an extra and entirely unnecessary expense of perhaps fifty dollars is entailed upon the railroad.

A few days later, the writer, happening to meet the engineman of train No. 2, spoke to him in regard to the affair. $\mathrm{He}$ appeared to be very much surprised that his conduct should be questioned or criticised in any way. He had supposed it was every man's duty to shift for himself; to jump another train whenever an opportunity presented itself, and to get to his destination as quickly as possible. The question of the interest of the company was a side issue, to which he paid little attention. If loyalty of this kind was a matter of importance to the company, why, he contended, was the attention of the men not called to such matters in some emphatic way? So far as he was aware, the management had little to say on any subject except as its views were set forth in the rules and regulations. In his opinion it was every man for himself on the one hand, and every official for himself on the other; and whenever their interests or opinions clashed, it became the duty of the management and the grievance committee to settle the differences. This engineman was not far wrong so far as concerned the actual conditions of his daily work; and yet the management of a railroad takes a good deal 
more interest in such matters than this man had any idea of.

Some time ago a vice-president of one of our railroad systems addressed a gathering of some five hundred railroad station-agents and clerks. He had a good deal to say to the men about loyalty. He tried to impress upon his hearers that railroad men should think less about their wages and their material prosperity and more about character and the duties they owed to their employers and to the public. The prosperity of the men was in every way dependent upon the prosperity of the road; consequently, every act of loyalty, every little economy, was a genuine factor in obtaining satisfactory results and returns for the road. In the matter of supplies, for example, employees could do splendid work for the road if they would only put their minds to it. But it was not such an easy matter nowadays to put a stop to waste in some departments, even when its practice was shameful and persistent. Of course, it was an easy matter to find fault with a station-agent if he used a pint of ink over and above his allowance; but when the operating department consumed thousands of gallons of oil per year more than was absolutely necessary, the problem became much more complicated. However, seeing that reporters were excluded from the hall, he would venture to say that in the single case of oil it was possible for 
engine crews, by the exercise of the simplest loyalty and regard for the prosperity of the road, to reduce the expenditure in that one item to the extent of many thousands of dollars per year. But, of course, in the interest of harmony it would never do to tell enginemen and firemen that they are deliberately wasteful or lacking in loyalty to their employers.

To say the least, one gets the impression from these remarks that railroad officials are called upon to pursue their labors with something in the nature of a "sword of Damocles" suspended over their heads. However, it must not be supposed that instances of loyalty on a railroad are few and far between. On the contrary, from time to time the attention of the management is directed to instances of conspicuous and profitable loyalty.

Some time ago one of the largest freight yards in the western part of the state enjoyed a very unenviable reputation for breakages of draw-bars, derailments of cars, and all sorts of unnecessary delays to passenger trains. Finally a change was made in the yard-master. The new man began operations with heart-to-heart conversations with the yardmen. If they had grievances he was ready to straighten them out. The men had his sympathy and backing, and in return he requested their coöperation in order to convert the record of the yard from the worst to the best on the system. 
Working in this sympathetic yet practical way, in a year's time he had succeeded even beyond his expectation. While handling a much larger volume of business, the operating expenses and the bills for breakages were reduced many thousands of dollars.

Illustrations of a similar nature can be multiplied indefinitely, but one will serve as well as a hundred to demonstrate the fact that railroad men as a rule give little thought to the matter, and that railroad managers, while quite aware of its significance and value, seldom go out of the beaten routine of their regular duties to impress upon their employees the importance of the issues at stake. The following somewhat remarkable illustration will throw additional light on the subject :-

On one of the busiest sections of a New England railroad a certain foreman has charge of a gang of men. This foreman is a good average man, something of a "hustler," and thoroughly capable and experienced. When carefully examined, however, his record revealed the fact that he had been unable to keep a man on his gang more than a month or two at a time. During ten or twelve years' service he had to break in and teach the business, practically in vain, to upwards of two hundred green men. Now there is a right and a wrong way of driving spikes and tamping ties, and poor and inexperienced work means broken rails, jumping of track 


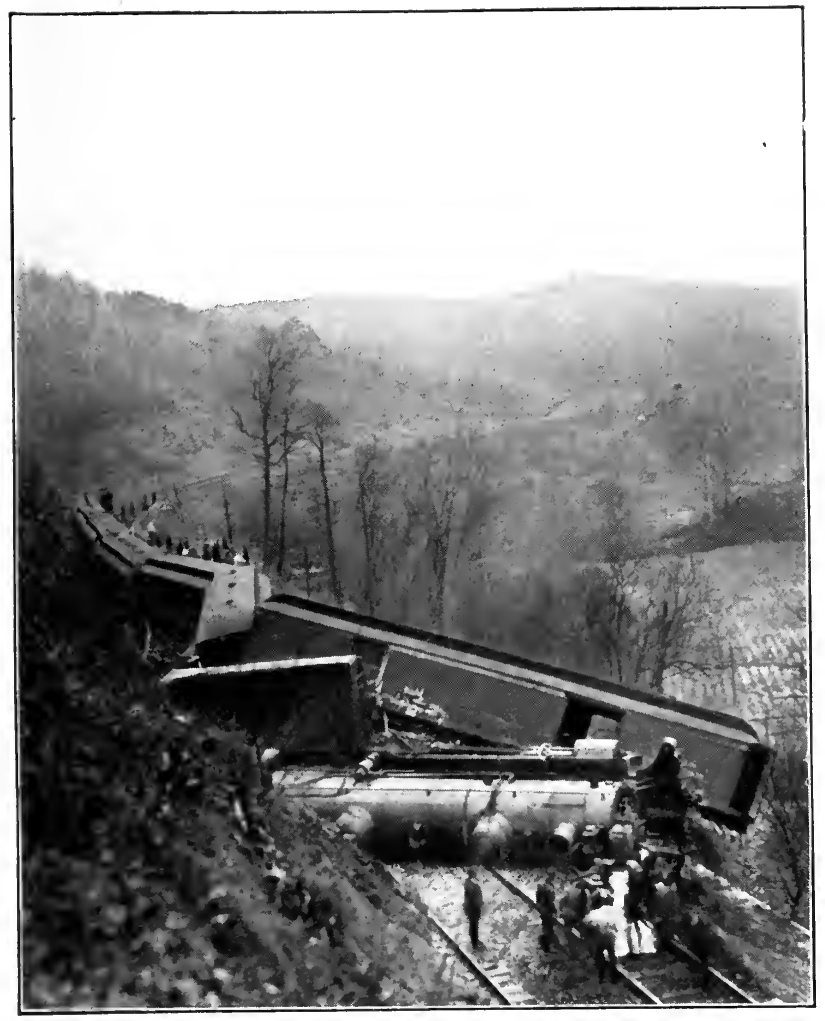

A TYPICAL DERAILMENT 


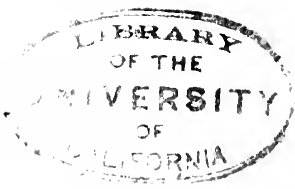


by cars, and a variety of accidents. The foreman in question is a thoroughly conscientious man. In driving his men in unreasonable fashion he fancies he is working in the interests of the railroad company. He considers himself loyal to the backbone, and yet he is probably the most expensive section foreman on the division.

At another point on the same railroad a different kind of a section foreman is stationed. This man has been on one and the same section for fifteen years, and of his original gang of seven men he still retains five. Of the two who are missing, one is dead, the other accumulated a little competency and retired from the service. This foreman is, comparatively speaking, a very quiet man. He is methodical and exact in everything he does. He always addresses his men in a low tone, but with considerable emphasis. His men like him, and they work behind his back in exactly the same manner as when he is standing over them. His conduct is not so much a matter of temperament as of downright calculation and of thought upon the real value and meaning of loyalty to the interests of his employers.

Drawing up the facts in the cases of these two foremen, the writer sent them to an experienced road-master, with the request that he would kindly give him an idea as to what, in his opinion, would be the difference in actual cash value of the ser- 
vices to the railroad of these two foremen. He replied that he was much interested in the question, and had looked up the records of the sections with considerable minuteness, and was of the opinion that the conduct and loyalty of the foreman in the second illustration represented a saving to the company of at least a thousand dollars a year. But in answer to a further inquiry as to what notice or encouragement the loyalty of the men received in his department, he replied that no particular attention was paid to it by the management, that such matters were allowed to drift, for the simple reason that the men were organized and that the agreements between the company and the unions call for promotion in turn, or what practically amounts to the same thing, and that, in short, there was certainly no organized method or means by which loyalty could be recognized or rewarded.

For the purpose of demonstrating the value of a thoughtful consideration of the interests of a railroad corporation, no illustration can be considered too insignificant. At a certain junction point a man has charge of fifty lamps. At another station another man secures equally good results from the same number of lamps while burning a fraction of a cent's worth less oil per lamp per night. By actual investigation and test, it was discovered that the second man handled the business with a saving to 
the company of practically one dollar per year per lamp. This was very interesting when one considers the thousands of switch and other lamps that burn nightly all the year round on a railroad system. Carrying the inquiry a little farther, the writer was able to ascertain that, so far as known, only two or three railroads in the United States take any notice of such information when they happen to possess it; they do not commend the employees for faithful service, and thus stimulate others to like meritorious efforts.

The Santa Fé Railroad is a notable exception to the general rule. In December, 1907, this road published a list of employees who had been heartily thanked by the management and given merit marks for loyalty to the road and the public, not only in cases of emergency, but in the simplest cases of thoughtfulness and economical workmanship. The following is taken from a list of forty :-

“E. H. Vaden, Engineer, and W. L. Sims, Fireman, ten merit marks each for discovering switch in bad condition and without a light, making it safe and afterwards providing a light."

At the risk of making a slight digression from the main line of my argument, I am tempted to add a few lines regarding methods of management on the Santa Fé. They are taken from a report of one of the officials, and probably represent the most 
up-to-date and sanest railroad management in the country to-day:

"To make an effort to reduce injuries and accidents to the lowest possible minimum, the company has felt justified in creating an office to handle in a systematic manner the question of preventing accidents and injuries. Great and astonishing results can be obtained along these lines by constant attention and earnest work on the part of the person in charge of this office, and by securing the coöperation of all employees and the assistance of the heads of the different departments. It is, therefore, very necessary that the 'safety officer' be as thoroughly acquainted as possible with all the men over the entire system, and personally call their attention to the importance of lending their assistance to this cause."

In contrast to the personal attention that is paid to the human element on the Santa Fé, let us glance at the methods pursued on railroads in the East. You will find in our railroad offices an exact record and working history of every piece of equipment, from a spike to a locomotive. Every draw-bar, every coupler, every passenger coach, and practically every engine-tire has to give an account of itself. The performances of these "parts" are carefully scrutinized and watched. You will be shown all sorts of diagrams, charts, and volumes of statis- 
tics going to show the care and expense devoted to equipment and machinery. But if you happen to ask for a few human statistics you are likely to be disappointed. For instance, if a certain train crew runs a freight train two hundred times in a year, breaking seventy draw-bars and upon different occasions delaying thirty-seven passenger trains, and another crew under very similar conditions pulls out only thirteen draw-bars and delays only nine passenger trains, you may consider the records quite important; but in the railroad offices you will find no statistics of this nature, no comparative statements and diagrams illustrative of the workmanship and character of different men and of the value and significance of the human element in the running of a railroad. In a word, you will infer from your investigation that if it is n't a machine or a piece of machinery it is n't worth bothering about.

Finally, let us take a very significant illustration, in which the traveling public should be somewhat interested. The other day a through passenger train arrived at a junction in the western part of Massachusetts. It was on its way east, and was practically on time. But at this point it became necessary for the engineman to renew the water-supply. Consequently he cut off his engine and ran down some little distance to the water-stand. After an interval of twenty minutes, as the engine had not returned 
to the train, the station-master went down to investigate the delay. He found the engineman and fireman sitting quietly in the cab waiting for a brakeman to come and turn on the water. It was some brakeman's duty to do this work at this point, and as he failed to appear, business came to a standstill. The engineman knew his rights and stuck to them. The idea of loyalty to the interests of the corporation and the public could not be permitted to enter into the question, for the reason that to do another man's work, even in a case of emergency, would be to surrender rights and privileges which had been fought for and secured after months of agitation and diplomacy. The train was thirty minutes late at its destination. In such cases the management is helpless.

It matters little that my illustrations may be criticised as uncommon occurrences. The principle that tolerates the situation is surely out of place on a railroad. By way of contrast, the following item taken from the merit list on the Santa Fé Railroad is both interesting and significant :-

" J. E. Helms, Engineer, and M. C. Collins, Fireman, ten merit marks for coaling up engine 1029 when the coal chute was out of service."

Strange as the statement may seem at first sight, we railroad people at the present day are suffering from a very peculiar form of mental blindness. Per- 
haps the point will be more comprehensible if we call it "department paralysis." Our vision seems to be strictly limited to our own departments or spheres of action. In this way every department on a railroad is loyal to itself and more or less forgetful of the other departments. For example, the operating department is responsible for the care and prompt movement of trains. In a general way it is taken for granted that these movements must be made with safety as well as dispatch. And yet, looking into the matter closely, we are able to discover that dispatch and not safety is the main feature and business. Unfortunately there is no safety department on a railroad, or rather safety takes pot-luck in all the departments. Altogether, safety finds it no easy matter to secure recognition, and city governments, railroad commissioners, and railroad officials all seem to suffer from department paralysis upon occasions when loyalty to the interests of the traveling public would seem to demand a much clearer and wider vision. To all appearances it is impossible for these departments to see beyond the precincts of their own particular hobby or vocation. Let us take a very pertinent illustration :-

The other day, in the vicinity of Boston, several teams were smashed and two persons were killed at a well-known and very dangerous crossing. It being Christmas time, there had been an almost 
continuous procession of vehicles all day long over the crossing. At a moment when perhaps the crush was greatest, the gong in the gate-house gave warning that an express train was approaching. Immediately there ensued a wild scramble to hustle the stream of humanity over the crossing and out of the way of the train. It was no easy task for the gateman. Regardless of the descending gates, a number of teams, unable to turn aside, made a final dash to get to the other side. To drop the gates on the backs of the horses was out of the question, and, as a last resort, frantic yet useless attempts were made to flag the approaching train. In the midst of the excitement the flyer dashed upon the scene with disastrous results.

The following day the accident was thoroughly and fearlessly discussed in the newspapers. There was no difference of opinion on the subject. Practically speaking, every one representing the state, the city, the railroad, and the newspapers, agreed to concentrate their minds on the grade-crossing problem. It should be abolished. This is the universal "hobby" and a good one, no doubt, but apparently no one can see an inch farther. The questions why and how people are killed almost every day at these crossings received no attention whatever. Public opinion, not unreasonably perhaps, is satisfied with the assurance that everything hu- 
manly and reasonably possible under the circumstances was done by the railroad men concerned in it to get the teams out of the way of the trains. But it did not occur to any one that the whole system of keeping teams out of the way of trains is inherently and inexcusably wrong. The list of victims who are sacrificed to this popular mistake is being added to daily. If the public has any right at all on these crossings, it goes without question that, while they are making use of their rights and in the act of crossing, their safety should depend, not upon their efforts to scramble out of the way of the trains, but upon the moral and legal obligation of the railroads to keep the trains out of the way of the vehicles.

This view, of course, is based on the supposition that the safety of the public is of more importance than the speed of the trains over these crossings. In the case we are now considering, if an empty coal car had been on the crossing it would have been amply protected from the passenger train. Not only is this true, but the tracks of another railroad cross this highway diagonally at this point, and while trains are crossing they are doubly protected by semaphore targets and derailing switches. Teams, however, and passengers on foot have to depend on emergency arrangements which, as we all know, are practically useless. If railroads can afford to protect their rolling-stock in the way de- 
scribed, the interests and property of the public might reasonably be expected to receive equal consideration. In plain language, the pressing of a button in crossing-houses, in connection with proper signals, would give the public the protection so urgently called for. Altogether the foregoing may be taken as a very good object lesson on the safety problem on our railroads.

This crossing accident took place in December, 1907. Within a mile of the scene, on the next crossing, in the month of July, 1908, another accident occurred under similar conditions. In this case a wagon was demolished, two horses were killed, and a number of passengers on an express train were injured. Comment is unnecessary.

For the rest, the interest and significance of this essay will be sadly misunderstood if the impression is in any way derived from it that the railroad employee is singled out and must stand alone as an object of adverse criticism. As a matter of fact, a volume can be written in our defense. Only too many of us can remember the time when a deserving employee could be, and frequently was, discharged on the flimsiest pretext. His breakfast disagreed with a yard-master or he happened to have domestic troubles on his mind: for less reason than this good men were sent packing. Not ten years ago the service on New England railroads 
swarmed with favorites and brothers-in-law. Faithful old employees were sent adrift without a moment's warning or sympathy, to make room for youngsters with a "pull." Many an honest old servitor, not so very long ago either, with justice and reason might have flung the retort of old Adam, in "As You Like It," at his superior. "Is 'old dog' my reward? Most true, I have lost my teeth in your service." But we have changed all that. Nevertheless, these things rankle. They say history repeats itself. Justice certainly does; and as for injustice it reacts and rebounds, and perhaps, after many days, it returns and demands a settlement at compound interest. The situation to-day between labor and capital is but a chapter in the natural history of the instinct of self-defense.

Finally, in regard to the lack of loyalty to the world at large, the railroad employee is far from being the only offender. While it may be said to be strictly unintentional, this lack of loyalty covers our railroads as with a blanket. The illustrations given above have been chosen with strict impartiality, and regardless of the personality of the offenders. With the panorama of railroad life before us, as I have endeavored to sketch it, we railroad men should be able to contemplate the conditions, and our conduct in relation to them, as in a looking-glass. While the writer's sincere desire from be- 
ginning to end has been to avoid giving unnecessary offense to any one, yet it should not be forgotten that to take away life, either needlessly or heedlessly, on a railroad is an offense against society that calls for the utmost rigor of treatment. 


\section{V \\ THE SQUARE DEAL}

IN the days of the Roman Republic, when a consul was invested with supreme power, he received a caution or command somewhat as follows: "See to it that the Republic receives no injury."

This injunction is quite as significant and important to-day, both to individuals and to public offcials, as it was a thousand years ago. Then, as now, the interests of the community were the first and paramount consideration. But in discussing questions relating to these interests, such as, for instance, those which have arisen between labor and management on our railroads, public opinion, as represented by the press and the laws, should insist upon a fair field, no favor, and absolutely open play on all sides.

We need only glance at the safety problem on American railroads to appreciate it thoroughly. During 1907, on a single well-known railroad, thirty passengers were killed and 1596 injured; 572 trespassers killed and 526 injured: 72 people were killed at grade crossings and 518 injured; twelve contractor's men were killed and ten injured: the total killed numbered 686, and the injured 2650 . 
These figures are not inclusive of employees. The biggest single item of the year's disaster for personal injuries fell under the head of collisions, 76 of them resulting in 456 claims, to the account of which the charge was $\$ 145,748$. The total was 876 claims for personal injuries, costing $\$ 746,075$, still leaving 2345 unsettled cases at the expiration of the year.

Some time ago, in the Chicago " Record-Herald," E. P. Ripley, president of the Santa Fé system, was quoted as follows: "One of the most serious conditions which this country is facing to-day is the indifference and disregard which the employee has for the interests of the employer."

"The Santa Fé," continued Mr. Ripley, "hopes to establish a better esprit de corps among its employees, and expects that a liberal pension system will have that tendency. We have on this system as much loyalty as most railroads enjoy, if not more, but it is not what it should be. The lack of loyalty among employees is a condition from which all corporations are now suffering, and it presents a most serious problem."

It matters little to what railroad one turns for information on this subject, Mr. Ripley's remarks, in a greater or less degree, apply to them all. Quite recently, in discussing this topic, the manager of another railroad uttered the same opinion from a 
somewhat different standpoint. He remarked in substance, "During the last week, at three different sessions, a committee of employees came to this office for the purpose of arbitrating, or coming to some understanding about, a matter of discipline. These men fought tooth and nail for what they considered their rights in this case, and finally, at the third hearing, an agreement was arrived at, which, if you choose, you may call a compromise. So far so good. But now to-day, these same men, or rather two of them, representing different organizations, have been up here again. Some kind of a dispute has arisen between these organizations, and they called upon me, with assurances of belief in my ability and impartiality, to act as final arbitrator between them. This means, of course, that I must devote two or three hours of my time to their private interests. Be this as it may, I consented to act as arbitrator, but at the same time I could n't help wondering how these men could find it in their hearts to accept my verdict in their private affairs, about which I know comparatively little, while they persistently question my judgment, and practically my honesty of purpose, in matters of discipline and management. In a word," he concluded, "why don't the employees trust the management to administer the affairs of the railroad conscientiously and fairly, and to give to each employee a square deal ?" 
During the palmy days of what may be called autocratic management, when a railroad man started out in the morning, the paymaster, or the office-boy, for that matter, could have told you the exact amount the man would have been entitled to on his return. The employee was willing, and in fact had agreed, to travel or to work from a point $A$ to a point $B$ for a certain fixed sum. So far as his pay was concerned, it made no difference whether he covered the distance in eight hours or eighteen. If a yardmaster delayed him for two or three hours before starting, and if he lost half a day on the road by reason of wrecks, disablement of locomotive, or a washout, so much the worse for him. His duty was to go from $\mathrm{A}$ to $\mathrm{B}$ and to do what he was told to on the way, without question, even if it took him from sunrise to sunrise to cover the distance. There was no help or rescue in sight, no appeal from the discipline in those days; and if the work was not to his liking, the world was wide, and a dozen men were ready to step into his place.

Nevertheless, the one-sidedness and injustice of the whole proceeding were manifest to everybody, and from year to year it remained to be talked about, objected to, and brooded over. But with ever-increasing business and complication of conditions, a much better educated class of men found their way into the railroad service. In moving a train from 


\section{THE SQUARE DEAL}

place to place, greater intelligence was required. A conductor to-day can frequently run from one end of the road to the other in a purely mechanical fashion; but in the early days of railroading, with a single track, a confusion of flags and train orders, and a multitude of unforeseen difficulties awaiting him at every station, it took little less than genius to make a successful railroad man.

The really heart-breaking story of the hardship and heroism of the trainmen of those days has never been written, but a touch of the stern reality and pathos of it all can be imagined from the single consideration, that of seventeen freight conductors who in the year I 883 ran trains through the Hoosac Tunnel, only five in the year 1888 , that is, five years later, were still to be found on the pay-rolls. In nearly every instance, death in violent form had removed the others. Of course, as we all know, the most popular type of heroism is to be looked for on the battlefield; but there are hundreds of railroad veterans on the streets to-day, undecorated and unremembered, whose services to the country are all worthy of popular sympathy and national gratitude.

As a result of these extraordinary conditions and the continual killing of employees, a new and more intelligent class of men was called upon, in course of time, to undertake the dangerous duties of railroad service. With increased intelligence and broader 
mental equipment, the thinking process in the brain of the railroad man expanded, and very naturally his awakened attention was not exclusively centred on the business of his employers. It soon became known to officials, and to the world, that we had grievances. Before long, rumblings of discontent were heard on all sides. Between ourselves we began to discuss matters of right and wrong. The men got together in groups, in small gatherings. Here and there, all over the country, little Runnymedes were attended by all conscientious, determined railroad men. With an ever-increasing demand for our services, came consciousness of importance and power. Attention was called to the injustice, the inconsistency of the situation. We petitioned and agitated for trifles. Inch by inch ground was gained. Frequently we were beaten back, sometimes routed, at other times the battle was drawn; but after every encounter, regardless of result, the ghost of the future remained on the field to disturb the slumbers of the management. So, through the years, the struggle proceeded, concession followed concession, until all kinds of injustice and favoritism, and in fact the whole system of purely autocratic management, had gone by the board, and fair play for the railroad trainman was an accomplished fact. For the future, to ask was to receive. Face to face with organizations of deter- 


\section{THE SQUARE DEAL}

mined men, with the crops and manufactures of half a continent waiting to be moved to the seaboard, what was a management or a combination of managements going to do about it ?

Thus, by evolution and revolution, a mighty change has come over the scene. To-day, when a railroad man makes a trip from point $A$ to point $B$, it is altogether different from the performance to which I called attention at the beginning of this essay. At the end of his trip, the man now takes out his pencil and does some figuring. Neither the superintendent nor the paymaster has the slightest idea what the engineman's, the conductor's, or the brakeman's bill for a day's work is going to be. If a man is delayed on a road by the negligence of a fellow employee, the company will have to pay for the extra time. If he makes a straight trip, with one or two stops, he has a certain rate; if in the performance of his duties he is called upon to make an extra stop or to pick up a car of perishable goods, he will call for a special rate and much more money. His day's trip frequently bristles with possibilities in the way of special rates and overtime. In the matter of overtime, he may have the opportunity to be just or unjust, as it pleases him; anyway, the company is at his mercy. Again, if at the end of a hundred-mile run, or thereabouts, for which an engineman would receive from four to five dollars, 
he is requested to take his engine out on the road again and move a car a distance of twenty feet, he will turn in his bill to the company for a greater amount than a gate-tender or a switchman would receive for his whole day's work, from six in the morning until six at night, without a minute for meals.

Again, if a man gets into trouble, he is called into the office for an investigation. If it turns out that the accident was unquestionably the fault of the employee, he, of course, is liable to be disciplined for it in some way; but if as a result of the accident, the whole road is tied up for twelve hours, and he remains on duty half a day longer than his usual time, he will receive payment for this overtime in full, regardless of the fact that he himself was wholly responsible for the delay.

Far from criticising this state of affairs, I consider the demonstration I have given of the exact status of the railroad man at the present day a magnificent tribute to righteous and necessary organization. Up to this point the public has had no cause to complain, and discipline has not been interfered with. The treasury has borne the whole burden. While it is doubtless true that the liberal terms and concessions to which I refer have been brought about, so to speak, at the point of the bayonet, nevertheless many privileges and advantages are 
enjoyed by railroad men, which cannot be said to owe their origin to compulsion or pressure of any kind. The care shown by nearly all railroads for the welfare of the employee, and the millions of dollars that have been expended for his social and intellectual betterment, must also be taken as direct evidence of square and honest treatment. To combat the evils of the saloon, and in the interest of good citizenship, both on and off the railroad, the corporations have gone extensively and expensively into the construction and maintenance of readingrooms and hospitals, as well as relief, savings, and loan associations. There is, indeed, a fine sense of business judgment hidden away in these different methods of looking after the interests of the employees, and there is hardly a road in the country that does not recognize the principle that to obtain competent, trained assistants, especially in the operating department, it is essential that the men be surrounded with all sorts of inducements to remain in the service, and to be loyal to the interests of their employers. This philanthropic and betterment work is to be found on all railroads, and conspicuously so on the Baltimore \& Ohio. The following particulars of relief and betterment work on the above railroad may be taken as a lesson of what corporations with souls are doing in the interests of employees. 
Membership in the Relief Department of the Baltimore \& Ohio is compulsory on the part of all employed in the direct operation of the road. The employees themselves have part in the direction of the affairs of the organization. The company makes all collections and payments, under its guarantee of responsibility for every penny coming into or going out through its hands. The company also pledges itself to pay four per cent interest on the monthly balances of current accounts ; no charge is made for office rent, and all the facilities of the road are at command, without cost. Operating expenditure is thus reduced to a minimum, and upon transactions during the year 1906-1907, which represented a million dollars distributed in benefits, the expense averaged but a dollar and sixty-eight cents per capita of membership. The aggregate of the benefits paid from the founding of the Relief to the close of the year 1906-1907, was thirteen millions of dollars.

The Baltimore \& Ohio plan for pension payments, in vogue for the past twenty-three years, is in conjunction with the Relief Department, but is not, as that is, maintained by the contributions of employees. The pension system is maintained entirely by the company, which contributes for the purpose about $\$ 90,000$ annually. During the year 1906-1907 the fund paid in pensions was over $\$ 95,000$, to about 
400 pensioners. Since its inauguration in 1884, there has been paid out in pensions, $\$ 1,008,000$.

Again, the foundation of two other features Savings and Loan - in the Baltimore \& Ohio dates back a full quarter of a century. The Savings is strictly a trust fund, around it being thrown the unequivocal protection of the United States government in the decision handed down by its courts. Of course this is understood by employee-depositors; consequently there is absolute confidence. There are no runs, no anxiety as to savings, and no fear that what has been laid aside for a rainy day will be risked. Meantime, upon it the company is guaranteeing four per cent and earnings; the interest and dividend returns thus amount to never less than five and sometimes five and a half per cent. The total of the savings deposits to June 30, 1907, reached eight and a half million dollars, and interest and dividends paid to employee-depositors to that time came to a million and a half dollars.

The Baltimore \& Ohio loan feature is still more remarkable. The object is to enable the employees to own their own homes. All are real-estate transactions, and it is a remarkable fact that the administration of this feature, throughout twenty-five years, has been entirely without appreciable loss on any single investment. Employee-borrowers have entered into personal obligations representing the 
building of two thousand houses and the purchase of three thousand homesteads. The transactions of the loan section to June 30 represented six and three-quarter millions of dollars, when there was also a million and a quarter in the treasury, upon which the company's guarantee of four per cent held good.

Rest-houses are another form through which welfare work in the direct interest of the employee is carried on as part of the regular operation of the Baltimore \& Ohio Railroad. The aim is to furnish a comfortable and convenient place, open at all hours, to the employee coming in from his run, whose first want is a bath, with plenty of hot water, and subsequently a restful bed. The work carried on by the Railroad Y. M. C. A. is of a similar nature. The old-time dark cabooses, dingy freight cars, and decrepit coaches, serving as night-holes into which to crawl for the sleeping hours till the time for the next run, are now nothing but an unpleasant memory. The Railroad Y. M. C. A., with its commodious lounging-rooms, bright and airy dining-rooms, clean lunch-counters, well-appointed kitchens, billiard rooms and bowling alleys, general assembly halls, libraries, attractive bedrooms and baths, is the practical exemplification to-day of the fitness of things. The disbursements of the Baltimore \& Ohio Railroad for these purposes have in 
single years exceeded fifty thousand dollars, and every penny is profitably expended from the purely business standpoint. Bettering the man betters his work.

Furthermore, incident to the administration of the Relief Department, the company, through a corps of medical examiners and surgeons, closely supervises the health of its employees and the sanitary conditions of the places where their duties are performed. This corps is in charge of a chief surgeon and chief medical examiner, both prominent in their professions; and although the number of men in their charge exceeds forty thousand, any complicated or persistent disability of an employee secures the personal supervision of the chief surgeon.

This is surely a remarkable demonstration of what one corporation is doing, and has done, for the benefit of its employees. It is very doubtful if any government or any other industrial institution in the world can show any such record, and one which extends over such a long term of years. Fair and humane treatment of employees cannot be carried any further.

Having in this way, for the present, made an end of the evidence as regards the men, let us now turn to the management. It will, I think, be admitted that the running and operation of trains on American railroads calls for some system of management 
and discipline that shall be absolutely untrammeled and free from outside influence or interference. In a word, the manager of the operating department of a railroad should be permitted to manage. Public opinion, of course, is always free to express itself as it thinks fit on this and on kindred subjects, but it will be found to be utterly unjust in its position if it allows itself in any way to connive at the undermining of authority, and at the same time holds this authority responsible for results. Yet it does not call for a national mind-reader to extract from the history of public sentiment the uncomfortable conclusion that the laws and the press of the country, to a great extent, still harbor their ancient grudge, and are not prepared to treat railroad managers impartially. So accustomed have managers become to adverse criticism that they are now almost tonguetied on the subject of their duties, and simple sufferance has become the badge of the fraternity. The manager may now be likened to a horse, willing and able to trot his distance with credit to himself and his owners ; but behind him, on the boxseat, sits public opinion, the labor organization at his side. The horse is willing enough, and eager to work and to do his duty, but every effort to exert himself or to get into his stride is rewarded with a violent jerk of the rein. The effect of this treatment on any kind of an animal can be imagined. That the 
traveling public should be at the mercy of a threecornered management of this nature, is rather remarkable. If managers nowadays were inclined to be autocratic or overbearing in matters relating to the public safety, there might be some excuse for the situation. On the contrary, to most people it will appear that they have already parted with the best part of their birthright. The following is the agreement on the subject, in force on nearly all railroads :

"Employees shall not be disciplined or dismissed without cause. In case discipline is thought to be unjust, the employee may refer his case, in writing, to the superintendent, after which he shall be given a hearing within seven days. The aggrieved party may be present at all investigations and may be represented by a fellow employee of the same class. In the event of this investigation proving unsatisfactory, the case may be appealed to higher officials in regular order. If the accused is found blameless, his record will remain as previous thereto, and he shall receive pay for all time lost."

Such an agreement will, I think, appear to most people to be remarkably fair and generous. Unfortunately for the interest of the public, it approaches the danger point. It is very doubtful if many, or any, private industrial establishments could be persuaded to sign any such agreement with their em- 
ployees. Manifestly it makes a cipher of the superintendent. But taking our agreement just as it is, the manager should at least be allowed to manage, and appeal should be limited to the officials of the road. The line must be drawn just where responsibility is wanted and needed. That the management of a railroad should invite interference or assistance from grievance committees or national organizations of labor men, in matters of discipline, is absurd. The situation has been forced upon them. It has been forced upon them during "rush hours," when business was at high tide and pressure, and when the public was clamoring for its fast trains and for the prompt delivery of freight. Such are the stormy times on railroads, when discipline is lax and when concessions are granted at the expense of the public safety. Blame the management if you will, - the results and consequences are before us for consideration and remedy. Most of us understand something about rebates on a shipment of oil or cotton goods, and about the penalties that are enforced against offenders; but we do not seem to realize the fact that to-day on our railroads there are, in actual operation, rebates on the efficiency of the service, which are being paid for by the people, not in dollars and cents, but in blood and suffering.

But putting on one side public opinion and its influence on the efficiency of railroad service, what 
is the nature of the treatment that the employee himself, with his eyes wide open and his wits about him, is willing to give to the management and to the public, when he has the power and the opportunity to work in a little legislation for himself? For illustration, let us take what is commonly called the "Bumping Process." Of course no management in its right mind would ever originate or put into service any such suicidal arrangement. From beginning to end it is a ludicrous, at times a pathetic, commentary on the seniority rule. It works somewhat in this way:-

On account of slack business, a crew consisting of a conductor and two or three men is relieved from duty. The conductor immediately looks over his list and picks out another job to his liking, the holder of which happens to be his junior in the service. The man who is thus turned out does the same to some one else, and meanwhile the discharged brakemen have been "bumping" other brakemen. So it goes on from one end of the division to the other, until some twenty or thirty men have been "bumped " out of their accustomed and hard-earned places. Finally, three or four of the youngest employees are bumped into space, at the end of the string, and the "bumping" ceases for lack of material. The management has had absolutely nothing to do with the affair; it can protect neither its own 
interests nor those of the public. The whole business must be looked upon as the natural sequel of the seniority principle. It is a concession granted during "rush hours," when bumping was not anticipated. To understand this thoroughly, let us take a concrete illustration.

On a certain railroad there is a section, say from $\mathrm{X}$ to $\mathrm{Y}$, over which a local freight train has plied daily for a number of years. Along this route there are, perhaps, as many as fifty large foundries and industrial plants, to attend to the requirements of which this local freight was put on the road. The conductor of this train has attended to this business with satisfaction to his employers, and to the patrons of the road, for three or four years. He thoroughly understands the ins and outs of his route, all about the different switches, side-tracks, dangerous places, and difficulties that are to be encountered. $\mathrm{He}$ is personally acquainted with the foremen of the different establishments. He knows just what they want and when they want it; he understands when and where they want cars loaded and emptied. He has the phraseology of the different side-tracks on the tip of his tongue. When he arrives at any little town, his switch list reads something like this :-

"Six for Dublin St." "Two for Jerrys." "Three for The Middle." "Seven for The Hole."

In short, our conductor is the right man in the 


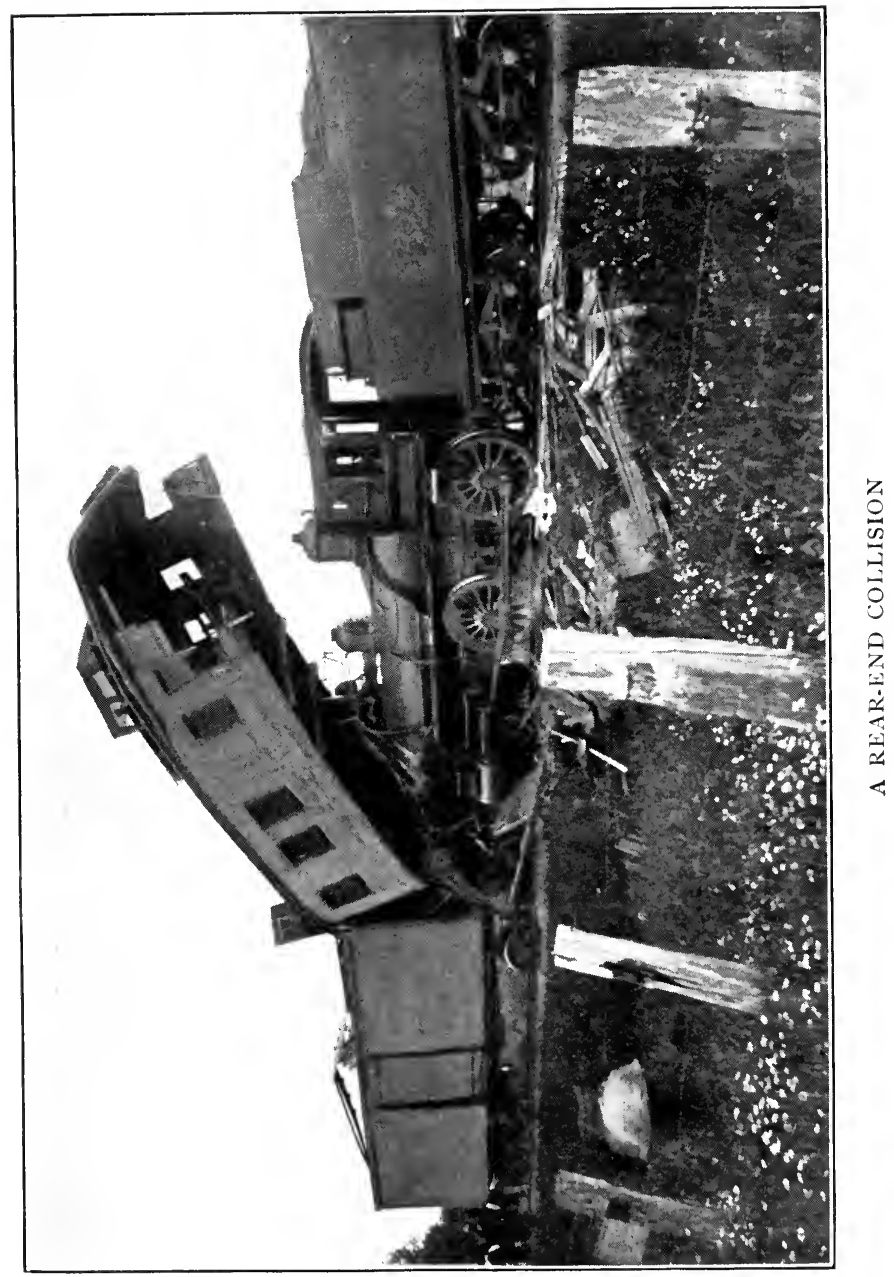




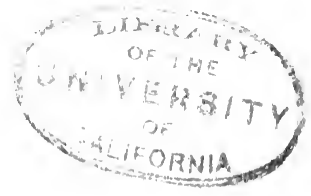


right place. This is so not only from a business point of view, but from the social aspect as well, for he has made a home for himself, and all his social interests are centred in a little town on this route. But suddenly, without any warning or reason, he is simply "bumped" out of the job, and a new man, his senior, from another section of the road, takes his place. This is an actual occurrence, and it is a sad commentary on the straits to which some managements are reduced. It shows the seniority principle run into the ground. It is individualism triumphant. Even to the whole body of employees it is a distasteful proceeding. The senior man simply "grabs the job," and consequently twenty other men are displaced in rotation, the management remaining silent.

And yet there are men, even in high places, who are prepared to defend this bumping principle. In studying these railroad matters, and while calling upon managers of different railroads, I was always anxious to get the general opinions of the officials. One can usually tell, from the "atmosphere" in these offices, what can be expected in the way of treatment of employees and so forth out on the road. It was in order to get some of these impressions - some of this silent information - that I called upon the United States Commissioner of Labor in Washington. I asked him for his opinion 
of the bumping principle. The commissioner was outspoken in his defense of the bumping business; in fact, he wished to know what possible objection there could be to it. In so many words, and with considerable emphasis, he inquired if it was not a much more desirable state of affairs that the men should be allowed to pick out their jobs in this way, than that superintendents should be at liberty to give the preference to their cousins, their brothersin-law, and other incompetents ? In fact, managers are not to be trusted. If I wished for evidence, I could turn to the insurance scandals, - the cream of the appointments handed over to relatives and good-for-nothings. The commissioner was also of the opinion that in only too many instances railroad managers are in the habit of making rules which they know only too well it is impossible for employees to obey.

In the matter of the operating department, there is an abundance of evidence of an interesting description. What may in many ways be called abuse of the management is a national habit of long standing. In years gone by, this adverse criticism was frequently only too well merited. But the time has now come, in the interest of the public safety, for some serious second thought on the subject. That the habit still persists in the most unexpected quarters, is a matter of easiest demonstration. At 
the present day the Interstate Commerce Commission is the laboratory in which all these railroad questions are ground up, analyzed, classified, and finally sent out in legal packages for public consumption. With the idea of getting the "atmosphere " of this department, I quite recently called upon the secretary. He conducted me over the premises, introduced me to everybody, and was most kind and courteous in his attentions. He drew my attention to a dozen or more framed and illuminated testimonials, with which the walls of his office were pretty well covered. The tenor of these documents was all the same. Railroad men, telegraphers, organizations and brotherhoods of laboring men, from different sections of the country, unanimously testified to their gratitude to the secretary for his efforts and success in fighting their battles and winning their victories. In a word, he was their friend.

Remembering where I was, I thereupon looked about me for testimonials from railroad officials or corporations. I expected to see evidence of the secretary's interest and work in behalf of the manager's side of the problem, in relation, for instance, to the bringing of men and managements together in the interest of the public, for whose use and benefit, as I look at it, railroads are operated. But in this I was disappointed. My attention was then 
called to a number of pens, perhaps half a dozen, with which sundry bills, in the interests of labor, had been signed by different presidents. But one side of the question was emphasized.

Finally, I was introduced into a room in which were seated seven or eight of the railroad inspectors employed by the commission. I had no sooner given expression to my views, than I became aware that I was getting into hot water. With one or two exceptions, these men were of the opinion that I had taken hold of the wrong end of the problem. It was pointed out to me that superintendents and managers nowadays are promoted from the wrong material. The inspectors thought that the officials were nearly always picked out of the clerical force, instead of from practical, out-on-the-road men, such as engineers and conductors. Consequently, in their opinion, the managing departments all over the country are sadly inefficient. As a result, a general decapitation of incompetent superintendents is now in order, and is the one thing needful to secure the greatest possible degree of efficiency in the railroad service.

For something like ten years altogether I have devoted my spare time to the study of this safety problem on our railroads. During this period I have never received a word of advice, or encouragement, or assistance to the extent of a copper, from any 
manager or from anybody connected with the management of railroads. My incentive and encouragement have proceeded in an entirely different way. Some people are content to stand on their little pedestals and watch the world go round. The energies and thoughts of quite a number are absorbed in the climbing of pay-rolls. Others, again, have sensibilities that must be attended to. These touches of nature should be cultivated. As the world runs to-day, "business from the start means, only too often, business to the finish." I do not think that the American people, the great business community, at any rate, realizes either the nature or the extent of these distressing accidents with sufficient acuteness. In the rush of affairs, sensibility runs the risk of getting smothered. There is a tendency to call upon money and machinery to accomplish everything.

Finally, let me add that, apart from my opinions on this railroad situation, or perhaps in spite of them, I am the heartiest kind of an optimist. At the present day, such splendid possibilities are latent in every sphere of thought and action that one almost trembles at the contemplation of them. Even now, as it seems to me, every man in his little world may be something of a Prospero, for every righteous thought is a winged Ariel on highest mission. 


\section{VI}

\section{THE HUMAN EQUATION}

IT makes little difference what phase of the situation between labor and management on American railroads we choose to investigate, the supreme importance of personality and personal responsibility is impressed upon us at every turn. As with the safety problem in the operating department, so with all questions relating to piece-work and the bonus system, - the principle at stake is not only the absolute right, but the fundamental obligation, of every man to do his level best under all circumstances, just as truly and inevitably in the best interests of a railroad as of human progress and civilization. The story of the stifling of personality and of the neglect of the human equation in American industrial life, and on the railroads in particular, will probably have to be related and insisted upon over and over again before public opinion can be brought to realize the widespread nature and importance of the issue.

The principles involved in an ordinary preventable accident on a railroad can be picked out and followed through different stages of railroad life, all the way up to the leveling process which, generally 
speaking, the labor unions insist upon, in promotion by seniority and in matters relating to mechanical work in the railroad shops. The steps in the process are all as plain and unmistakable as the rounds of a ladder. Let us begin with one of the first appearances or germs of the trouble.

A freight train is backed into a yard or sidetrack, and by reason of rough handling or carelessness a small collision occurs, and several cars loaded with valuable merchandise are jammed down and off the end of the track into the swamp. The superintendent investigates the case and decides that the engineman was guilty of rough and careless handling. The engineman appeals from this decision, claiming that a wrong motion was given by the brakeman, or the brakes did not hold, - anyway he appeals, and his contention is taken up and supported by his organization. After weeks of discussion and attempted arbitration, the whole business is quietly dropped, because the men decline to give in and the management, with the business interests of a wide section of country in actual peril, are not prepared to tie up the road and fight the issue to a finish. It is useless to minimize the widespread effect of this interference. I have given an illustration of a principle that is at work on all railroads, and, in the way I have described, the men are furnished with a precedent, and the managers 
with a very good idea of the difficulties to be expected in the future. So the manager now goes to work and orders bunters put up at the end of these tracks in all yards and sidings. He has been driven to the conclusion that, although it may be out of his power to teach and enforce carefulness and personal responsibility, he can nevertheless put up bunters which, when butted against, will act as practical reminders in regard to the location of the cars and the duties of the trainmen.

Although the incident described is merely a figurative illustration, the bunter principle itself is of widespread application, and to-day is practically the mainstay and sheet anchor of the American railroad manager. To a much greater extent than an outsider would imagine, these bunters, derailing switches, and other mechanical devices for the protection of life and property, are, in the main, confessions of weakness and indications that the personality of the men along these particular lines has been tried and found wanting.

As another illustration of our topic, but of a somewhat different nature, let us now take a glance at what is usually known as the "Nine-Hour Law," - more especially in its application to telegraph operators.

Twelve or fifteen hours at a stretch is too long a period for any man or boy to remain in harness. 
As I look at it, the primary object of this law is, or should be, to increase the efficiency of the service. This is particularly desirable, for the reason that some of the worst wrecks in the history of railroading have been attributed to sleepy and careless telegraph operators. But it by no means follows that, because the law has increased the operator's pay and shortened his day's work, it has also increased his efficiency. You can depend upon a good man, who works twelve hours at a stretch, while you can place little reliance upon a shiftless fellow who is called upon to work only nine. To increase efficiency in any department or industry, you must touch or act upon personality in some way. This giving of something for nothing by the United States government is at best a very questionable proceeding, and it is a pity that the nine-hour law could not have been framed with at least some reference to merit, attention to duty, and length of service. The man who works eight hours at high pressure is much more likely to be overworked, and, generally speaking, is more worthy of assistance than the twelve-hour man, who may handle on an average one messagé per hour, and consequently has difficulty in keeping awake. Unprejudiced judges are of the opinion that, as framed at present, the law will have no effect whatever upon the efficiency of the service. Of course the function of a railroad 
manager is to promote efficiency, but laws of this description ignore the usual and constituted authority and divert the attention of the employees to their unions and to the national government. But now we will take up this matter of personality and the human equation from a vastly more important point of view.

A very serious and somewhat remarkable accident took place quite recently - an engine attached to a passenger train ran into an open draw and dropped thirty feet, leaving the tender and four coaches, containing seventy-five passengers, on the brink. The following day, in a report of this accident, the Boston "Transcript" quoted President Tuttle of the Boston \& Maine Railroad, as follows :-

"You can't open that draw, you can't pull the bolts that block it, until all signals are set for danger, and they remain at danger while the draw is open. They do not disappear until the draw is closed and the signals for a clear track are set. The engineman knew these signals were there, and he knew what they meant. A railroad may supply every safety device known to modern science for precaution, it may put in the perfection of safety appliances for the safety of its passengers and its stock, but you can't get by the human equation. You've got to stop right there. You can 
only discharge the man and get another, and, in turn, he is liable to do the same thing."

Every word of the above statement of the president of the Boston \& Maine Railroad is true. It is the conclusion of common sense, of the law, and of the prophets on the subject. And yet the criticism which I intend to apply to it is most damaging.

It is, alas, only too true that practically very little good is accomplished by discharging a man who runs a passenger train into an open draw. It is simply a case of locking the stable door after the horse has been stolen. But the principle of punishment for offenses of this nature is universally recognized, and in the matter of railroad accidents it thus becomes the duty of the managers, supported by public opinion, to see to it that this punishment is inflicted at the right time and in the right place. On a railroad, with human life and much valuable property at stake, a system of discipline that does not punish for trifles is a mockery. As a practical matter of fact, all mistakes and accidents, without serious consequences, can be written down as trifles; and taking the situation in a wide sense, covering all railroads, it is safe to say that there is no power in the country to-day that is either able or willing to discipline enginemen for trifles. When a passenger train has been brought to the brink 
of a draw, it is too late a day to apply your prevention method.

The battle in regard to this matter has long ago been fought and won by the men. The Brotherhood of Locomotive Engineers is now in a position to tire out any board of railroad management in the country. The statement made in Faneuil Hall by a railroad man, that in rush times the management will "lap up any schedule that is placed before them," was no empty boast. The right of unlimited appeal to be found in the schedules of the organizations has knocked the ground from under the superintendent and made the punishment for trifles a practical impossibility. The public may just as well be informed of the facts now as later. The men upon whose vigilance and caution the safety of railroad travel is altogether dependent are not being educated in a school in which even the rudiments or principles of safety are being taught or insisted upon. That a great majority of railroad employees are sound in their habits and thoroughly honest and conscientious in their intentions, is not open to question; but it is practically the fault of these good men that the careless individuals are not subject to discipline, and so cannot be weeded out before the day of reckoning. But, as a matter of fact, the system is almost as fatal to the best man as to the worst, and in the words of President Tuttle, 
"You can discharge a man and get another, and, in turn, he is liable to do the same thing."

Furthermore, however unpalatable the truth may be, it is nevertheless an unquestionable fact that the American railroad man, above all others, is most in need of an inflexible system of discipline. The reasons are obvious. To begin with, the railroad man is a typical American. $\mathrm{He}$ is fearless, quick, clever, and resourceful. He cuts loose, only too easily, from custom and tradition. He has supreme confidence in his own individual importance and ability. In unmistakable quality and quantity he is in possession of the sterling characteristics that have made the American the most resourceful antagonist by land or sea, the cleverest designer and inventor, the most fearless innovator and reformer, and the poorest railroad man, from the safety standpoint, in the world to-day.

Nothing can be more simple than the explanation of this paradox. In the mental composition of the American railroad man there is no such idea or faculty as dogged obedience. And yet it must be evident to the most superficial thinker on this subject that never can there be any prospect for, or approach to, safety in railroad travel, without this indispensable ingredient of personal character. It is the sine qua non of successful railroad operation. "Theirs not to reason why" is the solution of the 
safety problem in a single forceful expression. And yet in a lifetime of railroad service, I can honestly affirm that I never met more than half a dozen railroad men who had any conception, either in theory or practice, of this principle of dogged obedience. Furthermore, I never came across a manager who was big enough to preach the doctrine, and I am equally certain I have never read in the newspapers or magazines any widespread expression of public opinion that would lead a railroad manager to expect public support and approval of any such principle. Consequently, my argument is an arraignment not only of the men, the unions, and the managements, but of the manifest opinion and public policy of the American people. The price that is being paid in tribute to this lack of dogged obedience and its attendant evils is graphically emphasized in the Twenty-first Annual Report of the Interstate Commerce Commission, issued December 23, 1907, as follows :-

"Accidents to trains on the railroads in the United States continue to occur in such large numbers that the record, as has been repeatedly declared by conservative judges, is a world-wide reproach to the railroad profession in America."

That the men should lack the faculty I speak of is not, under the circumstances, so very surprising; but that a great many railroad managers, 
as well, should remain uncertain and doubtful as to its fundamental importance, is by no means so easy to understand. Some time ago the writer of this essay received in writing, from the head of the operating department of one of our largest railroad systems, the following question:-

"Is it not equally essential that the meaning of and reason for a rule should be evident on its face as that the rule itself, that is, its wording, should be plain and unmistakable?"

My reply was as follows :-

"By no means. From the safety standpoint the order itself is primary; the reason for its being in the time-table is secondary. Is it not very significant that the principle of dogged obedience should be open to question on a railroad, while, in the case of a city ordinance or a state law, no liberty of thought or action in such matters is tolerated for a minute?"

The following illustration is interesting and well to the point : -

In our time-tables we have a rule for the guidance of enginemen on what are called "helping engines," which reads something like this: "Never hang up the numbers of the train you are going to help on your headlight, until you are actually hitched on to said train." The reason for this rule does not appear on its face, and yet the rigid necessity for 
dogged obedience in regard to it will at once be understood, when we study its origin.

About twenty years ago, while working as telegraph operator at East Deerfield, Mass., I received a telegram ordering an extra engine out of the round-house to help a regular freight train, No. 94, which was expected in from the east. Meanwhile the helping engine stood waiting on a siding with "94" displayed on its headlight. Before long an extra or "wild" freight train from the west, with orders to meet No. 94 at East Deerfield on single track, came along, and, mistaking the engine with " 94 " on its headlight for the regular train, kept on its way without stopping. No. 94 and this wild freight met in a cut, and "piled up" in probably the worst "head-on" freight collision in the history of the old Fitchburg Railroad.

Every rule in the time-table has its history written in suffering and dollars; and while, of course, it is advisable for employees to be conversant with their meaning and significance, it is evident that the principle of dogged obedience is the only safe method for employees to pursue in regard to them. An inflexible enforcement of this principle would be looked upon as little short of tyranny; and yet, seriously and fairly considered, it is nothing but the subordination which every railroad man owes to the community in the interest of safety and gen- 
eral efficiency. That the organizations of railroad men do not insist upon, or even countenance, this absolute subordination to authority, is thoroughly understood by every man and manager in the service. We are all tarred with the same brush, and rather than acknowledge the weakness of our position, we prefer to keep calling on the public to pay the penalty. It is time to call a halt when the liberty and liberal views of a few endanger the safety of the many.

But in passing from this branch of my subject, I wish to call attention to an almost unnoticed fact in regard to the efficiency of railroad service. Taking an accident bulletin, issued by the Interstate Commerce Commission, at random, I copy the following :-

"The total number of collisions and derailments during April, May, and June, 1907, was 3777, of which 220 collisions and 22 I derailments affected passenger trains. The damage to cars, engine, and roadway by these accidents amounted to $\$ 3,232,673 . "$

This report, treating as it does exclusively of collisions and derailments, is serious enough, but the note that is appended to it is the significant feature of the situation :-

"Collisions and derailments which cause no death or personal injury, and which cause not over $\$$ I 50.00 
damage to the property of the railroad, are not reported."

Seeing that the public should be in possession of all the facts in regard to efficiency of service, it occurs to me that a list of narrow escapes and of collisions and derailments which cause no deaths or personal injury, would make very interesting reading. These are the very "trifles" to which I have already called attention. They are the seed from which we reap our crop of disasters. They are well worth reporting and paying attention to, and no annual or other statement of the situation on the railroad is worth much if it fails to recognize the significance of this feature.

But apart from the influence and power of the railroad organization upon the individuality and personal conduct of its members in relation to train wrecks and discipline, there is another branch of the topic that is perhaps still more interesting, from a human and national point of view.

Comparatively speaking, public attention has been but slightly directed in any specific way to the matter of accidents to employees on American railroads. It is certainly one of the most distressing features to be studied in connection with the safety problem. Collisions, derailments, defective hand-holds and brake apparatus, and the like, cause injuries to great numbers of employees. For example, 
at Haverhill, N. H., the other day, five employees were instantly killed, through the alleged carelessness or oversight of a fellow employee. Such instances, of course, are particularly painful topics for discussion among railroad men, and yet this is the kind of an accident one reads about in the newspapers almost daily. But in twenty-four hours the reading public will forget the very worst of these accidents to employees. Their frequency takes the edge off their significance. During the year 1907, on a single American railroad, $104 \mathrm{em}-$ ployees were killed outright, and 3575 were injured. The cost of these accidents to the railroad in question was something like $\$ 285,000$. With an employers' liability law in force and operation, as in countries abroad, the increase in total paid to employees alone on this road would have carried the aggregate to half a million dollars. The magnitude and importance of the safety problem in relation to employees is still more evident when we consider that for the year ending June 30, 1907, the casualty list on American railroads shows a total of all persons killed, from all causes, of 5000, and injured 72,286 ; the totals for employees alone being 4353 killed and 62,687 injured.

The following figures in regard to actual train accidents and the casualties resulting therefrom show a rather discouraging state of affairs, from the fact 
that the employees themselves were in the main responsible for them. In 1904 the killed and injured employees in train accidents numbered 7834 ; in 1905, 7850; in 1906, 8362; and in 1907, 9935. As with all other items, so with accidents to employees, the total of casualties has largely increased year by year.

But one of the most distressing features to be considered in connection with accidents to employees, whether caused by their own carelessness or otherwise, is the absolute indifference with which news and statistics of such casualties appear to be received by the average railroad man. So far as an impartial investigator would be able to discover, "It's too bad" is about the limit of criticism and action in such matters. The indifference I call attention to, so far as the minds of the employees are concerned, is not real, and the actual reason and history of the seeming neglect can easily be located and analyzed.

The railroad employee, as a unit, is whole-souled and sympathetic; not a suspicion of indifference can be imputed to him, either as a man or as a brother. Individually speaking, when a passenger or an employee is injured, there is no sorrow like his sorrow; but, unfortunately, the organizations or machines through which alone his desires and sympathies can be expressed, have never shown 


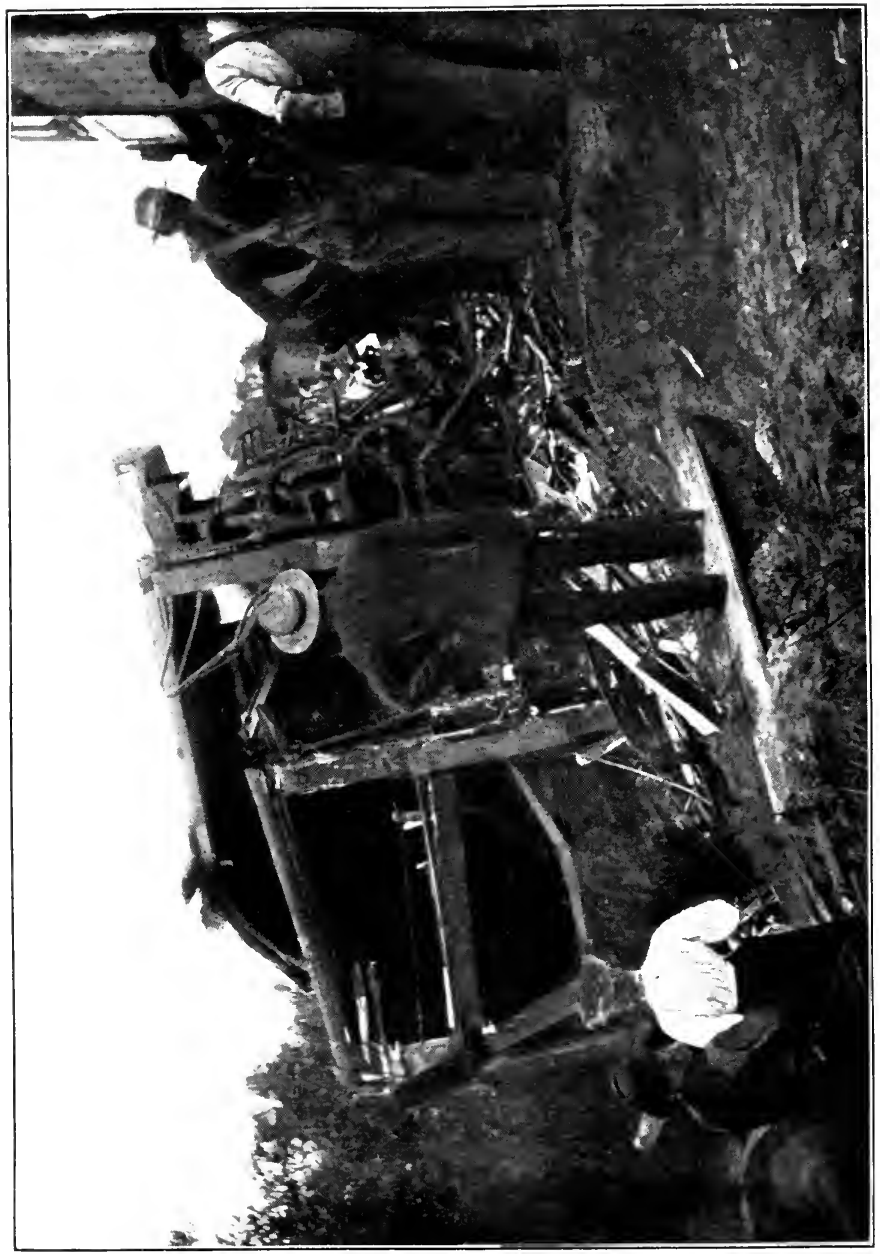





\section{THE HUMAN EQUATION}

any disposition to interest themselves in any practical way in matters relating to the safety of the public, or of the employees, whenever such interest is liable to develop into a probe of the conduct and efficiency of the railroad man. The heads of the national organizations of railroad men, with particular reference to those connected with the operating department, occupy positions that are usually threequarters political. The wishes and sentiments of great majorities of employees on certain railroads can be, and have been, set aside by the political shake of the head of one man in Washington or Chicago. The acquiescence of the rank and file in this state of affairs is paid for in legislation and concessions. Nevertheless, from the human and social point of view, it would seem as if the organizations, or men-machines as we may call them, should bestir themselves in this matter of accidents to their members. In order to do this, cooperation with the management is necessary; so the following questions very naturally arise :-

By consultation, or otherwise, has any personality been put into the business? Have our organizations ever said to their members, "Come, boys, let us reason together: when a man runs a signal, or disobeys orders, it is a disgrace to our machine. In reality we, the employees, are the principal stockholders in a railroad. When passengers, or our own 
members, are killed or injured, we have to pay a large proportion of the bill. We pay in loss of prestige and character, and every time one of us makes a mistake, it is a blot on our 'scutcheon. We should see to it that this matter is made personal to every member of our organization. We should coöperate with managers in locating the blame for these accidents, and, without regard to consequences, we should insist upon the removal of offenders."

Is there any evidence to show that this is the actual state of affairs? If so, I have yet to meet a man who is aware of it. But, on the other hand, if no such influence is being exerted by the organizations, in all candor, and in the name of public safety, I ask, why not? For, right here, the public puts in its appearance and the following additional question must forthwith be answered :

Are our organizations prepared to say to the public, "We are sorry, but the fact is, our machine is constructed purely upon selfish principles. Our time and efforts are exclusively occupied in fencing with the management. When passengers, even our own brothers, are killed, it is up to the superintendent every time. Let him change the rules if he thinks fit, but according to precedent and the rules of our organization in such cases, we are not expected to show any signs of sympathy or humanity. Consequently, to all interests apart from what may 
be called the political welfare of the whole machine, we are deaf, dumb, and blind?"

Is this an overdrawn picture? I think not. It is simply a truthful matter-of-fact description of railroad organizations, from whose calculations and behavior the personal and sympathetic element in regard to these safety questions has been eliminated.

But now, widening our horizon a little, we have next to take note that these questions of personal character, personal responsibility, and unhampered personal effort, are real and intense problems for thoughtful people to study, not only in relation to preventable accidents, but in every department of railroad life.

Some time ago, in an issue of the "Engineering Magazine," a note of warning was sounded against the result of certain American manufacturing methods. It was pointed out that the principle of securing the largest output of uniform character, at minimum cost, made automata of the operatives, and discouraged skilled and trained artisans to so great an extent that the quality of the men to-day, for lack of proper inspiration, was generally poor and unreliable. According to the opinion expressed in the article that I refer to, many American manufacturers are beginning to realize the necessity of attracting men of high character to their employ, of surrounding them with an en- 
vironment tending towards sobriety, integrity, and industry, and rewarding them according to their efforts, in order to avoid the effects of this so-called "American tendency."

That American methods of conducting business should be considered retrogressive, on account of lack or poverty of inspiration, certainly points to unhealthy conditions somewhere. If these American tendencies can be shown to have the effect of discouraging individual effort and the natural growth and ambition of the worker on railroads or elsewhere, the matter certainly calls for serious attention. To say the least of it, it betokens a very peculiar state of affairs, for the reason that if there be one characteristic that more than another distinguishes the American citizen from the rest of the world, it is his freedom of personal action, his propensity for striking new and unexplored trails in almost every branch of research, industry, and invention. The American is par excellence the world's inventor. And yet, without the utmost liberty of thought and action, an inventor would cut but a sorry figure. It follows, therefore, that any curtailment of or interference with these distinctively American gifts and instincts will, as they say, bear watching.

Quite a number of years ago an American firm secured a contract for the erection of a large fac- 
tory somewhere near Manchester, England. The contractor soon discovered that no persuasion or encouragement would induce the British workman to lay more than a certain number of bricks per hour, according to the fixed law and schedule of his union. In order to complete the work within the allotted time, the contractor was compelled to send for American bricklayers. These men, who were paid according to their industry and personal effort, were able to lay four bricks to the Englishman's one. The American could beat the Englishman four to one, not because he was, to that extent, a cleverer and quicker workman, but because at that time and place he was a free man. Transferred to American shops and factories, and in a different atmosphere, the foreign workman easily adapts himself to conditions and is able to hold his own.

According to the writer in the "Engineering Magazine," American manufacturers are taking measures to stimulate and revive the principle of individual effort, in order to secure excellence in workmanship ; but, according to other authorities, these efforts are being counteracted by the labor unions on the railroads and elsewhere, which appear to be following in the footsteps and adopting the methods of the British organizations. However, the ideas and ideals of many wide-awake manufac- 
turers and managers have found practical exemplification in various manufacturing establishments, as well as in railroad shops in different parts of the country.

Perhaps the best field for a short consideration of this interesting subject, so far as railroads are concerned, is to be found on the Santa Fé Railroad system. The introduction of the individual-effort reward or bonus system of stimulating employees to extra or unusual effort, and of compensating them suitably therefor, is probably the most important of all the betterment work on this railroad. The inauguration of the system followed the strike of the machinists, boiler-makers, and blacksmiths, in May, I904. The credit for its introduction on the Santa Fé is due to Mr. J. W. Kendrick, Second Vice-President. Mr. Charles H. Fry, associate editor of the "Railroad Gazette," who has written a valuable and comprehensive report of this betterment work, gives the following as its principal features and objects :-

"To restore and promote cordial relations, based on mutual respect and confidence, between employer and employee ;

"To restore the worker to himself by freeing him from the small and debasing tyrannies of petty and arbitrary officials on the one side, and from individuality-destroying union domination on the other; 


\section{THE HUMAN EQUATION}

"To give the company better, more reliable, and more trustworthy employees;

"To increase automatically, and without fixed limit, the pay of good men, this increase of pay depending on themselves and not on their immediate superiors ;

"To increase the capacity of the shops without adding new equipment;

"To increase the reliability of work turned out and the efficiency of operation performed;

"To do all these things, not only without cost to the company, but with a marked reduction in its expenses."

The programme was certainly ambitious and praiseworthy, and in Mr. Fry's report the results, after a thorough trial extending over several years, are given in the following paragraph :-

"It can safely be said that the betterment work has resulted as anticipated in restoring harmony between employer and employee, in restoring selfrespect to the latter and increasing his efficiency and reliability. Also it has raised his wages ten to twenty per cent on the average. In addition, for every dollar of supervising and special expense incurred, the company has saved at least ten dollars in reduced costs."

But just here two very important points require to be noticed and emphasized. In the operations of 
a railroad, efficiency must never be sacrificed for the sake of economy, and on the Santa Fé Railroad, when questions arise in which there is even the remote possibility of impairment of efficiency, all economical propositions or arrangements are at once postponed or vetoed altogether. Again, it is manifest that as a result of the improved methods and greater individual effort, certain reductions in working force will become possible. In regard to this matter the Santa Fé management claims that such reduction, when necessary, can easily be effected, simply by not replacing men who naturally drop out. This has been their uniform policy, and therefore, from their point of view, there is no possible ground for objection by employees on that score.

The individual-effort reward system on the Santa Fé thus far has been limited to the maintenance of equipment and to locomotive operation. The labor employed in the shops is, of course, distinctly nonunion. The saving effected under these methods on tools and machinery alone, at Topeka, was $\$$ II 9,000 , and the total economy on I633 locomotives (repairs and renewals) for the year 1906 amounted to $\$ 1,737,626$. These facts and figures are derived from a comparison of the cost of actual and identically similar work before and after the inauguration of the bonus system. 
It is impossible at this time to enter into a minute explanation or description of the system which is to-day in actual operation on the Santa Fé Railroad, and under which satisfactory results, both to employer and employee, are being obtained. The work itself is notable not so much because of its economical results as on account of its moral and sociological aspects. Without taking any side in the questions at all, it is evident that the movement and work on the Santa Fé, from beginning to end, has been an appeal to individual effort and character, and a protest against the recognized ideals of the labor unions. But it will not be found necessary to go into details of the Santa Fé system in order to illustrate and emphasize the principles that are at stake and the nature of the problem that must, before long, be settled, one way or the other, by an educated and enlightened public opinion.

On the Santa Fé Railroad, prior to the installation of the bonus system, a vast number of timestudies had to be made and schedules prepared. Every operation or piece of work to be bonused had to be studied by competent men, to determine, from the machine and other conditions, a fair or standard time to apply to it. Thousands of such studies have been made at the Topeka shops, and properly recorded and preserved on regular blanks.

The following illustrations are only partially de- 
scriptive of the Santa Fé method, but they are sufficiently accurate to cover the principles involved, the benefits that are derived from them, and some of the objections which have been advanced by the union men on the railroads, who are opposed to the bonus system in any form.

You take a certain piece of machinery, say a part of a locomotive. You make a "study" of this part. After making one hundred tests, under all sorts of conditions, you make a schedule in your machineshop for this particular operation or piece of work. You then fix upon a standard time for doing this work. Standard time is simply the time which it ought reasonably to take to do the work without killing effort, but by eliminating every unnecessary waste. The elimination of waste is the fair and square proposition you present to your workman. You say to him, "Make a standard time on this piece of machinery, and I will pay you twenty per cent above your hourly rate, that is, above your regular pay. If you take more than standard time, your bonus will diminish until at fifty per cent above standard time it will simply merge into your day rate. On the other hand, if less than standard time is taken, your bonus will increase above twenty per cent. But, under any conditions or circumstances, you will always receive your full day's wage."

The situation becomes still plainer, if you explain 
it to your workman in this way. You say to him, "During the past year I have watched your work closely, and made hundreds of 'studies' in regard to the 'part' you turn out with that machine. I find that you have averaged about six to the hour. Now I am convinced that you can just as well turn out seven. Your pay is now $\$ 2.50$ per day; if in the future you can make seven instead of six of these ' parts' in an hour, I will pay you $\$ 3.00$ per day. In fact, your pay will increase in exact proportion to your cleverness and industry. Furthermore, if by any manner or means you can invent a way, such, for instance, as an improvement in the mechanism or in the operation of your machine whereby you are enabled to turn out a dozen of these 'parts' in an hour, I will see to it that your pay is increased accordingly, without any limit whatever."

Continuing our general illustration, we will now take it for granted that you are able to start this bonus system in your factory or shop, in which, under ordinary circumstances, you give employment to one hundred union men. At the end of a certain period you find, on account of the extra effort put forth by the most ambitious and cleverest men, that the number of these "parts" which you require in your business, or on your railroad, can easily be turned out by seventy-five men. So without delay you reduce the working force in your shop ac- 
cordingly. It matters not how you do this, whether by simple discharge or by omitting to fill vacancies as they occur in a natural way, the fact remains that at the end of the year you have decreased your force twenty-five per cent, and besides, without adding to your equipment, you have made a substantial reduction in your operating expenses.

Meanwhile the men who have lost their jobs have lodged a complaint with their union, and you are soon confronted with a grievance committee. These gentlemen inform you that the bonus system is all wrong, from beginning to end. From the union standpoint they will explain to you that the idea is, not to offer a reward for quickest and best work, nor to encourage the best men to get rich quick, or to vaunt their superiority over their duller and less fortunate comrades, but to make the job, whatever it may be, last as long as possible, and thus to afford employment to the greatest number of workers, at a fair and fixed rate of wages to every individual, regardless of ability or ambition, or of the profits and interests of the establishment. You are further informed that the grievance committee cannot enter into the discussion of ethical and sociological questions. The race is doing pretty well as a whole, and posterity will accord to labor its due share of credit. Meanwhile the men will be called out of your shop, and the issue between the bonus system of reward 
for individual effort and the leveling process in shop-work will be fought to a finish.

Take another illustration: You make a great many "studies" in relation to the use of oil and other supplies on a locomotive on your railroad. You arrive at a fair standard of expense. You conclude there must be considerable waste going on somewhere, so you say to the engine crews, "So much per month is a fair average of expense for such and such tools and supplies on your engine. If you can lower this average, we will share the amount saved in this way." So you put the system in force on one thousand locomotives and save thereby four thousand dollars per month, which you divide with the men. But in doing this you have increased the pay of the careful men, and done nothing for those who are not interested in the general welfare of your railroad. The grievance committee takes the matter up with you; it protests against the whole business, and puts forth the argument that it is a dangerous proceeding, for you are guilty of encouraging a certain class of men to let engines "run hot" in order that they may secure your bonus for economy. In a word, you are requested to put a stop to this phase of your bonus system on the railroad.

Regardless of my somewhat crude and incomplete method of explaining the working of a bonus 
system on a railroad, my illustrations afford a very good idea of the Santa Fé system, which is in successful operation at the present day, as well as the proposed plans of the New York, New Haven \& Hartford management, which quite recently the labor unions compelled the railroad to abandon.

But apart from successful operation in one quarter and defeat in another, the principles at stake in this bonus system are of world-wide interest and importance. Bearing this in mind, a few direct and pertinent questions have occurred to me, which I submit for the thoughtful consideration of my fellow workers on the railroads, as well as of libertyloving people everywhere.

In the interest of human progress, and in particular with a view to efficiency of railroad service, do you think a railroad man should be permitted and encouraged to do his level best under all circumstances? Would you recognize and promote individual effort and good work in your sawmill, if you owned one, for the good of the business and in the interest of your pocketbook? Would you recognize and promote individual effort, attention to duty, and efficiency of service on a railroad, understanding, as you do, that upon these personal characteristics the welfare of the railroad and the safety of the traveling public are almost wholly dependent? Again, would you hesitate to encourage and reward the 
economical administration of the affairs of your own town or your sawmill, for fear lest the departments or the machinery might be deliberately ruined by employees, or by your fellow townsmen, in their efforts to secure said reward and encouragement?

If, after painstaking experiment, you become convinced that the plan would result in benefit to the interests of both management and men, would you hesitate to offer a bonus, or reward on coöperative principles, as an incentive to the economical use of supplies on a locomotive, for fear lest unprincipled engine crews should play tricks with the engine in order to secure the bonus?

Furthermore, if the encouragement of the best men and the best service can be shown to work against the interests of second-class men and poorer service, would you be willing, on a railroad, to sacrifice these second-class men and their interests, in so far as this action should become necessary, to secure the greatest possible efficiency for the safeguarding of the traveling public?

Finally, in the history of the development and civilization of the human race, is it possible to point to a single item of real progress, efficiency, or achievement, that has not been the direct result of the sacrifice of something below to the more important interests of something above?

Does it not therefore follow that any legislation 


\section{THE HUMAN EQUATION}

or labor movement that has the effect of checking individual effort, or of interfering in any way with the free play of the best that is in any man, must necessarily reduce the standard and ideals of labor? for such movements are an inversion of the laws of progress, and at the same time a reflection on the best thought and tradition of the American people. 


\section{VII}

\section{DISCIPLINE}

Ar the present day, public attention is being constantly aroused and focused upon all questions that immediately concern the general welfare of the people. In this way the efficiency of the service on American railroads has, of late, been freely discussed, not only by railroad men, but by thoughtful people in all the walks of life. The reason for this universal interest is to be found in the fact that an inquiry into an ordinary preventable railroad accident entails, at the same time, a study of the actual working conditions that exist in America between the rights and interests of the workingman, and the more important rights and interests of the general public. Of course, figures and tables in regard to efficiency of service cannot always be taken at their face value, and yet the conclusions that one is sometimes compelled to draw from them are altogether too significant to be lightly dismissed from the public mind.

For example, in the year 1906, a total of 1,200,$\infty, 000$ passengers was carried on British railroads on 27,000 miles of track, against $800,000,000$ passengers carried on American railroads on a mileage 
of 200,000 . Generally speaking, collisions and derailments form quite a reliable standard from which to make comparisons in regard to efficiency of service. It must also be remembered that the chances for accidents are naturally increased with increase of traffic and consequent multiplication of train movements. One might reasonably expect, therefore, to find the density of conditions in Great Britain reflected in a startling list of fatalities, as compared with the United States. Yet if we take the year 1906 to illustrate our theories and anticipated conclusions, we find that there were 13,455 collisions and derailments in this country, and only 239 in Great Britain. In the same year 146 passengers were killed and 6000 injured in the United States, against 58 passengers killed and 631 injured in Great Britain. The number of employees killed and injured in train accidents was respectively I 3 and I40 in Great Britain, against 879 and 7483 in this country.

It is not surprising, therefore, that figures and returns like the above, repeated from year to year with the same marked and, indeed, ever-increasing disparity, should give rise to widespread discussion and criticism, consequently leading up to a better understanding of the nature of the problem that is now submitted, with all necessary facts and illustrations, practically for the first time, to the Amer- 


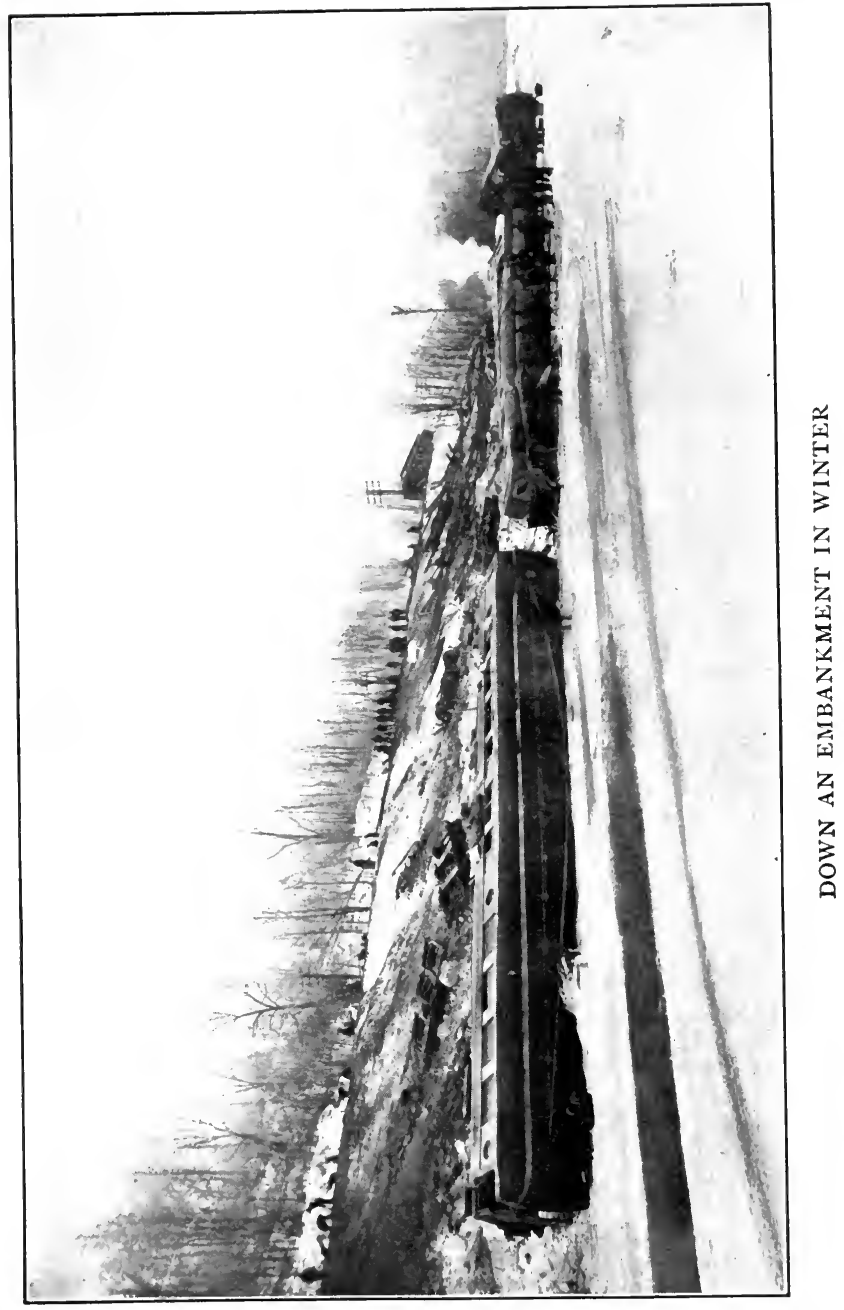



ican people. For it must be understood, to begin with, that, from its very nature and from the circumstances connected with the safety problem, the intervention of public opinion and of some kind of public action is imperatively called for. Numerous difficulties, mistakes, and inconsistencies relating to the handling of trains, to the conduct of employees, and to the present status of the railroad manager, have been exposed and explained during the course of these confessions. But, after all, these are merely side issues and details of the service ; the real heart of the situation, as insisted upon from first to last in these pages, is significantly outlined in a recent issue of the "Engineering Magazine," as follows :

"Even more serious, as a predisposing cause of railroad accidents, is the lamentable lack of discipline, which is becoming increasingly manifest in these days of labor-union interference. This has been carried to such a point that the officials of our railroads have no longer that direct control of the employees which is absolutely essential to the maintenance of discipline. Until this condition has been changed it is hopeless to look for any material reduction in the number of killed and injured on our railroads."

Such, then, being the truthful and logical diagnosis of the situation, the final and most important question of all remains to be considered. From in- 
dividuals in no way connected with railroad life, as well as from employees and managers in different sections of the country, the general interest in the matter has been expressed in the following inquiries: "What are you now going to do about it? Granting this and granting that, what is your plan of construction or reconstruction? What can you propose as a practical method of reform ?"

After a careful review and consideration of the conditions that obtain on American railroads at the present day, these significant and final questions, in the opinion of the writer, must all be answered in terms of external authority. It is really too bad to have to come to the conclusion that no reform can be expected, or indeed is possible, from within. The men, the organizations, and the managements must now be called upon to submit to publicity and to correction, to be administered by the stern arm of the law. A proper adjustment of the interests of the men and the management, with a view to the safety of travel, is, under present conditions, absolutely impossible.

Ample opportunity and time have been afforded these parties to solve the safety problem between themselves, without outside interference. The Canadian government has already come to the conclusion that it is useless to wait any longer, and accordingly it has taken measures to safeguard the 
rights of the traveling public. In like manner, just as soon as the government of the United States arrives at the same conclusion and sees fit to designate carelessness on a railroad as a crime, punishable in the same way as carelessness in driving horses or automobiles on a crowded thoroughfare, a revolution will take place in the service on American railroads. When the management and the men are called upon to face public examination and public criticism, there will be no more hair-splitting in the interpretation and administration of discipline. The men and the management will then very quickly recognize the necessity of adjusting their differences and combining their forces in the interests of the public. In a word, authority will become supreme, and it will not take long for it to assert itself in terms of effectual discipline. Such, according to my view of it, is the only possible solution of the safety problem on American railroads.

All other topics and questions, although closely related to the problem, are in reality merely matters of detail. For example, the lack of adequate supervision means, of course, unchecked negligence, and points the way to no end of trouble; and yet the most comprehensive system of supervision imaginable would be of little use, unsupported by a reasonable and effective system of discipline. While, therefore, my opinion as to the immediate neces- 
sity for the intervention of the national government holds good, a general description of the American method of discipline, upon which the efficiency of the service is, in the mean time, absolutely dependent, should nevertheless prove interesting to all classes of readers.

To a great extent, a system of discipline represents a state of mind, the ideals of an individual or of a community, and sometimes, under certain special conditions, an economical habit or business necessity. In the old countries of Europe, where the public interests smother individual rights as well as the schedules of labor organizations, the railroads have taken for their motto, " $\mathrm{He}$ that sinneth shall die." Cassio, faithful and true, with an honorable and spotless record in the public service, falls from grace in an unguarded moment, and is sorrowfully yet absolutely doomed to dismissal by the high-minded Othello. "Nevermore be officer of mine." Such in spirit, and, to a great extent, in actual railroad life, is the European interpretation of discipline. The European officials work upon the plan, and with the unswerving determination to protect the traveling public at all costs. The record of accidents on their railroads leaves little doubt as to the correctness of their methods of railroading. On the other hand, in the United States, the railroad manager, backed to a certain extent by 
public opinion, says to an offending employee, "Your sin has enlightened and purified you, go back to your job." This is the mental method of discipline. A man is called upon to think, without at the same time being called upon to feel.

On a railroad nowadays, when a "green" man makes a mistake, he is quietly informed by his superintendent that five or ten demerit marks have been placed against his name on the record book. The shock he receives on the commission of his first mistake is not very striking. $\mathrm{He}$ has perhaps been called upon to think, but in order to give his thoughts pungency and direction, he should also have been called upon to feel. Good habits are induced by feeling plus thought much more surely and expeditiously than by thought alone. Feeling plus thought is the scientific route. Some day, perhaps, thought alone will prove sufficient, but a railroad is no place to experiment with Utopian possibilities. What is necessary is the best and quickest way to originate good habits. The whole nervous system in man is first organized by habit. The feeling plus thought method of discipline is humane as well as scientific, and is the most potent instigator and prompter of habit.

According to Webster, discipline is "subjection to severe and systematic training." In the American method of discipline on railroads, there is no 
systematic training of any kind; sensation or feeling plays no part in it, and thought is left to take care of itself.

Theoretically, the mental process has a good deal to be said in its favor; but in actual operation the system has proved to be disastrous, and the records on American railroads illustrate only too eloquently the fallacy of the principle, under any conditions, where human lives are at stake. It is simply a question between the ethics and philosophy of Portia, and the blind impartiality of Othello as applied to the railroad business. In social affairs and in relation to conduct between individuals, the standards of Portia are gracious and commendable; but on a battleship, in the army, and just as surely on a railroad, the services of the rugged Othello will be found at all times to be the most effectual. In the United States, however, there is a certain altruistic sentiment that would fain submerge the ethics and principles of the old-time disciplinarian. Not only does this criticism apply to affairs on a railroad, but our educational methods, in every direction, seem to be threatened with the same peril. On all sides there now appears to be a disinclination to use authority. There seems to be something in the nature of a national kick against constraint or discipline of any kind. The ideals and rugged characteristics of American manhood, both on rail- 
roads and in our schools, are threatened with the coddling process.

Within the last ten or fifteen years, many railroads have changed or modified their system of discipline, as a tribute, in part, to this popular sentiment. Perhaps in making these changes the managers did the best they could under the circumstances. They found themselves fast losing the backing and authority necessary to enforce the old system, and the new method was at least a working arrangement with harmony for its basis.

A great majority of the railroads of the United States are now using some sort of a merit system in the administration of discipline. Most of these methods are adaptations of the Brown system, which was invented by Mr. G. R. Brown, at one time vice-president of the Pennsylvania. Brown figured it out for himself, while he was taking all the steps from trainman up, on the Fall Brook Railroad; and when he got to be general manager he put it in on his road. The system, as modified by most of the roads, is a sort of bookkeeping, with debits and credits in the shape of marks, to the account of each man. Generally speaking, a perfect record for any term of years may not be entered as a credit item in the book, although conspicuous instances of heroism or devotion to duty are sometimes noted. But a perfect record for a certain 
period will wipe out previous debits. An employee has access to his record book at any time, otherwise the record is kept in absolute secrecy. On some roads "rolls of honor" are kept and published, usually in the railroad magazines. The names of the men, together with an account of the meritorious action, receive special mention. But, on the other hand, there is no mention, either of names or particulars, in regard to the debits when employees make mistakes.

Railroad managers appear to be satisfied with this Brown system of discipline, and the statement has repeatedly appeared in the public prints that the adoption of these rules has resulted in better service to the companies. So far as the safety of travel and the general efficiency of the service are concerned, the figures and reports issued periodically by the Interstate Commerce Commission are calculated to convey a very different impression. Railroad officials inform us that the Brown system is an attempt to promote good feeling between the men and the management. This is doubtless true, but the statement lets the cat out of the bag. The employee appreciates the fact that the sting is extracted from a reprimand when it is administered in secret. Doubtless, if the sole aim has been to secure harmonious relations between men and management, little fault can be found with the Brown system; 
but it appears in a somewhat different light when we study it in relation to the safety problem.

For example, a man makes a serious mistake, without actual injury to persons or damage to property. He is punished to the extent of ten demerit marks. In the course of a few months five or six other men commit the same mistake. In every instance a secret record of the mistake has been kept. When a mistake remains unchecked, sooner or later it arrives at the epidemic stage and reaches its climax in a wreck, and then finally a man is discharged for it. The demerit marks have had no corrective or preventive effect whatever. Under this system the trouble is allowed to evolve in a natural way, from a simple case of unchecked negligence into a disaster in which, perhaps, a community is called upon to suffer.

On the other hand, a system that takes publicity and the pocketbook for its principal factors enlists every corrective element in its favor. You cannot separate suspension and loss of pay from publicity, to a certain degree. In all systems of punishment or correction, in a police court or elsewhere, there are usually two or three elements that are depended upon to bring about beneficial results. These factors are the shame that is attached to the publication of names, the pecuniary loss in the shape of a fine, and the danger of imprisonment. The Brown sys- 
tem has abolished publicity and done away with pecuniary loss. The employee is now aware that no one can touch his pocketbook, no one can wound his pride, or hold him up as an example to his fellows. Of course it is too bad that a railroad man should be called upon to take his discipline home with him, that his wife and children should have to share the shame and the penalty; and yet the decisions of courts and of human tribunals everywhere are all subject to the same criticism.

The Brown system, in a modified form, is to-day the American method; and while its supposed primary object may be to increase efficiency, its actual working is all in the interests of harmony between the men and management. The proof of the efficiency of any system of discipline is to be found in the freedom from accidents of all sorts. Within the last few months, I have heard railroad managers who heartily approve of the Brown system, deplore in the same breath the alarming increase of accidents. One of these gentlemen went so far as to inform me that it is the only possible system, so long as the men and the political influence of the organizations are allowed to control the situation.

The men very much prefer to take punishment on the installment plan, in the dark, to any settlement on a cash basis in open and above-board fashion. Discipline in the dark, on the installment plan, 
has all the facts, experience, and records of the past and present, and the probabilities of the future, arrayed against it. When you ask the manager how it happens that the United States does not recognize the efficacy of the mental method on the installment plan, and treat him as the Brown system treats the employees, he merely shrugs his shoulders. When an infraction of the "safety-appliance law" or the "nine-hour law" is brought home to a manager, the action of the government or the law recognizing the superior efficacy of the mental treatment might reasonably be expected to say to him, "I give you ten demerit marks. Your mistake has enlightened and purified you ; go back to your desk." A manager is surely as susceptible to mental influence and suggestion as an engineman or a conductor. Yet there is not a suspicion of the Brown system of discipline in the actual fines and imprisonment which the government has agreed upon as the best and quickest way to enforce obedience in the interests of the public welfare.

The general introduction of the Brown system on American railroads has been brought about by the "irritation" of the men when their pay or their time has been interfered with. This was, in general, the power that gave the impetus and encouragement to the movement. 
The exact amount of "irritation" in loss of money to employees for one month has been figured out by one railroad, as follows:-

Discharged Demerits

Discharged Demerits

Discharged Demerits

Discharged Demerits

\section{Discharged} Demerits

\section{Engineers}

4 Merits

455 Amount saved to the men

$\$ 1706$

\section{Firemen}

2 Merits

1265 Amount saved to the men

10

$\$ 263$

\section{Conductors}

4 Merits

485 Amount saved to the men

10

$\$ 1523$

Operators

Io Merits

3 ro Amount saved to the men

\section{Trainmen}

2I Merits

696 Amount saved to the men
$\$ 1553$
0

That is to say, a certain number of men had been awarded "demerits" for offenses instead of suspension with loss of pay, which in one month would have amounted to $\$ 5559$. Of course, most of this amount would have been earned by spare men, but this consideration by no means allays the "irritation " of the regular men. 
Multiply this irritation by the number of railroads in the United States, and the Brown system of discipline is accounted for. From the safety point of view, the greater the "irritation" the more evident becomes the necessity for some system calculated to control and put a stop to the negligence that produces the irritation. The Brown system very effectively allays this irritation at the expense of the public safety, by treating the negligence as a matter of secondary importance.

But although the Brown system and its modifications may reasonably be termed the American method, nevertheless here and there one comes across an instance of an American railroad that has discarded it and adopted a radically different method, with exceedingly satisfactory results. One of the roads that has broken away from the Brown system is the Chicago \& Alton.

A few months ago, while in Bloomington, Ill., the writer paid a visit to what is termed "The C. \& A. Stereopticon Car." So far as I am aware, there are only two or three of these cars on American railroads. The car is, in fact, a training school and lecture hall for the benefit of the employees. Mr. Perdue, the man in charge, is a veteran employee of over thirty years' experience, extending over practically every department of railroad life. In order to enter the service of the Chicago \& Alton, 
every man has to pass through this car and take the necessary examinations. In this way Mr. Perdue has become personally acquainted with practically every man in the operating department of the Chicago \& Alton. He knows the weak men and the strong men, and his watchful eye is over them all. He has the necessary authority to call any man into the car for reëxamination, and to withhold him from duty if necessary, in the interests of the service.

Mr. Perdue kindly allowed me to remain in the car while he was conducting the exercises. There were some twenty or thirty railroad men seated before him. The lecturer held in his hand a small bundle of papers. They were the record of the disciplines for the month. Some of the wrong-doers had been called into the car to listen to a description and an analysis of their mistakes. Mr. Perdue is very kindly, yet forceful, both in manner and speech. He talks vigorously to the men in their own everyday language. He takes one accident after another, and by the actual representation of it on his screen he demonstrates just how it happened and how to avoid it for the future. He then tells a certain man to stand up, and questions him closely as to what he would do under such and such circumstances. Finally, he turns to his screen and shows his audience how to smash a carload of household goods by 
rough handling and by giving careless motions, and, on the other hand, how to be loyal to the road and at the same time true to themselves by rendering careful and efficient service.

Altogether Mr. Perdue's work and story are so interesting that I am tempted to give a part in his own words :-

"I have kept a record of the men handled during the past two or three years. I promoted 148 brakemen to be conductors, 264 firemen to be engineers, and instructed in all 3839 men. Practically all the men passed, because if they failed to begin with, they kept coming to me until I had educated them up to my standard. I believe the Chicago \& Alton has the finest and most loyal body of employees on any railroad in the United States. I may be accused of blowing my own trumpet, but I honestly believe it is nearly all due to my method of training and discipline. By the way, this method is copyrighted by President Murphy of the Cincinnati Southern Railroad. Of course the method is one thing, and the man who handles the method is another, and a most important consideration. That is why I point with pride to my record with the boys on the Chicago \& Alton. I want them to get the credit for it, for without their coöperation my work would be thrown away. To begin with, I make a point of getting the men interested, not only in 
their own records, but in the records and reputation of the Chicago \& Alton. I tell you one thing, and that is, you cannot, with impunity, malign or abuse the Chicago \& Alton Railroad in the hearing of one of my boys.

"Then, again, I have no favorites. I make it a point to work with absolute impartiality and uniformity. Every man knows he must stand or fall on his own merits, that is, on his record as a flagman, a fireman, or an engineer; and when he gets into trouble, his character as a man is taken into account. Please don't lose sight of the fact that I made these Chicago \& Alton boys. I made good men out of them because $I$ aroused an interest in every man. We are all proud to be able to say that we work for the Chicago \& Alton, and we point to our road as the best, safest, and most comfortable in the country to-day. To give you an idea of our splendid service, you should take a ride on our ' $\mathrm{Red}$ Train,' on 'The Prairie Express' or 'The Hummer.'

"In 1904, during the World's Fair at St. Louis, we carried thousands more passengers than any other road, and we neither killed nor injured a single passenger. I spent two thirds of my time riding round with the boys during the Fair season. We heard of numerous accidents happening on other roads, and one thing leading to another, the word was finally passed around, 'Boys, not a scratch to a 
passenger on the Chicago \& Alton.' And we lived up to our motto, I can tell you. This kind of work is part of my method. It is a system of personal effort and personal direction, and I can tell you it pays. If you don't think so, just take a look at the accident records of the other roads during the same period.

"In regard to discipline, I don't believe in being too severe. It 's what you hold up your sleeve and have the power to use periodically, that counts. Yet we are severe enough on the Chicago \& Alton. No merit or demerit marks for us. For minor offenses, from five to ten days' lay-off, with loss of pay. For neglecting to have your watch inspected, we give as many as fifteen days' lay-off; and once in a great while, the penalty for serious offenses goes up to thirty days. But discipline to any great extent is uncalled for. When a man has been through my car, he may need it once, but very seldom a second time. If you will compare the number of preventable accidents on the Chicago \& Alton during the years 1897,1898 , and 1899 with any year or period since I took charge of this system in 1900, you will get a very good idea of what the 'Stereopticon Car' and all that it stands for has done for the Chicago \& Alton Railroad."

But now, making an end in this way of our survey of conditions on American railroads, there is 
yet one topic of another nature that should prove unusually interesting to the general public.

To the writer of this book it has always seemed strange that the public interest and anxiety in regard to these distressing railroad accidents should never yet have taken the form of a very natural curiosity to find out to what extent and by whom these matters have been systematically studied and thought out. Doubtless the public has the impression that its interests are being cared for somehow by somebody. But impressions of this kind must not be mistaken for evidence. What, for instance, are the names of the employees, the managers, the politicians, or the legislators who have studied these railroad accidents at close range and given the public the benefit of their investigations? If these authorities have given little time and no thought to the subject, the public should be informed why they have avoided the discussion. As a matter of fact, the investigation has been avoided, practically by all hands, for the reason that no man can honestly apply any kind of a probe to a serious railroad accident without running the risk of a clash with the labor organizations. No such neglect, for this or other reasons, of a great public issue can be pointed to in any other department of American industry or civilization.

For instance, from time to time we read in the 
public prints of prizes being offered by cities and states, and sometimes by the national government, for the best designs for some public building or memorial. Without delay architects and artists all over the country concentrate their minds on the subject. Those who are capable of submitting valuable opinions and plans are invited and encouraged to do so. Money and brains and professional pride are enlisted in the undertaking, and thus we actually secure the best results that the concentrated thought and talent of the profession is capable of producing.

Now it will certainly occur to most of us that it is quite as serious and important an undertaking to try to save thousands of lives on the railroads as it is to provide commodious and artistic public buildings. Upon examination at close range, however, it soon becomes evident that no concentration of thought whatever is being directed to this safety problem, such as all other questions of national importance immediately bring into play. If this point is well taken, it surely must result in bringing to light a most unusual and almost incomprehensible state of affairs. From my point of view, then, neither money, brains, nor professional pride are in any way enlisted in the undertaking, except along the lines of least resistance. The lines of least resistance in these railroad problems are concerned with and em- 
brace all manner of signals and safety devices for the protection of life and property. The thought and money that are being lavished on this side of the problem can be realized by a glance at any or all of the scientific periodicals. But the lines of greatest resistance, and at the same time of the greatest importance, which call for a study of the human element, that is to say of the conduct of the men in relation to efficiency of service, have as yet failed to receive the attention and thought which the importance of the problem undeniably calls for.

Undoubtedly this view of the matter will meet with considerable criticism. It is a distinct reflection on the policies and methods of the officials and the authorities to whom the public is in the habit of looking for assistance and enlightenment. Nevertheless, a short consideration of the subject will, I think, be sufficient to sustain my contention, and at the same time it will serve as an introduction to a chapter in the railroad business that is replete with interesting particulars, as well from the industrial as from the sociological point of view.

From the nature of the railroad business, with its multiplicity of rules, signals, and customs, which constitute the mysteries of the operating department, little assistance is to be expected, in a direct way, from the ideas and opinions of the general 
public in the devising or initiating of improved methods of operation. Public opinion, however, has its proper function and influence, which can be profitably utilized in other directions.

In the same way, judging from experience and our knowledge of the past, little assistance in the way of thought or coöperation is to be anticipated from the rank and file of the men. No amount of public stimulation or official encouragement has so far had any effect in rousing the average engineman, conductor, or station-agent, and inducing him to devote any part of his spare time or his talents to a fearless discussion of these railroad problems, which are so intimately related to the safety of the traveling public. Neither in the railroad magazines nor in the newspapers, will you ever come across an article or any kind of appeal calling upon the organizations to take a hand, in any public way, by coöperation with managers or otherwise, in improving the scandalous accident record, which at the present day is the distinguishing feature of the American railroad service. Every railroad man seems to be a specialist in his own department, and up to date there is no suspicion of a social conscience in any way connected with his job or his schedules. In a word, the employee has not devoted to the subject of railroad accidents any systematic thought or consideration whatever. 
Turning now to the officials of our railroads, to the train-masters, superintendents, and managers, the evidence is even less satisfactory; for it must be allowed that any systematic and persistent study of these matters on the part of the railroad officials would sooner or later become known to the public, through the press. But there is absolutely no evidence of the kind in existence. The press of the country can be carefully scrutinized and watched for an account of a railroad accident that has been fearlessly and thoroughly analyzed by railroad officials and published for the information of the public. Personally, after carefully watching the outcome of a score of cases, I am of the opinion that the investigation of a railroad accident by the management of an American railroad is neither more nor less than a hushing-up process, in which the officials are assisted by the railroad commissioners, who frequently dodge main issues by taking circuitous routes.

For instance, it cannot be denied that railroad commissioners in general are aware that interference with discipline in aggravated form is a recognized principle on our railroads. The Massachusetts Commissioners, for example, found themselves face to face with the issue, a few years ago, during their investigation of what is known as the Baker Bridge disaster. In their report of this accident, 
they characterized the principle as vicious and let it go at that; and yet they are just as well aware as I am of the duties and habits of a grievance committee, as well as of the fact that the privilege of unlimited appeal from the discipline of the superintendent is to be found in almost every agreement between men and management.

I am not presuming, in any way, to define the functions or duties of the railroad commissioners; my object is simply to discover, if possible, by whom and in what manner these railroad accidents are being studied and analyzed in the interests of the traveling public. All our evidence, therefore, points to the fact that train-masters, superintendents, and managers - that is to say, the only men in the country who are thoroughly posted in all the details of railroad life, and therefore the only men with the ability and equipment to think out these problems to successful solution - are absolutely tongue-tied and pen-paralyzed on the subject. Occasionally, perhaps, one of these gentlemen may emerge from his seclusion with an interesting essay on certain phases of railroad life. In a general way he may call attention to the importance of certain cardinal characteristics and virtues. He may emphasize a sermon on the absolute necessity of obedience to the rules, with numerous and interesting illustrations; but when it comes to a question 
of enlightening the public in regard to the actual working arrangements that exist between the management and men, he immediately draws a wide black line.

If a superintendent should have the temerity to come out in the open and describe, for the benefit of the public, the process of running his division by a combination of rules, schedules, and grievance committees, with himself as an almost impersonal factor in the midst of it all, turning the crank merely as director of the machinery, he would in short order be called upon to back up his story with his resignation. This would be a perfectly natural consequence of his loyalty to the public interests and of his lack of consideration for the traditions and etiquette of his office. Not only is this true, but his usefulness as a superintendent would be at an end; he would be placed on the unfair list by the employees, and thus he would quickly become persona non grata to his superiors, whose harmonious relations with the organizations he would constantly be in danger of upsetting.

But if the public should think fit to follow up the investigation suggested and initiated by the superintendent in this way, it would quickly find itself face to face with the fundamental antagonism that exists in the highest railroad circles between the rival interests of harmony and efficiency. So far 
as our railroads are concerned, this is the "land's end" of discussion on the safety problem. Harmony is the altar upon which the interests of the traveling public are continually being sacrificed. Harmony is the final adjuster, arbitrator, and referee. Harmony dictates the policy of the railroad, the nature and severity of its discipline, while efficiency follows in the rear, as best it can. Just as soon as the public gets interested sufficiently in preventable railroad accidents to call for all the facts in relation to them, then, and not until then, will harmony be dethroned from its dictatorship. So I think I am justified in repeating the statement that these preventable railroad accidents and the causes which lead up to them have not yet received proper attention and thought at the hands either of the public, of the employees, or of the managing bodies of the railroads. The superintendent allows the public to remain in ignorance out of regard for his job, and the manager does the same in the interest of harmony.

It must not be imagined, however, that the management is alone to blame in the matter. Only too often, in the past, when a railroad manager, in the interests of good service, has made a test case of his power, he has had the public as well as the men to contend against. As a matter of fact, even at the present day, the public is not in a mood to 
give much credit or attention to explanations and statements that emanate from railroad headquarters. It is an uncomfortable truth that public opinion, as a rule, looks upon official announcements or reports of railroad accidents as being more or less tainted, and the idea is deeply imbedded in the public mind that a superintendent is open to the same suspicion that is commonly attached to a manipulator of stocks in Wall Street.

As it seems to me, then, the conclusion that little enlightenment in regard to railroad accidents is to be looked for from management or men has impressed itself in some way on the public mind, and the appointment of boards of railroad commissioners to look after the public interests has been the natural consequence. But when we come to hunt up the evidence in regard to the study of railroad accidents by railroad commissioners, a most unlooked-for state of affairs is disclosed.

Undoubtedly most of the problems that come up before the commissioners for solution are well within the sphere of their talents and business ability, but a fair and impartial investigation of railroad accidents calls for a thorough examination and sifting of the evidence by men who are actually in touch with the working of the rules and the movements of the trains. It is not sufficient for commissioners to call for the evidence and to listen 


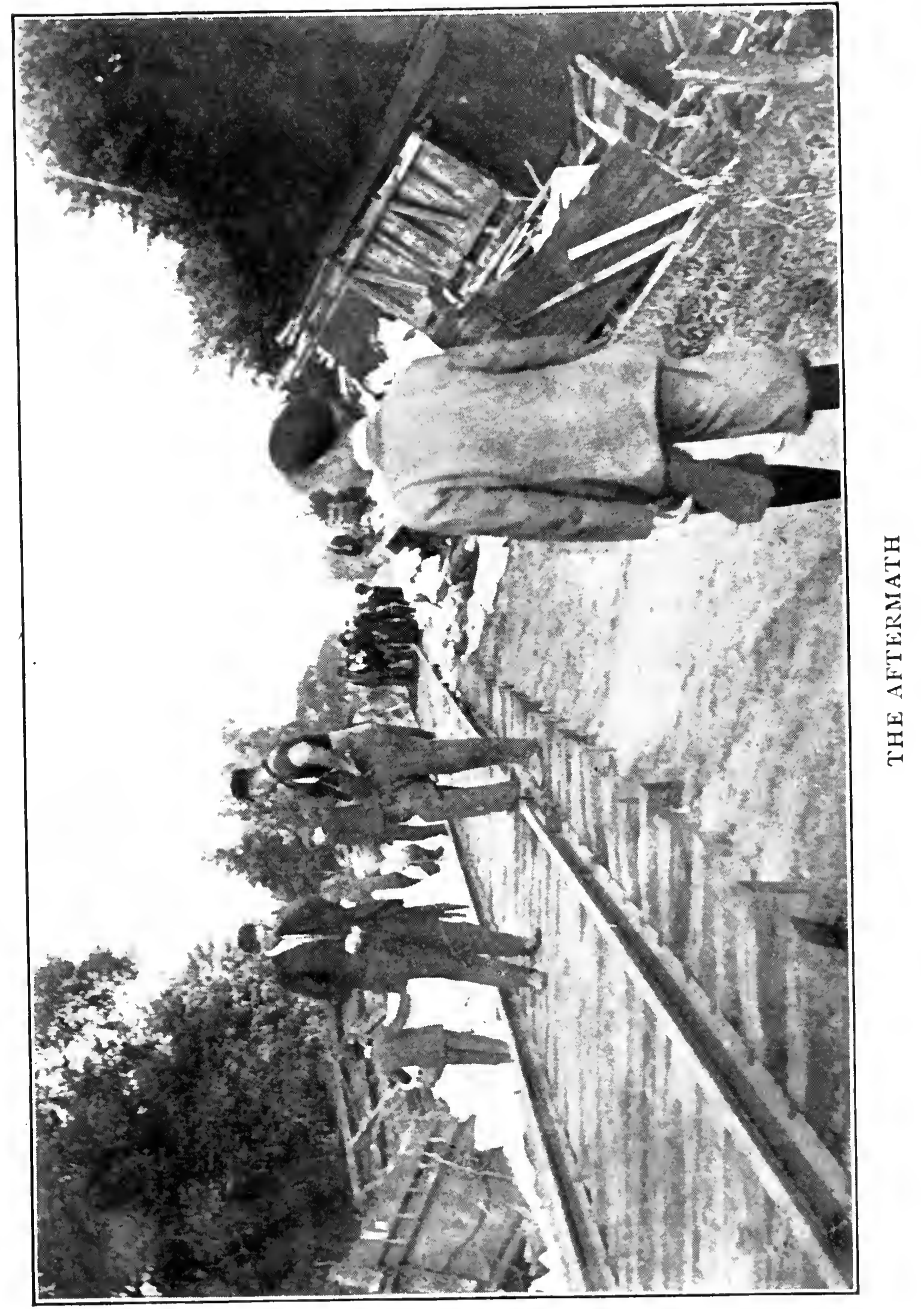



to a rehearsal of some of the rules that apply to the case. A fair-minded and unprejudiced listener at any "hearing" conducted by these boards would quickly be impressed with the conclusion that in New England, at any rate, the commissioners are not fitted by training, study, or experience to furnish the public with intelligent criticism of the simplest case of a preventable railroad accident. I have not the slightest hesitation in recording this as the whispered opinion of all railroad men who have given any thought to the subject, although, of course, it would be highly imprudent for any one to say so out loud.

Not only to railroad men, but to the public as well, the following illustration will be as plain and to the point as words can make it :-

On September 15, 1907, a head-on collision occurred near West Canaan, N. H., between two passenger trains, in which twenty-five passengers were killed and about as many more injured. The accident was the result of an error, either in sending or receiving a train order-possibly both the sender and receiver were at fault. One of these men was the train dispatcher in the main office, the other was a telegraph operator at a way station. With a view of placing the responsibility and explaining the disaster, an investigation was immediately entered into by the Board of Railroad Com- 
missioners of the State of New Hampshire. These gentlemen were assisted in their duties by the attorney-general of the state, their legal adviser. Replying to the direct question of the board, "How do you think this accident happened? What occasioned it ?" the general superintendent of the Boston \& Maine Railroad, himself an operator and train dispatcher, testified as follows :-

"I would say, in my thirty years' experience, closely connected with the dispatching of trains, we run something like 700,000 trains a year, - I have never known a similar error to be made and I never have heard of it. The error certainly was made, and due, as I believe, to a failure of the mental process, either in the brain of the dispatcher at Concord, the operator at Canaan, or both, and it is utterly impossible for me to determine which one made the failure, or whether or not they both made it."

Such was the opinion of an expert railroad man, recognized as such by the commissioners themselves. Thereupon the general superintendent, at the request and for the benefit of the board, entered into a minute and exact account of the methods employed in moving and handling trains on the Boston \& Maine Railroad, in so far as this was necessary to explain the situation at the time of the accident. The narrative of the general superin- 
tendent was interrupted at frequent intervals by questions from the attorney-general and the commissioners. He, the manager, was called upon to explain, not only the rules of the road, but the commonest principles and movements in the train service. "What is a 'block'?" "What do you mean by 'O. K.' and 'complete '?" "Explain in detail your train-order system." "As a matter of curiosity let me ask how this signal works." These questions are not put as a mere legal form or habit, for many of the points call for reiterated explanation before they are comprehended by the board. The language is plain enough: they don't understand this, they are not familiar with that, and the section of track on which the accident happened they know nothing about. In a word, the board goes to school to learn something about the elements of railroading and the details of train movements by telegraph, and having in this way been thoroughly drilled into an understanding of the accident, and having listened to all the evidence, the investigation comes to an end.

On October II, 1907, the finding or report of the commissioners was published. After reviewing the accident, the evidence in relation to it, and the methods of operation in the train service of the Boston \& Maine Railroad, all of which was, in fact, simply a reproduction of the testimony of the gen- 
eral superintendent, the board concludes its analysis by pointing to the train dispatcher at Concord as the "more than probable" transgressor, and actually undertakes to describe the train of mental wanderings by means of which the error was arrived at ! In the face of the declaration of the expert railroad manager that it was impossible to single out the offender, the commissioners, on the same evidence, but without the expert understanding of it, are satisfied to send this train dispatcher out into the world with the stigma of implied guilt and responsibility for the death of twenty-five people on his head. Train dispatchers all over the country were very much exercised and indignant at this "finding" of the commissioners, and I am convinced it would be very difficult to find a telegraph operator in the United States who would be willing to say a word in its favor.

That public officials should feel themselves justified in expressing opinions having the nature of verdicts, upon delicate questions relating to the train-order system of train movements, while confessing themselves ignorant of the terms "O.K." and "complete," is beyond the comprehension of railroad men; and public opinion would quickly see the point and recognize the justice of this criticism, if its attention should happen to be called to the members of a naval board of inquiry, for example, 
whose previous experience had been such that they were unfamiliar with the terms "port" and "starboard."

A careful perusal of the foregoing arguments and illustrations should have the effect of impressing upon the public mind two simple, yet very significant, conclusions :-

In the first place, it will be evident that the safety problem on American railroads must be taken in hand and solved by the people. The present tangled condition of affairs can be straightened out only by supreme authority.

And our second conclusion is the revelation that the area in American industrial life covered by these preventable railroad accidents and the causes that lead up to them is practically, at the present day, a terra incognita. Of course the railroad man who steps out from the rank and file, and undertakes to give away the plans and topography of the country for the benefit of those who are interested in improving conditions, exposes himself to all sorts of cynical criticism in the minds of his fellows. However, as a matter of fact, your true philosopher thrives in this kind of atmosphere. $\mathrm{He}$ is born of the battle and the breeze, and spends a lifetime in fortifying the walls of his "tub," into which, when hard beset, he retires to enjoy himself. 


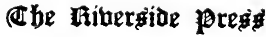

CAMBRIDGE - MASSACHUSETTS

$\mathbf{U} \cdot \mathbf{S} \cdot \mathbf{A}$ 




\section{$\therefore$}

$$
\text { . }
$$


THIS BOOK IS DUE ON THE LAST DATE STAMIPE BELOW

\section{AN INITIAL FINE OF 25 CENTS} WILL BE ASSESSED FOR FAILURE TO RETURN THIS BOOK ON THE DATE DUE. THE PENALTY WILL INCREASE TO 50 CENTS ON THE FOURTH DAY AND TO \$1.00 ON THE SEVENTH DAY OVERDUE.

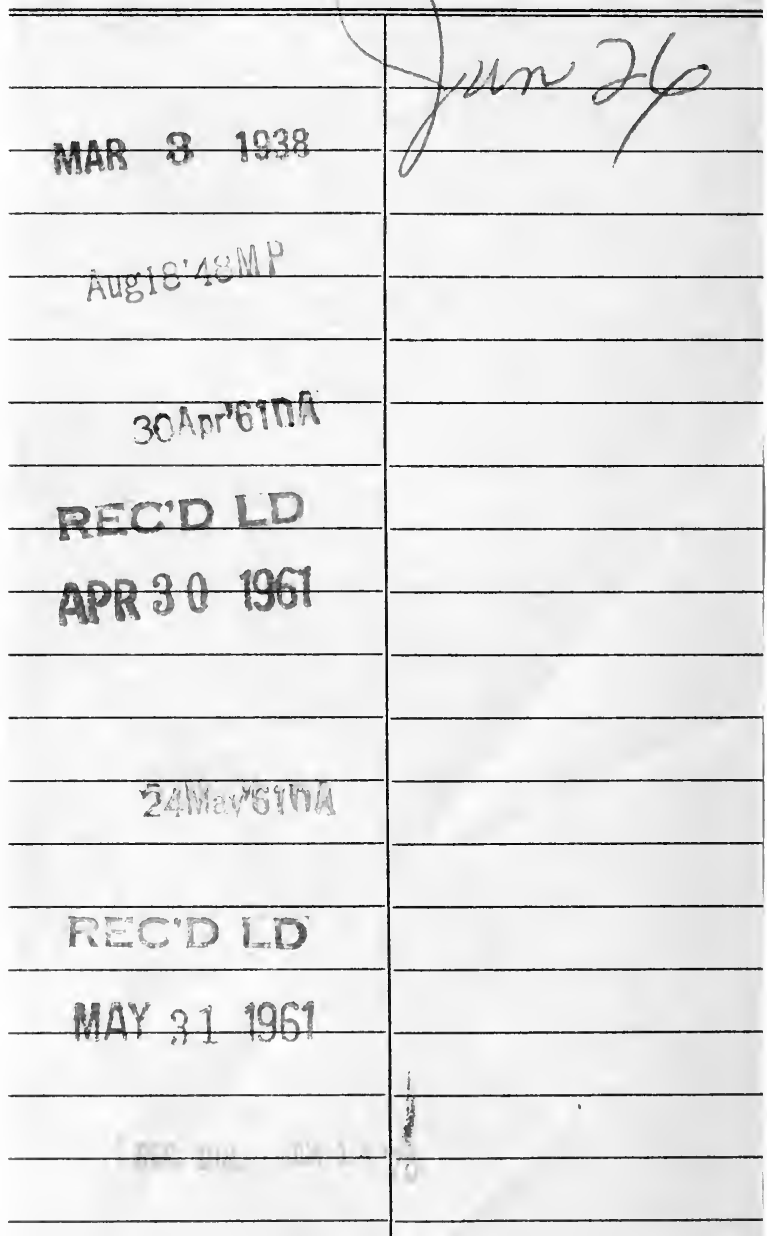


a os un

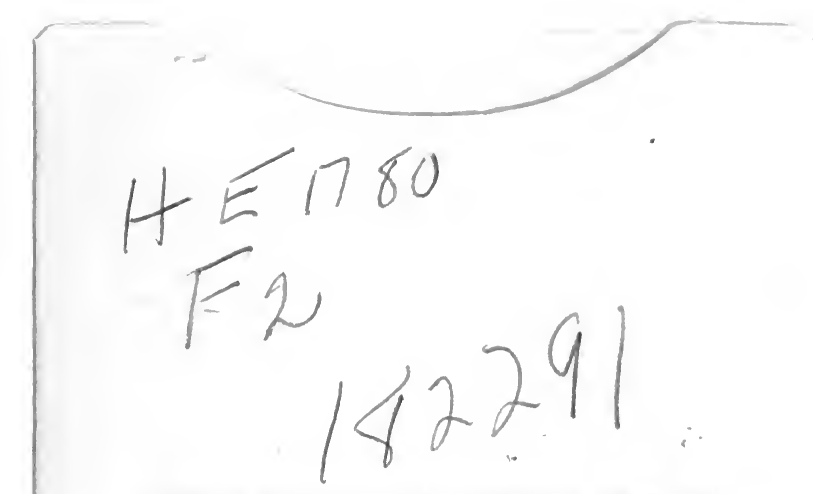

UNIVERSITY OF CALIFORNIA LIBRARY 
